\title{
Projeto de Sistema de Sincronização de Streams de Vídeo para Serviço Multicast
}

\author{
Denilson Cristiano Silva
}

Orientador: Prof. Dr. Edson dos Santos Moreira

Dissertação apresentada ao Instituto de Ciências Matemáticas e de Computação - ICMC-USP, como parte dos requisitos para obtenção do título de Mestre em Ciências - Área: Ciências de Computação e Matemática Computacional.

USP - São Carlos

Setembro de 2000 
Aos meus pais e irmãos. 


\title{
Agradecimentos
}

\author{
̀̀ Deus, \\ "Ainda que eu caminhe por um vale tenebroso, não temerei mal algum, porque estás comigo." (salmo \\ de Davi) \\ Aos meus pais e irmãos \\ A vocês que compartilharam dos meus ideais e os alimentaram incentivando-me a prosseguir na \\ jornada com ânimo e coragem.
}

Ao professor Dr. Edson dos Santos Moreira, meu orientador, amigo, incentivador, companheiro, ombro amigo, colaborador, confidente, meu sócio nessa minha conquista. Obrigado.

Aos demais professores do curso que mostraram que "ensinar é mostrar que é possível. Aprender é tornar possivel a si mesmo". Obrigado, Mestres, por sua sabedoria.

Aos meus colegas do Intermídia pela amizade, apoio e companheirismo.

Aos funcionátios

"Aqueles que por detrás das cortinas e com um show à parte, brindaram-me com um sorriso, com o seu apoio, para que tudo se realizasse a contento."

Meus colegas de moradia,

"Cada um que cruza o nosso caminho passa sozinho, pois cada pessoa é única e nenhuma substitui a outra.

Cada um que cruza o nosso caminho, passa sozinho, mas não vai só, nem nos deixa só. Leva um pouco de nós, deixa um pouco de si.

Há os que levam muito, mas há os que nada deixam.

Há aqueles que deixam tanto, que tudo que levam será pouco...

Por todas as nossas conquistas, nos orgulhamos...

Por nossos defeitos, nos desculpamos.

Por nossas diferenças, nos entendemos..."

A divisão de alegrias, dificuldades, vitórias, tristezas...

Fazem de você, José Geraldo, Igor e Vangrei alguém impossivel de se esquecer. 


\section{Sumário}

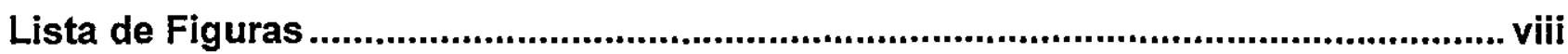

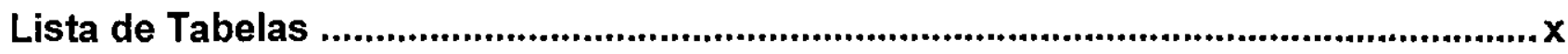

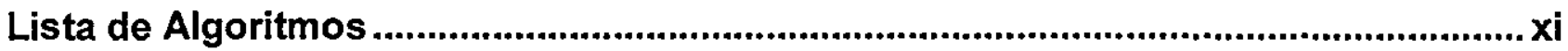

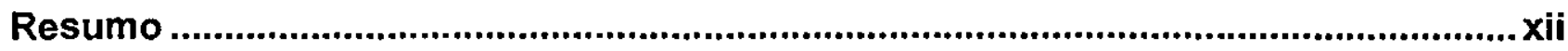

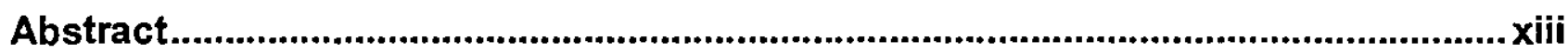

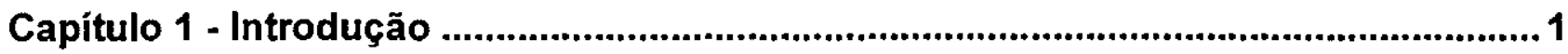

Capítulo 2 - TV e Vídeo Digital............................................................................................. 4

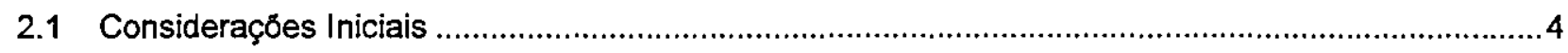

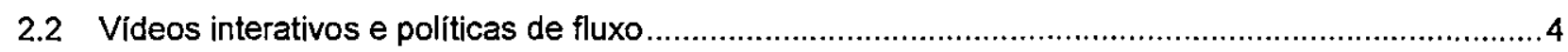

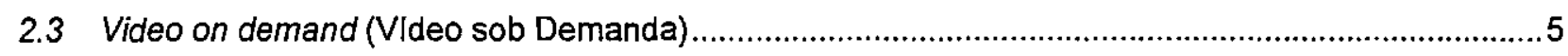

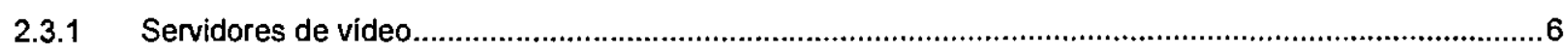

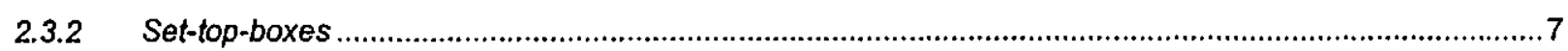

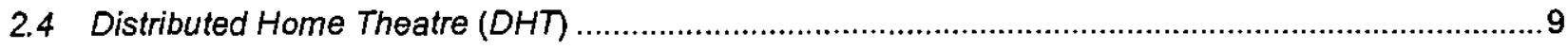

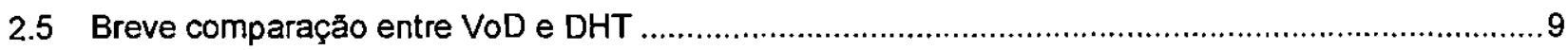

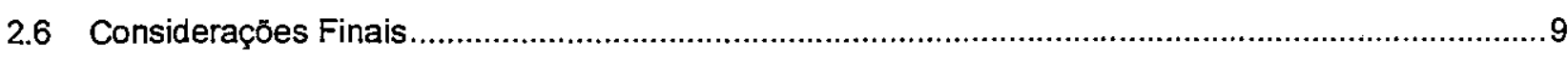

Capítulo 3 - Técnicas de sincronização de streams de vídeo .....................................10

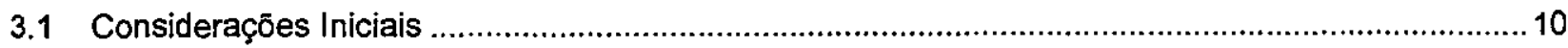

3.2 Tipos básicos das políticas de gerenciamento ............................................................................. 10

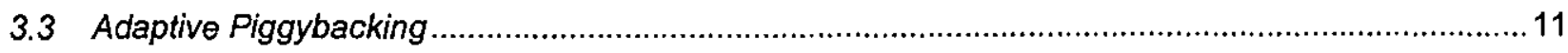

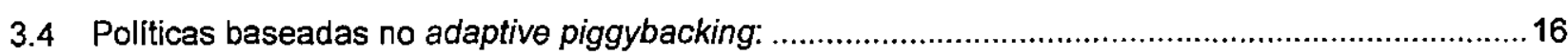

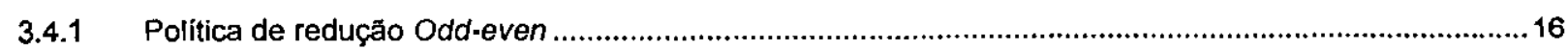

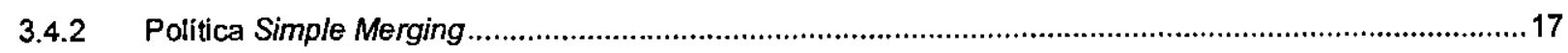

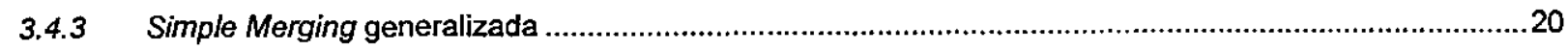

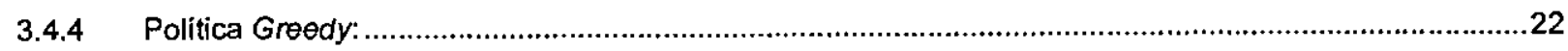

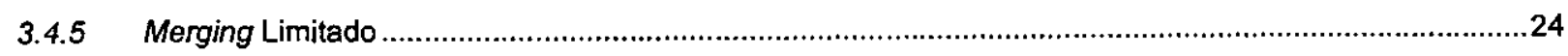




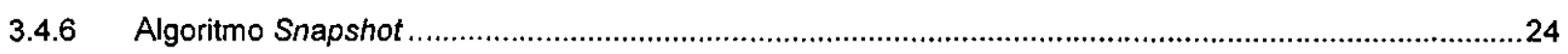

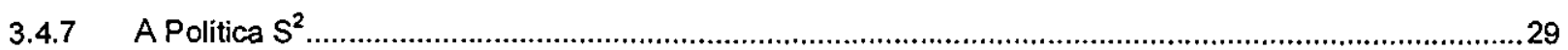

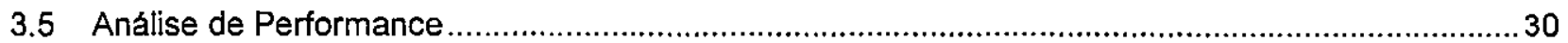

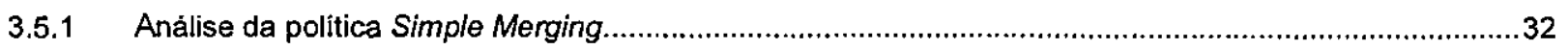

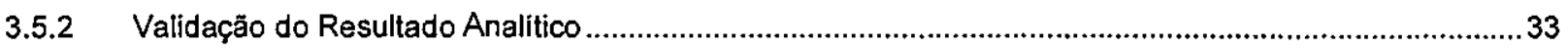

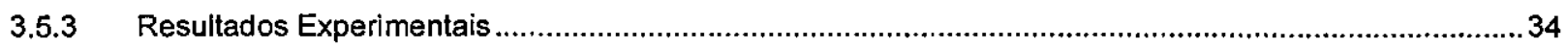

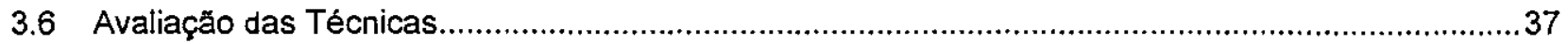

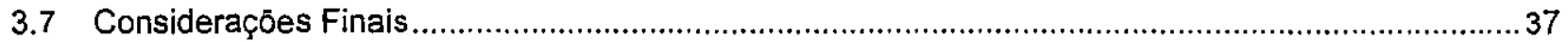

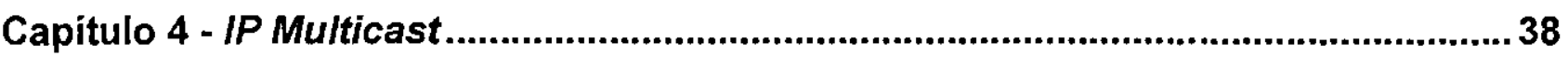

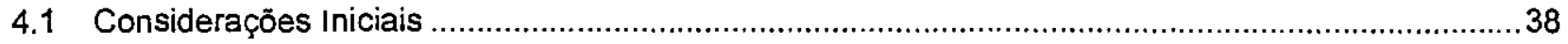

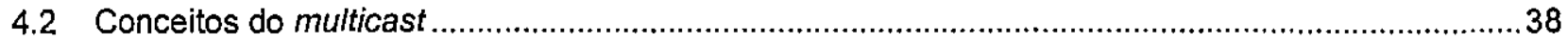

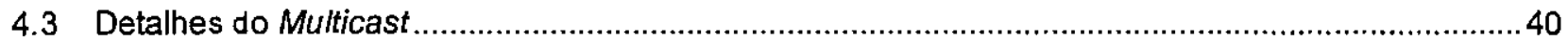

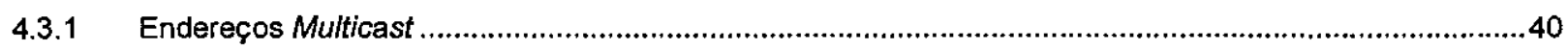

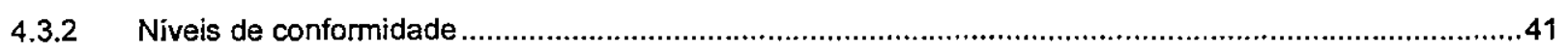

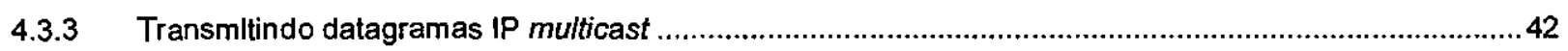

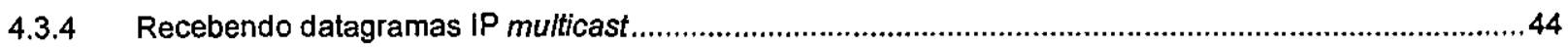

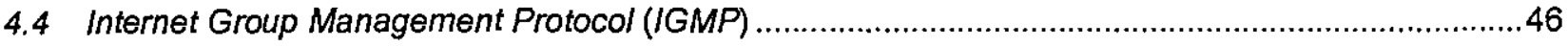

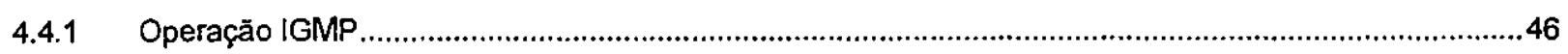

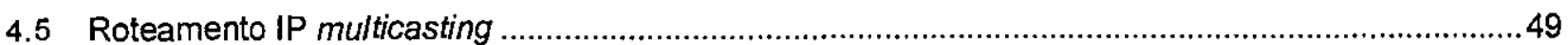

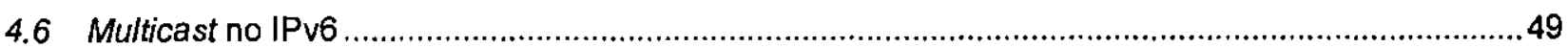

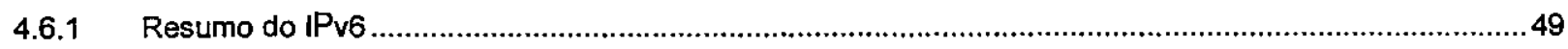

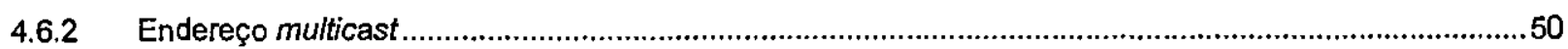

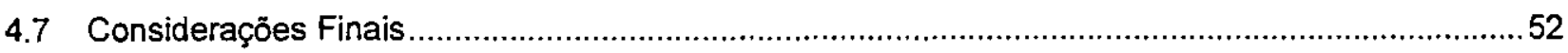

Capítulo 5 - ATM Multicast................................................................................................53

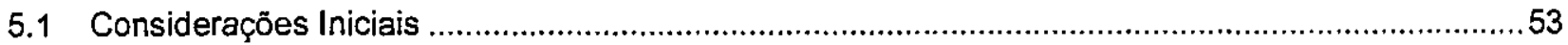

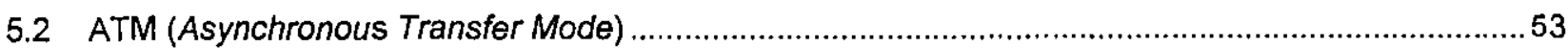

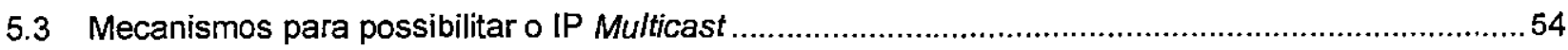

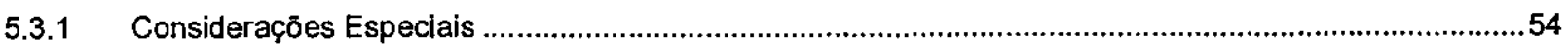

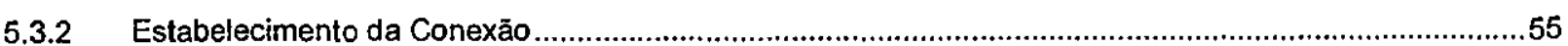

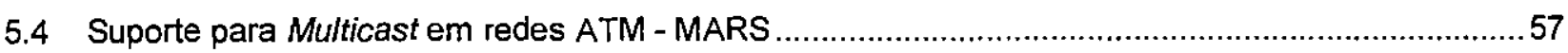

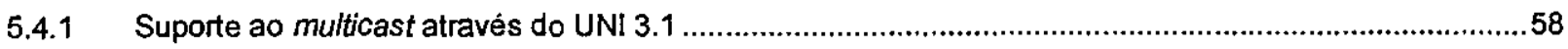

5.4.2 Visăo Geral do Multicast Address Resolution Server ……...................................................................59

5.4.3 Transmitindo para Grupos Multicast ....................................................................................................60

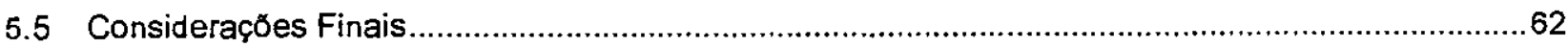

Capitulo 6 - Modelagem da implementação do Servidor de Vídeo SNAPSHOT.........63

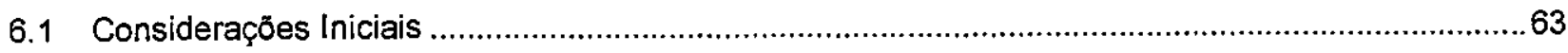

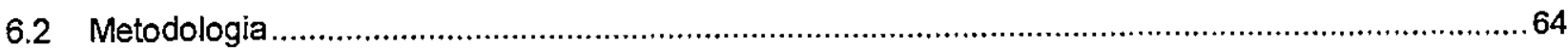




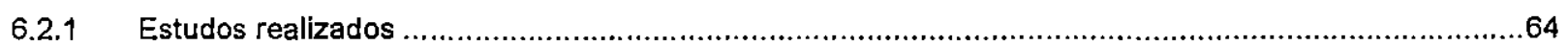

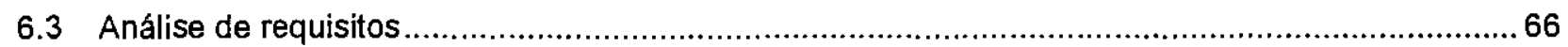

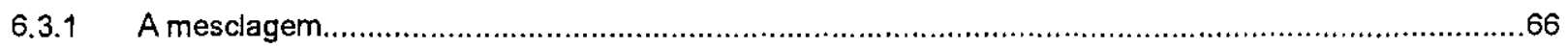

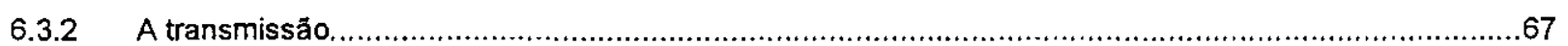

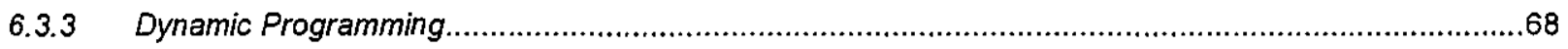

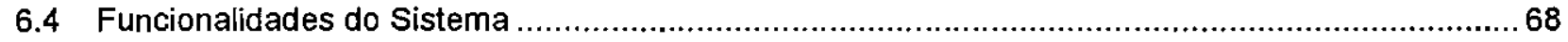

6.4.1 Interatividade entre o Administrador e o Sistema ..................................................................68

6.4.2 Interatividade entre o Cliente Remoto e o Sistema ..................................................................69

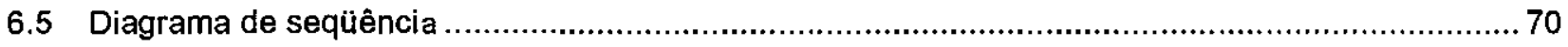

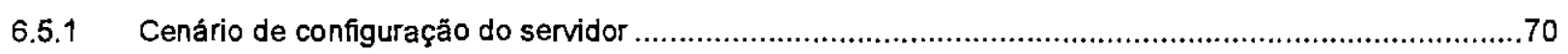

6.5.2 Cenário do Estabelecimento de uma seção de trabalho ...................................................72

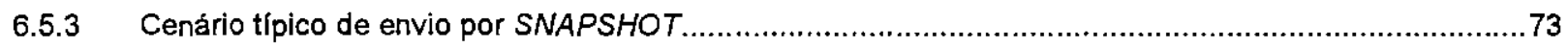

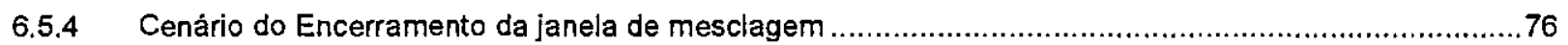

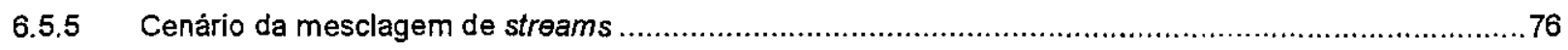

6.5.6 Cenário típico da definiçāo de velocidade ótima de transmissão ....................................................78

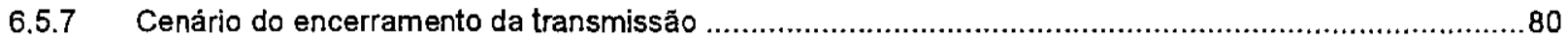

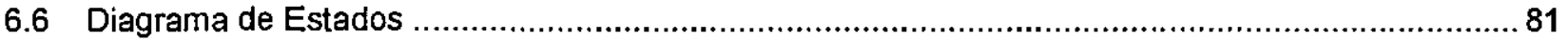

6.7 Diagrama de Classe do servidor de Video-on-Demand ...................................................82

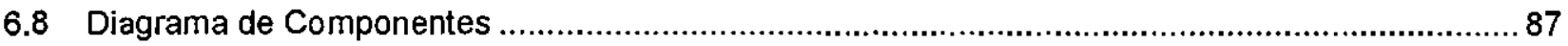

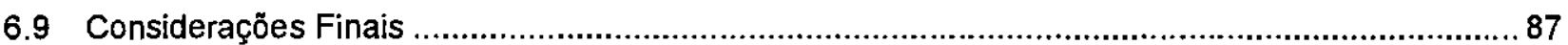

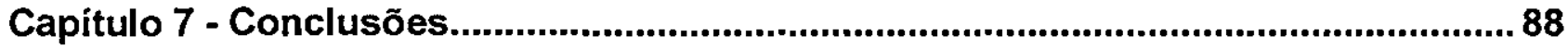

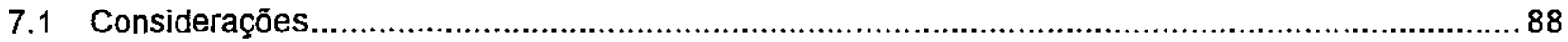

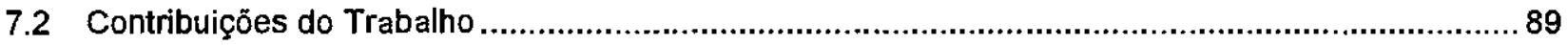

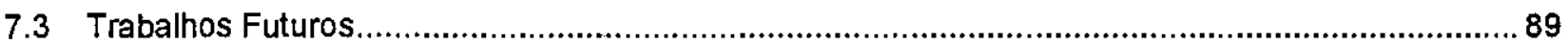

Referências Bibliográficas ...........................................................................................91 


\section{Lista de Figuras}

Figura 1.1: Arquitetura do Servidor de Vídeo.

Figura 2.1: Visão geral de um sistema de vídeo sob demanda. ................................................

Figura 2.2: A arquitetura de hardware para um servidor de vídeo típico. ......................................

Figura 2.3. A arquitetura de hardware para uma set-top-box simples ......................................... 8

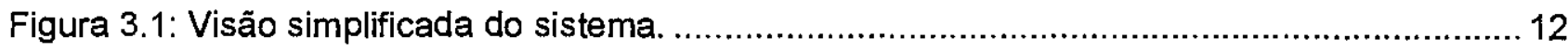

Figura 3.2: Estado do Sistema (do ponto de visão de um único objeto). .....................................14

Figura 3.3: Estado do Sistema (do ponto de visão de um único objeto)...................................... 17

Figura 3.4: Cenário da Política Simple Merging ................................................................... 18

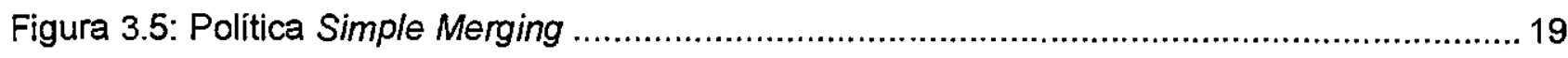

Figura 3.7: Cenário da Política de Mesclagem Greedy. .................................................................. 23

Figura 3.8: Árvores binárias altemativas e seus custos. ........................................................ 25

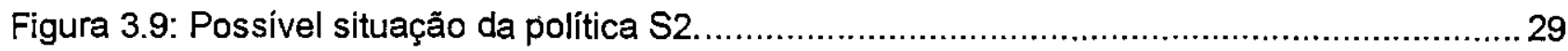

Figura 3.10: Chegada dos $\mathrm{V} / \mathrm{O}$ streams depois de um delay.....................................................

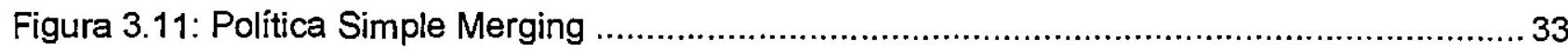

Figura 3.12: Comparação variando as taxas de chegada ........................................................... 34

Figura 3.13: Performance da política Simple Merging com tamanho da janela variável................ 35

Figura 3.14: Comparação variando o tamanho do vídeo........................................................... 35

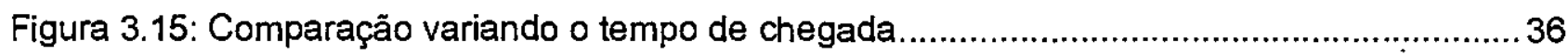

Figura 3.16: Performance do Snapshot variando o tamanho da janela ...........................................36

Figura 4.1: Mapeando endereços IP da Classe D para endereços Ethernet IEEE802.3 .............45

Figura 4.2: Protocolo de roteamento multicast ............................................................................48

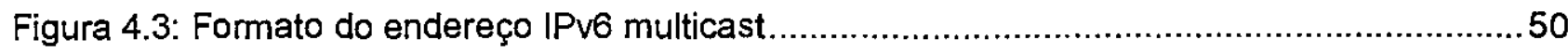


Figura 5.1: Uma conexão em uma rede ATM........................................................ 54

Figura 5.2: Seqüência de eventos para abrir/fechar uma conexão ATM ...............................56

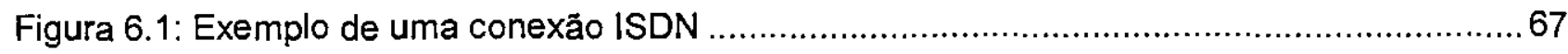

Figura 6.2 : Casos de uso de servidor de transmissão................................................ 68

Figura 6.3: Casos de uso do cliente da transmissão de VOD utilizando Snapshot......................69

Figura 6.4: Cenário de configuração do servidor ....................................................... 70

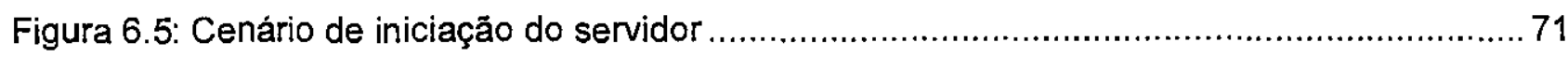

Figura 6.6: Cenário de configuração do servidor ...................................................... 71

Figura 6.7: Cenário da abertura de uma seção de trabalho .............................................. 72

Figura 6.8: Cenário do encerramento de uma seção de trabalho .......................................... 72

Figura 6.9: Cenário do envio da primeira stream do intervalo snapshot ...............................73

Figura 6.10: Cenário de envio das streams posteriores a primeira stream da janela.................. 74

Figura 6.11: Cenário Típico de envio por Snapshot utilizando o IP multicast ............................75

Figura 6.12: Cenário típico de envio após aberta a janela de Snapshot ................................75

Figura 6.13: Cenário da finalização do intervalo Snapshot................................................ 76

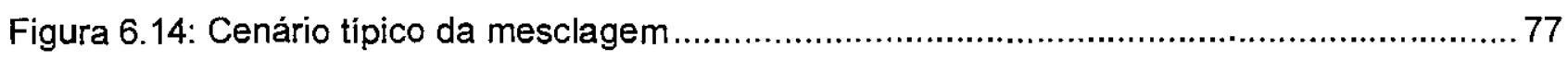

Figura 6.15: Cenário básico da transmissão de vídeo no momento da mesclagem ....................78

Figura 6.16: Fluxo de mensagens para criação da árvore de mesclagem..............................78

Figura 6.17: Fluxos de mensagens para o ajuste de velocidades ...................................... 79

Figura 6.18: Cenário da definição da velocidade ótima (algoritmo de programação dinâmica) ..... 80

Figura 6.19: Cenário da finalização transmissão da primeira stream do intervalo. ...................... 81

Figura 6.20: Estados do controle de mesclagens..................................................... 81

Figura 6.21: Diagrama de Classe Geral do sistema ................................................ 82

Figura 6.22: Diagrama de Classe do Algoritmo Snapshot ............................................. 83

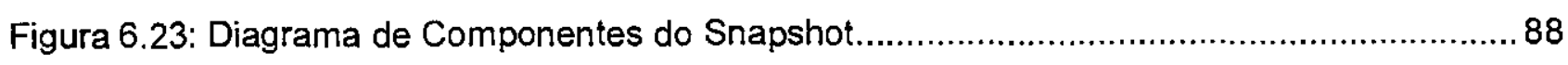

Figura 7.1: Modelo da arquitetura de implementação do Snapshot....................................... 89 


\section{Lista de Tabelas}

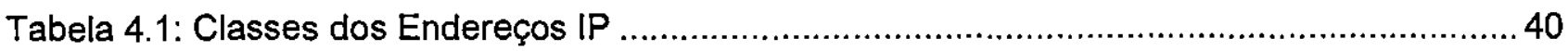

Tabela 4.2: Lista dos TTL thresholds e seus escopos................................................. 43

Tabela 5.1: Mensagens usadas para o estabelecimento e o encerramento da conexão..............56

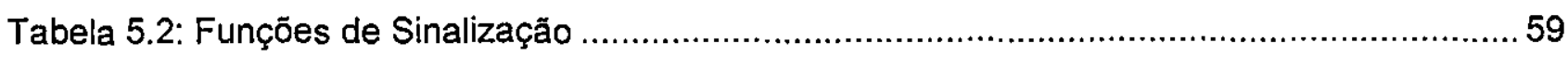

Tabela 5.3: Indicações geradas pela rede ............................................................... 59

Tabela 6.1: Descrição da administração do servidor.........................................................69

Tabela 6.2: Descrição do estabelecimento da seção de trabalho ............................................ 70

Tabela 6.3: Escopo de acesso do diagrama de classe do snapshot ..................................87 


\section{Lista de Algoritmos}

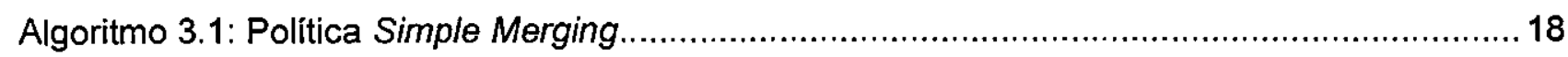

Algoritmo 3.2: Algoritmo de Programação Dinâmica (Dynamic Programming) ........................... 27

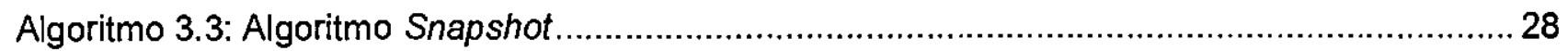




\section{Resumo}

Os requisitos de largura de banda para satisfazer as necessidades dos sistemas de vídeo sob demanda são críticos para a qualidade do serviço fornecido pelo servidor. Muitas técnicas tem sido propostas para reduzir estes requisitos. Este projeto modela uma aplicação que implementa a técnica do SNAPSHOT para reunir vários streams de vídeo permitindo o uso do multicasting. É baseada no método adaptive piggybacking que ajusta a taxa de exibição dos quadros dos streams novos (tornando-os mais rápidos) e velhos (tornando-os mais lentos) até que eles possam ser mesclados em um único stream. A modelagem foi feita em UML e alguns cenários de implementações são propostos. 


\section{Abstract}

The bandwidth requirements to comply with the needs of video-on-demand systems are critical for the quality of service provided by the server. Several techniques have been proposed to reduce these requirements. This project models an application wich implements the SNAPSHOT technique to assemble several video streams together allowing for the use of multicasting. It is based on the adaptive piggybacking method that adjusts the displaying rate of the video frames of the new (making them go faster) and old (making them go slower) streams until they can be merged into a single one. The modeling was made with UML and some scenatios of implementation are proposed. 


\section{Capítulo 1 - Introdução}

As aplicações de vídeo, por exemplo, Vídeo sob Demanda (Video on Demand - VoD), estão entre as de maior potencial comercial nas futuras Redes Digitais de Serviços Integtados de Faixa Larga (RDSI-FL) [Fon98]. Em um sistema de video-sob-demanda, o usuário assinante poderá escolher tanto a hora quanto o filme que deseja assistir. A qualidade do serviço pode ser caracterizada em termos do tempo de latência da requisição do cliente, definida pelo intervalo de tempo entre a chegada da requisição e a inicialização do serviço. A latência de uma requisição é influenciada por um númeto de fatores, os quais serão discutidos adiante [Agg96a].

Um sistema de video-sob-demanda pode ser modelado em uma arquitetura clienteservidor[Ste95]. Os clientes essencialmente consistem de usuários que podem acessar vídeos armazenados em discos no servidor, como ilustrado na Figura 1.1. O servidor consiste de um conjunto de discos $\left(D_{1} \ldots D_{N}\right)$, um conjunto de processadores $\left(N_{1} \ldots N_{K}\right)$, espaço em buffer, e uma memória secundária. $O$ banco de dados completo reside na memória secundária, e os mais freqüentemente acessados são cacheados em disco ${ }^{1}$. Sempre que houver uma requisição para um vídeo em particular, este é acessado pelos discos no servidor, transmitidos para o processador central, e então roteados para o cliente[Tob93]. Se o objeto requisitado não for residente no disco, então este deve ser recuperado da memória secundária e armazenado nos discos antes de serem inicializados; isto pode resultar em um ou mais objetos sendo retirados dos discos, devido a falta de espaço[Che94]. Então um I/O stream ${ }^{2}$ precisa ser escalonado. Considerando que a largura de banda é um recurso de grande valor, logo estes streams precisam ser gerenciados com cuidado [Gol95].

Um dos aspectos mais desafiadores destes sistemas é prover serviços-sob-demanda para múltiplos clientes simultaneamente, economizando I/O streams através de escalonamento; ou seja, usuários esperam acessar objetos, por exemplo, filmes, dentro de uma latência pequena e "razoável", mediante requisição [Ozd94]. A latência para servir uma requisição é definida como o tempo entre a

\footnotetext{
1 Assume-se que o caching nos discos é feito sob-demanda, no exemplo, um objeto não residente nos discos é buscado do armazenamento secundário somente quando é referenciado; algumas formas da política LRU (Menos Recentemente Usado) poderia ser usada para eliminar objetos dos discos (de forma a criar espaço para o novo objeto recuperado).

2 Refere-se a um fluxo de dados de mídia
} 
chegada da requisição ao tempo que o sistema inicializa a leitura do objeto (do disco); o delay adicional até que os dados sejam entregues ao dispositivo de exibição (display) é considerado relativamente desprezível. Latência pode ser atribuída á: a) insuficiente largura de banda para servir a requisição, b) insuficiente espaço em buffer para o escalonamento dos dados lidos dos discos, ou c) insuficiente armazenamento em disco, por exemplo, o objeto em questão poderia não ser residente no disco e conseqüentemente teria de ser recuperado do armazenamento secundário antes de ser escalonado para exibição[Bal96].

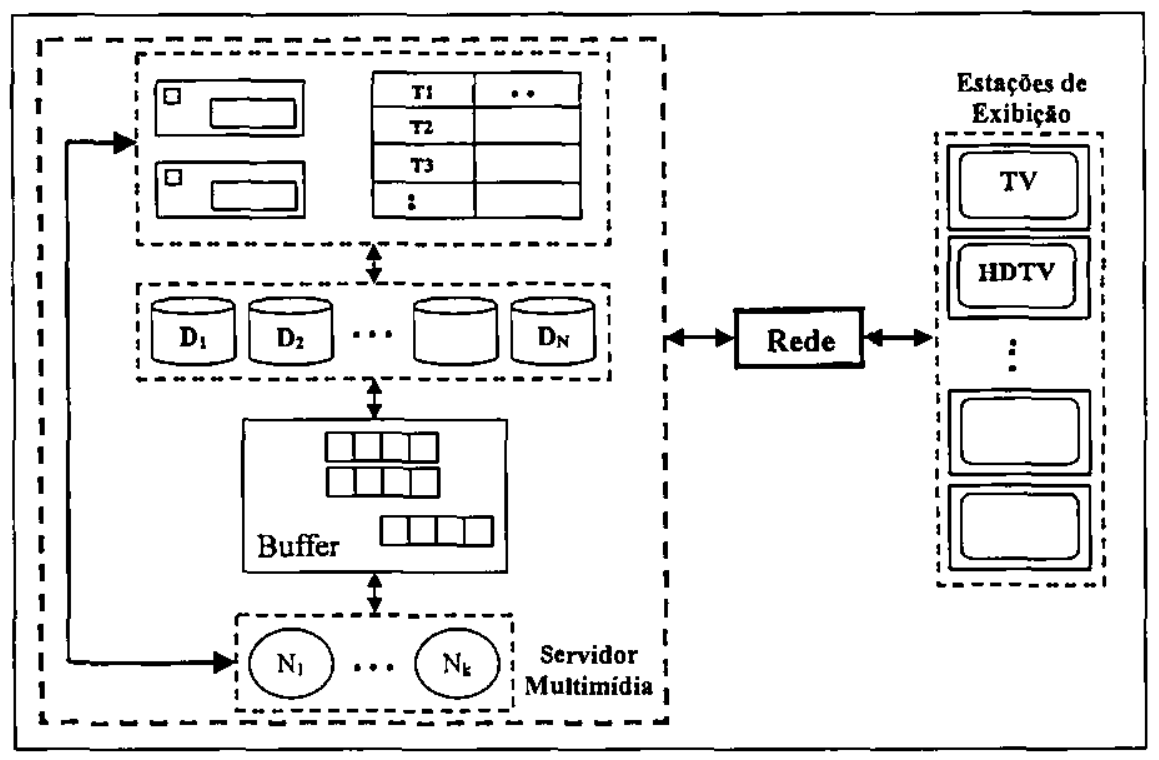

Figura 1.1: Arquitetura do Servidor de Vídeo.

Para melhor ilustração, pode-se assumir que o servidor, como mostrado na Figura 1.1, pode ser descrito pelos três parâmetros seguintes: 1) I/O bandwidth total disponível, 2) espaço para armazenamento em disco disponível, e 3) espaço em buffer disponível ${ }^{3}$. Estes parâmetros, em conjunção com o layout dos dados e esquemas de escalonamento, determinam o custo do servidor bem como a "qualidade de serviço" que eles podem oferecer; embora a qualidade do serviço é um termo de determinado modo ambiguo, a latência, em atender uma requisição de vídeo, é uma medida utilizável. Em geral, é muito comum que o I/O bandwidth seja um recurso crítico o qual contribui para o aumento da latência. [Agg96b].

Há muitas abordagens para redução da demanda de $1 / O$ no servidor através de compartilhamento, aumentando o número de requisições de usuários os quais poderão ser servidos simultaneamente. Entre essas abordagens destacam-se: a técnica de Batcbing, Bridging e Adaptive Piggybacking.

${ }^{3}$ Não é considerado características do dispositivo de armazenamento secundário nesta dissertação. 
Nesta dissertação, os estudos foram concentrados na adaptive piggybacking. Esta técnica fundamenta-se no ajuste das velocidades das streams durante o progresso das mesmas (para um mesmo objeto) com o objetivo de mesclá-las.

Este projeto propõe uma modelagem de uma técnica baseada no adaptive piggybacking, conhecida como Snapsbot. Por ser una aplicação distribuida em rede, é adotada a arquitetura CLIENTE/SERVIDOR. A técnica de SNAPSHOT é fundamentada em 1) mesclagem de streams, 2) transmissão com velocidade alterável durante o progresso dos streams (rápida e lenta) e 3) o algoritmo de programaçào dinâmica (dynamic programming). Tais fundamentos devem ser trazidos para o modelo, a fim de definir um modo de implementação.

Esta dissertaçào está organizada em sete capítulos. O conteúdo de todos esses capitulos é brevemente descrito a seguir:

$>$ Capítulo 2 apresenta uma visão getal das idéias básicas do sistema de video on demand e de sua implementação;

$>$ Capítulo 3 trata das políticas que tem por objetivo o getenciamento de streams de vídeo, destacando principalmente as políticas baseadas no adaptive piggybacking.

$>$ Capítulo 4 fornece algumas informações interessantes para compreensão dos protocolos multicast e implementações, introduzindo conceitos básicos do IP multicast.

$>$ Capitulo 5 aborda questões referentes ao multicast em redes ATM, apresentando algumas diferenças combinatórias entre como é realizado o multicast em redes ATM e em redes IP.

$>$ Capítulo 6 neste capítulo é proposto definir a modelagem de uma aplicação para a técnica SNAPSHOT, utilizando o UML, com finalidades de testes e avaliações servindo de base para a implementação de um software.

$>$ Capitulo 7 conclui a dissertação apresentando as conclusões do trabalho realizado, contribuições e sugestões para trabalhos futuros. 


\section{Capítulo 2 - TV e Vídeo Digital}

\subsection{Considerações Iniciais}

O video on demand $(V o D)$ é, às vezes, comparado a uma loja elettônica para a locação de vídeos. $\mathrm{O}$ usuário (cliente) seleciona qualquer um dos vídeos disponíveis e o leva para assistir em casa. A única diferença é que com o vídeo sob demanda a seleção é feita em casa, com o controle remoto do aparelho de TV ou via computador, e o vídeo é apresentado imediatamente[Tan96].

Neste capítulo, é apresentada uma visão geral das idéias básicas e de sua implementação e sua organização é a seguinte: a próxima apresenta uma introdução ao sistema de vídeo interativo e políticas de fluxo; a seção 2.3 apresenta os conceitos gerais que compõe o sistema de video on demand; na seção 2.4 apresenta os conceitos um outro sistema conhecido como Distributed Home Theatre (DHT); a seção 2.5 é uma breve comparação entre Video on demand e o Distributed Home Theatre.

\subsection{Vídeos interativos e políticas de fluxo}

Serviços de vídeo interativos são similares ao serviço de difusão de TV, mas apresentam uma alteração fundamental no paradigma da interface de TV. Eles foram projetados para suportar muitos canais simultâneos sobre um mesmo banco de dados. No sistema de TV tradicional, cada estação executa sua programação simultaneamente, e o usuário seleciona um canal específico. Em contraste, um sistema interativo faz com que toda a programação seja apresentada ao usuário sem nenhuma restrição. O usuário pode executar qualquer parte da programação a qualquer hora, um exemplo desta aplicação, é o vídeo sob demanda[Flu95]. 


\subsection{Video on demand (Vídeo sob Demanda)}

Esta seção apresenta uma visão geral das idéias básicas do sistema de video on demand e de sua implementação. A descrição de uma implementação real pode ser encontrada em [Nel95]. Um tratamento mais genérico da televisão interativa está em [Hod95]. Oı:tras referências relevantes são [Cha94]; [Hod93]; e [Lit94].

Para permirir aos usuários interromper, recomeçar e retroceder os vídeos, a solução seria a transmissão de uma cópia separada do vídeo para cada um desses usuários.

Por outro lado, se o vídeo sob demanda não oferecer estes recursos aos usuários, talvez seja suficiente que o provedor de vídeo comece os vídeos mais solicitados a cada, digamos, 10 minutos, e apresente-os sem intervalo. Um usuário que deseje assistir a um desses vídeos talvez tenha de esperar 10 minutos para que ele comece. Apesar da pausa/retomada não ser possível aqui, um espectador que retorne à sala depois de um pequeno intervalo pode mudar para o outro canal onde o mesmo vídeo está sendo apresentado com 10 minutos de atraso. Esse esquema é chamado de near video on demand e oferece um custo muito menor em potencial, pois a mesma imagem do servidor de vídeo pode ir para vários usuários ao mesmo tempo.

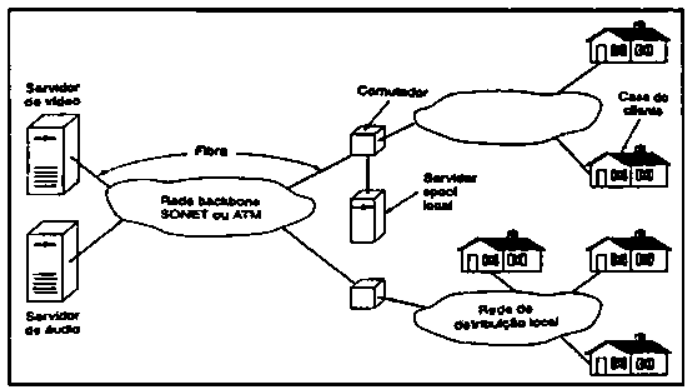

Figura 2.1: Visão geral de um sistema de vídeo sob demanda.

Assistir a filmes no esquema near video on demand é um dos inúmeros novos serviços que poderão ser oferecidos, uma vez que as redes de banda larga estejam disponiveis. O modelo genérico, usado por muitas pessoas é ilustrado na Figura 2.1. Na Figura, há uma rede de longa distância (nacional ou internacional) como backbone e grande largura de banda no centro do sistema. Conectadas ao backbone estão milhares de redes de distribuição locais, tais como TV a cabo ou sistemas de distribuição da companhia telefônica. Os sistemas de distribuição locais chegam até as casas das pessoas, onde terminam em set-top-boxes, na verdade PCs avançados e especializados.

Ligados ao backbone por cabos de fibra ótica de grande largura de banda estão vários provedores de informações. Alguns deles oferecerão vídeos pay-per-view, ou CDs de áudio pay-per-bear, nos quais o interessado paga para ver e para ouvir, respectivamente. Outros oferecerão serviços especializados como bomeshopping, noticias, reprises de filmes, acesso à WWW e inúmeras outras possibilidades estarào disponiveis em um futuro próximo[Car95]. 
Também incluidos no sistema estarào servidores locais (spooling servers), permitindo que os vídeos fiquem mais próximos dos usuários, para economizar largura de banda nos horários de pico. Será examinado, a seguir, o projeto dos principais componentes do sistema: os servidores de vídeo e os settop-boxes.

\subsubsection{Servidores de vídeo}

Para ter um recurso próximo, precisamos de servidores de vídeo com capacidade de armazenar e enviar um grande número de filmes simultaneamente. $O$ número total de filmes já feitos é estimado em 65.000 em 1995. Quando compactado em MPEG-2, um filme normal (2 horas) ocupa cerca 4 GB de espaço de armazenamento; portanto, considere uma locadora com 300 filmes, cada qual, com duas horas de duração, sendo necessário alocar 1,2 terabytes para armazenar todos os filmes. Logo fica claro que poderá haver problemas de armazenamento[Hac98].

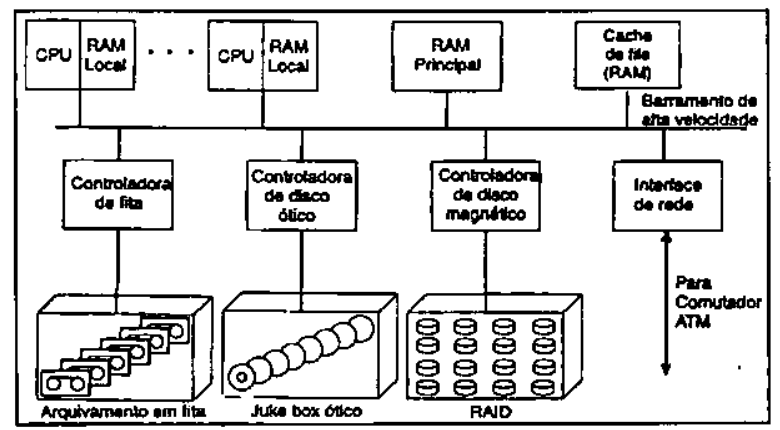

Figura 2.2: A arquitetura de hardware para um servidor de vídeo típico.

A arquitetura de hardware de um servidor de vídeo típico é ilustrada na Figura 2.2. O servidor tem uma ou mais CPUs RISC de alto desempenho, cada uma com alguma memótia local, uma memória principal compartilhada, uma boa memória RAM de cache para filmes mais solicitados, uma variedade de dispositivos de armazenamento para os filmes e um hardware de rede, normalmente uma interface ótica para uma rede ATM (ou SONET) em OC-3 ou mais. Esses subsistemas são conectados por um barramento de velocidade extremamente alta (pelo menos $1 \mathrm{~GB} / \mathrm{s}$ )[Che94].

Agora, será analisado o software de um servidor de vídeo. As CPUs são usadas para receber as solicitações dos usuários, localizar os filmes, movimentar dados entre os dispositivos, fazer as cobranças aos usuários. Algumas delas não dependem de tempo, mas outras dependem; portanto, algumas CPUs (ou todas elas) terão de executar um sistema operacional de tempo real. Esses sistemas normalmente dividem o trabalho em pequenas tarefas, cada um com um prazo conhecido.

O software da CPU também define a natureza da interface que o servidor (servidores de spoole set-top-boxes) apresenta aos clientes. Há dois projetos populares. O primeiro é um sistema de arquivos 
tradicional, no qual os clientes podem abrir, ler, gravar e fechar arquivos, sendo o sistema de arquivos baseado no UNLX.

O segundo tipo de interface é baseado no modelo do aparelho de videocassete. Os comandos para o servidor solicitam que ele abra o arquivo, reproduza seu conteúdo, faça uma pausa durante a reprodução e avance rapidamente ou retroceda no decorrer do processo. A diferença para o modelo UNIX é que uma vez executado o comando PLAY, o servidor envia os dados de maneira contínua e a uma taxa constante sem que nenhum outro comando seja necessário.

O núcleo do software do servidor de vídeo é o software de gerenciamento de disco. Ele tem duas funções principais: colocar os filmes no disco magnético quando tiverem de ser retirados da unidade de armazenamento ótico ou de fita e tratar as solicitações de disco para os muitos fluxos de saída. A colocação dos filmes é muito importante porque pode afetar muito o desempenho.

A outra tarefa do software de disco é dar assistência a todos os fluxos de saída de tempo real e atender a suas restrições de tempo. Um fluxo de vídeo MPEG-2 a 25 quadros por segundo precisa buscar e transmitir cerca de $14 \mathrm{~KB}$ a cada $40 \mathrm{~ms}$, mas a quantidade real varia muito porque os quadros I, P e B têm diferentes índices de compactação.

Outra questão do software é o controle de admissão. Se uma solicitação para um novo fluxo chegar, esta só será aceita se o desempenho em tempo real dos fluxos já existentes não for prejudicado.

Outro detalhe é a criptografia. Quando os filmes são transmitidos por multicast (por exemplo, se a rede de distribuição local for um sistema de TV a cabo), a criptografia é necessária para assegurar que só os clientes pagantes possam assistir ao filme.

\subsubsection{Set-top-boxes}

Para decodificar os fluxos MPEG, são necessários uma interface de rede e um decodificador MPEG. São descritas duas possibilidades.

$\mathrm{Na}$ primeira possibilidade, os usuários usam seus próprios computadores para decodificar e assistir aos filmes. Essa solução exige uma placa especial com soquetes contendo alguns chips especiais e um conector para a interface com a rede de distribuição local. Com isso, os filmes são apresentados no monitor do computador, possivelmente em uma janela. Pode-se chamar essa caixa de set-bottom-box, pois normalmente ela fica embaixo do monitor em vez de em cima dele. O custo dessa estratégia é mais baixo (sendo necessários uma placa com soquete e o software), utiliza um monitor de alta resolução não-entrelaçado, tem uma sofisticada interface com o usuário que se baseia no uso do mouse e pode ser facilmente integrada à WWW e a outras fontes de informaçāo e entretenimento voltadas para o computador. 
$\mathrm{Na}$ segunda possibilidade, o operador de rede local aluga ou vende uma STB à qual a rede e o aparelho de TV estào conectados.

O lado negativo desse enfoque é que o monitor de TV possui uma apresentação de baixa resolução e entrelaçada (o que o torna impróprio para material destinado a texto, como a WWW), além de apresentar uma interface ruim (o controle remoto), que torna improssível que o usuário faça qualquer coisa que não seja selecionar itens a partir de menus simples.

As principais funções da caixa STB são estabelecer uma interface com a rede de distribuição local, decodificar o sinal MPEG, sincronizat os fluxos de áudio e vídeo, produzir um sinal NTSC, PAL ou SECAM para o aparelho de TV e controlar o controle remoto e a interface com o usuário. Outras funções poderiam incluir servir de interface com aparelhagens de som, telefones e outros dispositivos.

Uma possível arquitetura para uma simples STB é ilustrada na Figura 2.3. O dispositivo consiste em uma controladora de CPU, ROM, RAM e E/S, em um decodificador de MPEG e em uma interface de rede. Opcionalmente, é possível acrescentar um chip de segurança para a criptogtafia dos filmes recebidos e das mensagens enviadas (números de cartões de crédito para telecompras, etc).

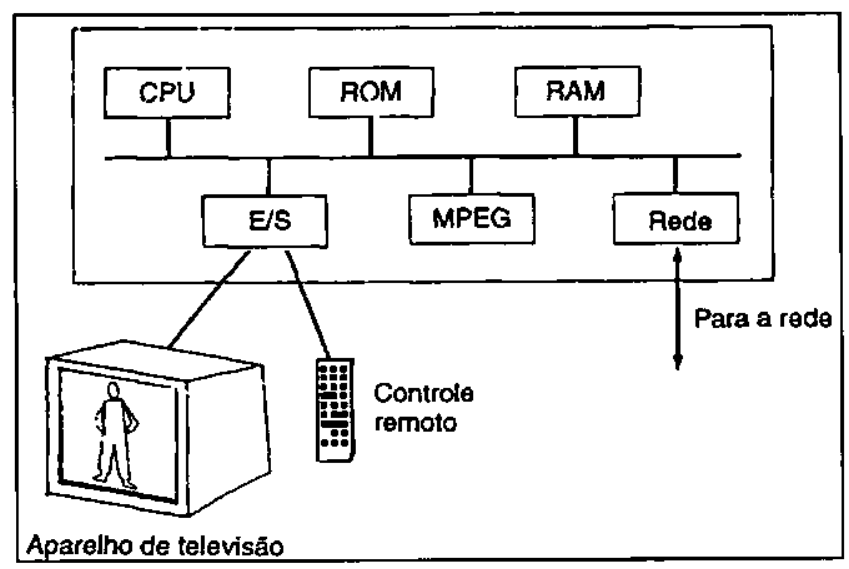

Figura 2.3. A arquitetura de hardware para uma set-top-box simples

Uma questão importante para o vídeo sob demanda é a sincronização de áudio e vídeo e o gerenciamento do jittert. O acréscimo de $500 \mathrm{~KB}$ extras de memória RAM possibilita 1 segundo de armazenamento em buffer para o MPEG-2, mas constitui uma despesa para o dispositivo.

Como a set-top-box é apenas um computador, ela precisatá de software, provavelmente um sistema operacional em tempo real, baseado em microkernel $\dot{f}$ e armazenado na memória ROM.

+ Jitter = variação do delay

` Corresponde a um núcleo do sistema operacional enxuto, provendo apenas os serviços básicos como comunicaçào. 


\subsection{Distributed Home Theatre (DHT)}

Conforme, a Distributed Home Theatre (DHT) possibilita que qualquer integrante de um grupo distribuido de usuários, aos quais um filme é simultaneamente exibido aos participantes de uma vídeoconferência, iniciar um debate sobre uma cena especifica[Fon97a].

Assume-se a existência de um fluxo individual de vídeo para cada usuário e assume-se também que todos os fluxos de uma sessão são distribuídos por um mesmo servidor, chamado de servidor de controle. Melhorias nesta arquitetura podem ser propostas. Uma opção é a de permitir que o servidor mais próximo do usuário distribua o filme. Neste caso, somente mensagens de controle são trocadas entre os servidores. Embora estas alternativas possam reduzir de forma significativa a demanda de largura de banda, elas exigem uma complexidade de servidor/comutador que pode não estar disponível em uma primeira implementação dos serviços de DHT.

Considera-se também uma rede de distribuição hierárquica composta por um backbone ATM, redes metropolitanas ATM e loops locais conectados a rede metropolitana através de bead ends ATM.

\subsection{Breve comparação entre VoD e DHT}

De acordo com, fornecer serviços de DHT custa mais caro do que fornecer serviços de vídeo sob demanda. Isto acontece porque os usuátios de um sistema DHT se conectam a um determinado servidor, enquanto que os usuários de um sistema de vídeo sob demanda se conectam ao servidor mais próximo. Em outras palavras, para um mesmo número de usuátios, o custo total de largura de banda de uma sessào de VoD é sempre o limite inferior do custo de banda passante de uma sessão de DHT.

\subsection{Considerações Finais}

Neste capítulo, foi introduzida uma visão geral das idéias básicas do video on demand $(V o D)$ e de sua implementação, além de conceitos básicos de distributed bome theatre (DHT)

Em ambientes de vídeo sob demanda, espera-se que após seleção do filme a exibição do mesmo inicie em curto intervalo de tempo. Isto é possível se existir banda passante disponível para satisfazer às requisições dos usuátios. Diversas técnicas foram propostas com o objetivo de reduzir a grande demanda de banda passante em servidores de vídeo. Estas técnicas são discutidas no próximo capítulo. 


\section{Capítulo 3 - Técnicas de sincronização de streams de vídeo}

\subsection{Considerações Iniciais}

Em sistema de video on demand, assinantes podem escolher tanto o filme quanto à hora da exibição. A qualidade do serviço pode ser caracterizada em termos do tempo de latência da requisição do cliente, definida como o tempo entre a chegada da requisição e a inicialização do serviço.

Sempre que uma requisição for feita ao servidor de vídeo um I/O stream precisa ser fixado. Desde que a largura de banda de I/O é um fator de peso para o sistema, estes streams são considerados como recursos chaves em um sistema de video on demand, e precisam ser gerenciados com cuidado.

Este capítulo trata das políticas que tem por objetivo o gerenciamento de streams de vídeo, destacando principalmente as políticas conhecidas como adaptive piggybacking. Este capítulo segue a seguinte organização: a próxima seção introduz os tipos básicos das políticas de gerenciamento de $\mathrm{I} / \mathrm{O}$ streams, a seção 3.3 trata da política adaptive piggybacking, na seção 3.4 são tratadas algumas técnicas baseadas no adaptive piggybacking, sendo que três técnicas são essenciais para este projeto, a saber: simple merging, simple merging generalizada e o Snapshot. Na seção 3.5 é apresentada uma análise de performance das técnicas, novamente focalizando as técnicas essenciais ao projeto, na seção 3.6 é apresentada uma avaliação das técnicas.

\subsection{Tipos básicos das políticas de gerenciamento}

Há muitas abordagens para redução da demanda de $\mathrm{I} / \mathrm{O}$ no servidor através de compartilhamento, aumentando o número de requisições de usuários os quais poderão ser servidos simultaneamente. Por exemplo, considere o seguinte: 
1. Batching: É um modo simples para reduzir os requerimentos de largura de banda [Dan96]. Nesta técnica, há um intervalo de tempo, chamado intervalo batching, para iniciar a transmissão do vídeo de modo que o grupo inteiro de requisições para o mesmo vídeo que chegar ao servidor durante este intervalo, possa ser servido usando único I/O stream. Logo para reduzir as exigências de I/O é necessário aumentar a latência, porém, grandes intervalos batching são incompativeis com a noção de um sistema de vídeo-sob-demanda[Kam94].

2. Bridging. Uma segunda técnica para reduzir a necessidade de largura de banda é chamada de bridging. Nesta técnica, é utilizada memória do processador central como um buffer. Se alguns quadros de um stream, em particular, for bufferizado ${ }^{6}$, logo qualquer subseqüente requisição para este vídeo dentro do correspondente intervalo, os dados poderão ser lidos do buffer ao invés de criar uma outra I/O stream do disco. Esta técnica possui a desvantagem que uma considerável quantidade de espaço em buffer pode ser requerida de forma a construir "pontes largas" o suficiente para render economias substanciais de largura de banda.

3. Adaptive Piggybacking. Ajusta a velocidades das streams durante o progtesso das mesmas (para um mesmo objeto) com o objetivo de mesclá-Jas[Fon97b]. De algum modo, a política adaptive piggybacking é similar a política batcbing, com a vantagem de eliminar a latência extra do intervalo batcbing.

Em geral, os seguintes parâtmetros podem ser usados para aperfeiçoar o número de requisições simultâneas que um sistema pode servir: 1) delay time (para batching), 2) política de união (para adaptive piggybacking), 3) políticas para alocação de buffer, e 4) técnicas para alteração da taxa para exibição (veja seção 3.3 para maiores detalhes). Redução na quantidade de largura de banda consumida através da agregação de requisições para um filme é considerado o objetivo principal destas políticas. A seguir, é introduzida a política de mesclagem adaptive piggybacking.

\subsection{Adaptive Piggybacking}

$\mathrm{Na}$ adaptive piggybacking, inicia-se um I/O stream para cada stream de apresentação, sob-demanda, e então permite que uma stream de apresentação faça uma adaptive piggybacking com um I/O stream de outra stream de apresentação (para o mesmo objeto). Isto pode ser visto como um dynamic merging de duas I/O streams em uma. Antes da união "merging", havia duas I/O streams, cada uma servindo uma (ou mais) stream (s) de apresentação, onde os streams de apresentação correspondem, temporariamente, a dois I/O streams do mesmo objeto. Depois do merge, há somente um I/O stream, o qual pode servir ambos streams

' Refere-se ao processo de armazenamentos de dados no buffer. 
de apresentação, e além disso os streams de apresentação estão em "sincronização". Isto é ilustrado na Figura 3.1, onde streams ${ }^{7}$ de apresentação 3 e 4 correspondem a requisições para o mesmo objeto e são servidas usando um único $\mathrm{I} / \mathrm{O}$ stream, nomeado, $\mathrm{I} / \mathrm{O}$ stream 3. Como descrito na seção 3.2 , este merging pode ser executado ajustando as taxas de cada requisição, por exemplo, ao invés de apresentar cada requisição a uma taxa constante, o sistema pode ajustar a taxa de apresentação de cada requisição, tanto para uma taxa "mais baixa" ou uma taxa "mais alta", de forma a cobrir a diferença temporal entre as exibiçōes; uma vez que a diferença foi coberta, ambas exibiçōes podem ser servidas através de um único I/O stream.

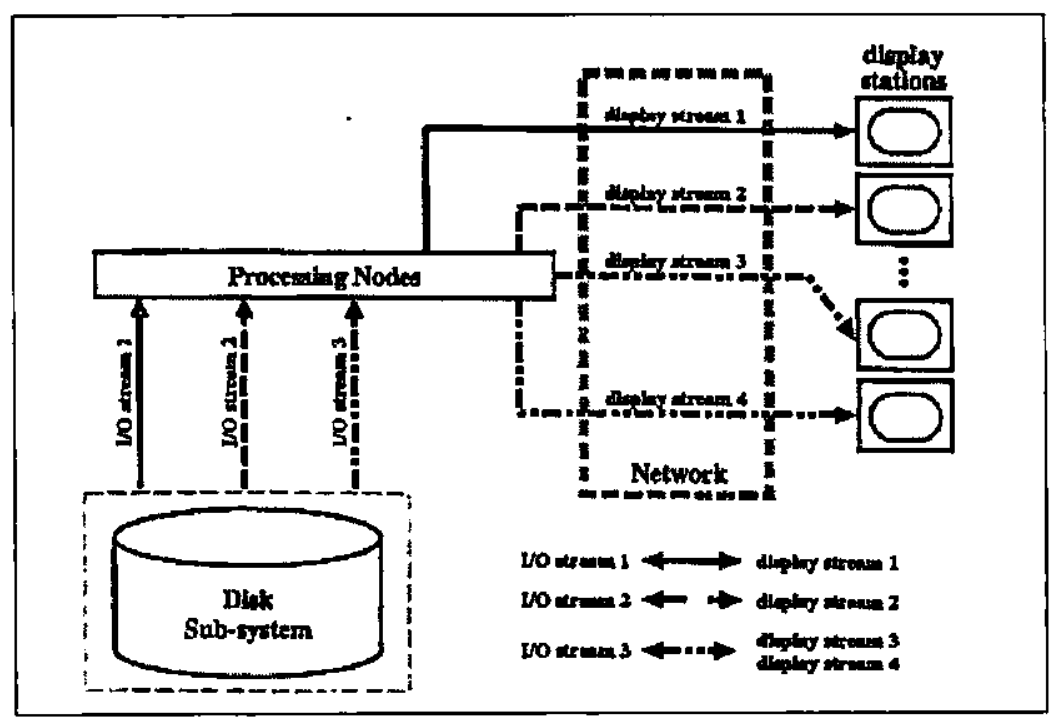

Figura 3.1: Visāo simplificada do sistema.

Pode-se ver a duração da apresentação de um objeto como uma continua linha de tamanho finito e considerar o problema do adaptive piggybacking como um problema de decisão; dado o estado global do sistema, por exemplo, a posição (relativa ao começo da apresentação) de cada stream de apresentação em progresso, deve-se escolher a taxa de apresentação de cada uma das requisições, de modo que a média total da demanda de I/O stream no sistema seja minizada.

Durante esse capítulo é investigada a redução da largura de banda atribuída ao adaptive piggybacking ao invés de uma arquitetura de servidor em particular. Entretanto, não é especificada nenhuma técnica em particular para alteração da taxa de apresentação. Ao invés, é associado um custo a cada I/O stream, onde o custo é uma função da correspondente taxa de apresentação. Em outras palavtas, o custo de

7 Os streams 3 e 4 devem ser transmitidos através da rede como um único stream o maior período de tempo possível. Políticas alternativas de transmissão que possa reduzir a utilização da largura de banda é assunto do capítulo 4. 
I/O para servir uma taxa de apresentação (rápida ou lenta) pode ser diferente do custo de servir uma taxa de apresentação normal. Por exemplo, o aumento da velocidade (ou diminuição) pode ser atingido, replicando dados, então o número total de bytes lidos do disco pode diferir, dependendo da taxa de apresentação de um stream. Se por outro lado o corte (ou duplicação) de quadros é usado, então o número total de bytes lidos do disco continuará sendo o mesmo, sem importar a taxa de apresentação do stream. No seguinte exemplo, não é feita nenhuma restrição com relação ao método usado para atingir diferentes taxas de apresentação.

Inicia-se derivando as condições gerais sob as quais os I/O streams $i$ e $j$ podem ser mesclados de modo a reduzir a demanda total de I/O no servidor. Para o restante desta seção, são consideradas somente as requisições para um mesmo objeto. Inicialmente, assume-se que a mesclagem pode ocorrer a qualquer momento durante a apresentação do objeto; esta afirmação é removida no final desta seção. Considere a seguinte notação:

$S_{k}^{\prime}=$ velocidade de apresentação (em quadros/seg) do stream de apresentação $k$ se não houver nenhuma chance de mesclagem, onde $k \in\{i, j\}$.

$S_{k}=$ velocidade de apresentação ajustada (em quadtos/seg) do stream de apresentação $k$ se houver alguma chance de mesclagem, onde $k \in\{i, j\}$.

$S_{k}^{*}=$ velocidade de apresentação (em quadros/seg) do stream de apresentação $k$ depois da mesclagem, onde $k \in\{i, j\}$.

$p_{M}=$ número total de quadros do objeto de vídeo.

$p_{k}=$ atual posição do objeto de apresentação (em quadros) do stream de $\mathrm{I} / \mathrm{O} K, k \in\{i, j\}$.

$p_{m}=$ posição (em quadros) de mesclagem entre os streams de I/O $i$ e $j$.

$C_{k}^{\prime}=$ largura de banda (em bits/seg) do I/O stream correspondente ao display stream $k$, com a velocidade $S_{k}^{\prime}$

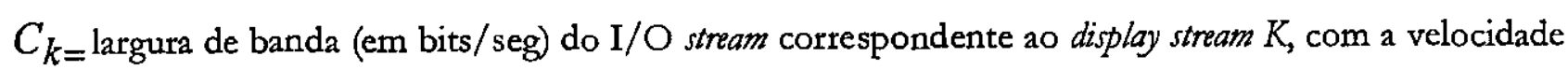
$S_{k}$

$d=$ distância (em quadros) entre os I/O streams $i$ e $j$, a qual é equivalente a $p_{j}-p_{i}$.

\footnotetext{
${ }^{8}$ Note que, poderia haver outros custos, além da largura de banda, associados com a leitura de dados em alta ou baixa taxas, por exemplo, espaço de buffer adicional; de qualquer maneira, considerando que não se está levando em conta uma arquitetura específica, nào será avaliado os custos do espaço em buffer nesta dissertação.
} 
$d_{m}=$ distância (em quadros) entre o ponto de mesclagem e a posição atual do $j$, o qual é igual a $p_{m}-p_{j}$

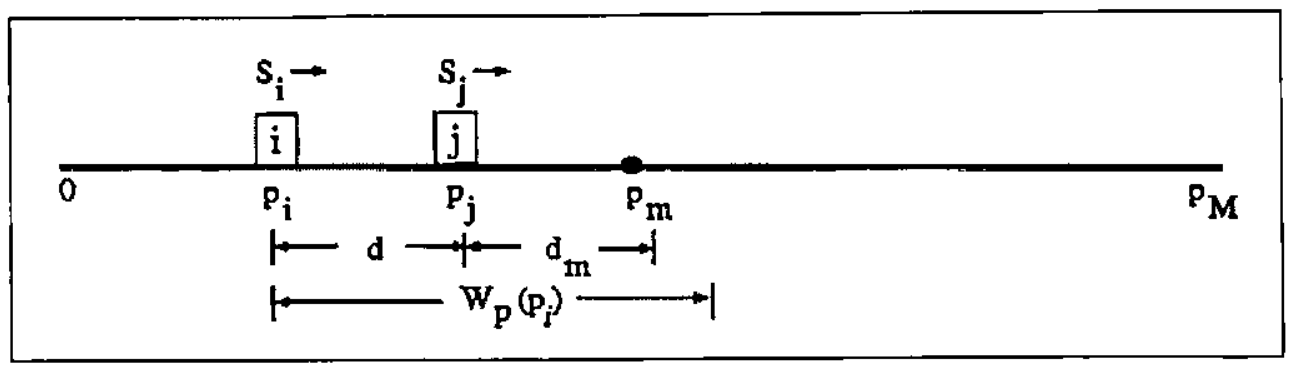

Figura 3.2: Estado do Sistema (do ponto de visão de um único objeto).

Figura 3.2 representa a duração da apresentação de um objeto como uma contínua linha de tamanho $p_{M}$. Cada display stream, por exemplo, stream $i$, é identificado pela sua posição na apresentação do objeto, $p_{i}$, e está se movendo a uma velocidade em particular, $S_{i}$. De forma a mesclar os I/O streams $i$ e $j$, primeiramente, deve-se garantir que:

$$
S_{i}>S_{j}
$$

Em segundo lugar, pode-se definir as restrições em relação à distância e o custo, os quais podem ser usados em qualquer política adaptive piggybacking, para identificar oportunidades de mesclagens, por exemplo, se é ou não possível a um custo eficaz para mesclar as stream $i$ e $j$. As restrições de custo garantem que o total da demanda de I/O (medidas em bits lidos do disco) com mesclagem é menor do que o total da demanda de I/O sem mesclagem. A restrição ao custo de I/O é o seguinte?:

$$
\frac{d C_{i}}{S_{i}}+\frac{d_{m} C_{i}}{S_{i}}+\frac{d_{m} C_{j}}{S_{j}}+\frac{\left(p_{M}-d-d_{m}-p_{i}\right) C_{j}^{*}}{S_{j}^{*}} \leq \frac{\left(p_{M}-p_{i}\right) C_{i}^{\prime}}{S_{j}^{*}}+\frac{\left(p_{M}-p_{i}-d\right) C_{j}^{\prime}}{S_{j}}
$$

Note que esta restrição é somente válida quando o número de bits lidos do disco não for independente da taxa de apresentação, ou seja, é significativo somente quando a replicação é utilizada. De outra forma, qualquer mesclagem antes do final do vídeo resultará em economia; logo equação 7 torna-se a única restrição, isto é, o tamanho do objeto (ou a duração da apresentação) é finito e conseqüentemente requer a seguinte restrição:

$$
p_{i}+d+d_{m} \leq p_{M}
$$

\footnotetext{
9.Desde que $\mathrm{I} / \mathrm{O}$ stream $i$ é mesclado com $j$, depois da mesclagem somente o custo do $\mathrm{I} / \mathrm{O}$ stream $j$ precisa ser considerado além do ponto de mesclagem.
} 
Finalmente, a restrição ao tempo de mesclagem é:

$$
\frac{d+d_{m}}{S_{i}}=\frac{d_{m}}{S_{j}}
$$

Considere $d_{1}$ como o máximo valor de $d$, de modo que a condição de custo de $\mathrm{I} / \mathrm{O}$ na equação (2) seja satisfeita. Obtêm-se $d_{1}$ usando a equação (4) para obter $d_{m}=d\left(S_{j} / S_{i}-S_{j}\right)$ e logo setando a igualdade na equação (2); Logo:

$$
d_{1}=\frac{\left.\frac{\left(p_{M}-p_{i}\right) c_{i}^{\prime}}{s_{i}^{\prime}}+\frac{\left(p M-p_{i}\right) c_{j}^{\prime}}{s_{j}^{\prime}}-\frac{\left(p_{M}-p_{i}\right) c_{j}^{*}}{s_{i}^{*}}\right]}{\left[\left(\frac{c_{i}}{s_{i}}-\frac{c_{j}^{*}}{s_{j}^{*}}+\frac{c_{j}^{\prime}}{s_{j}^{\prime}}\right)+\left(\frac{s_{j}}{s_{i}+s_{j}}\right)\left(\frac{c_{i}}{s_{i}}+\frac{c_{j}}{s_{j}}-\frac{c_{j}^{*}}{s_{j}^{*}}\right)\right]}
$$

Considere $d_{2}$ sendo o maior valor de $d$ de modo que a restrição com a distância na equação (3) é satisfeita. Novamente, $d_{2}$ pode ser obtida pela substituição da expressão para $d_{m}$ na equação (3) e resolvendo a igualdade:

$$
d_{2}=\frac{\left(p_{M}-p_{i}\right)\left(S_{i}-S_{j}\right)}{S_{i}}
$$

Considere $d^{*}$ como sendo a distância máxima entre dois I/O streams de modo que mesclando estes dois streams (em $d_{m}$ ), resulta em uma redução da demanda de I/O no servidor. Logo,

$$
d^{*}=\min \left(d_{1}, d_{2}\right)
$$

Pode-se agora aplicar este resultado para as várias políticas adaptive piggybacking, as quais são descritas a seguir. O objetivo é encontrar políticas adaptive piggybacking que possuem significante economia na demanda de I/O em comparação à política baseline ${ }^{10}$.

Para fazer observações sobre as decisões para o ajuste das taxas de transmissão considere novamente o estado do sistema ilustrado na Figura 3.2; claramente, os únicos eventos estocásticos no sistema são os pontos de chegada; os eventos como ponto de mesclagem de dois streams, o fim do display, são previsíveis. Logo, uma política de otimização pode avaliar todas as possibilidades das taxas

${ }^{10}$ Esta é a situação normal; quando uma requisição chega, não há tentativa de ajustar as taxas de transmissão, por exemplo, todas as requisições são associadas a velocidade normal $S_{n}$ e não há eventos de mesclagem no sistema. (Note que a falta de mesclagem não exclui a possibilidade de um batching inicial.) 
de transmissão, fazendo as decisões apropriadas com respeito a minimização da demanda de $\mathrm{I} / \mathrm{O}$, e então não reavaliando estas decisões até a chegada de uma nova requisição. Entretanto, isto poderia ser computacionalmente intensivo e logo impraticável. Ao invés, considera-se uma classe (mais simples) de políticas as quais fazem os ajustes das velocidades quando um doj quatro eventos seguintes ocorrerem: 1) chegada, 2) mesclagem, 3) dropoff, 4) window crossing. Um evento de ckıegada corresponde a inicialização de um novo I/O stream. Um evento de mesclagem corresponde a mesclagem de dois $\mathrm{I} / \mathrm{O}$ streams, e o evento de dropoff corresponde ao corte de um I/O stream. $O$ evento de window crossing refere-se a travessia do limite de uma janela, a qual está ilustrada na figura 3.2. Uma janela é definida como, $W_{p}\left(p_{i}\right)$, para a política $p$, como sendo a distância máxima possível entre os streams $i$ e $j$, à frente do stream $i$, de modo que uma mesclagem eficiente seja possivel; $W_{p}\left(p_{i}\right)$ é computada relativamente a posição $p_{i}$ na exibição de um objeto. $W_{p}\left(p_{i}\right)$ pode ser calculada usando a equação 7 .

Quanto mais cedo ocorrer a mesclagem (durante a exibição do objeto) mais recursos (por exemplo, largura de banda de disco, espaço em buffer) será conservado e usado para servir outras requisições. Logo, no restante deste capítulo assumi-se o máximo desvio possível da velocidade normal (tanto para a mais rápida quanto para a mais lenta). Em outras palavras, limita-se as políticas para considerar somente três possiveis taxas de transmissão: 1) a taxa mais lenta, $S_{\min }, 2$ ) a taxa normal, $S_{n}$ e 3) a taxa mais rápida, $S_{\max }$; as correspondentes demandas de $\mathrm{I} / \mathrm{O}$, ou taxas de custo, são $C_{\min }, C_{n}$ e $C_{\max }$

\subsection{Políticas baseadas no adaptive piggybacking ${ }^{11}$ :}

\subsubsection{Política de redução Odd-even}

Esta política de ajuste simples da taxa de transmissão tenta reduzir a demanda de I/O em até $50 \%$. A proposta básica é de fazer a mesclagem aos pares, de acordo com a seqüência de chegada, sempre que possível; Considere a nomenclatura $W_{o e}(0)$, medida relativamente ao início de um stream (veja Figura 3.3), para ser a janela de mesclagem para a política de redução odd-even.

\footnotetext{
$"$ As políticas simple merging simple merging generalizada e snapsbot, por estarem diretamente ligadas ao projeto, receberão uma análise mais detalhada.
} 


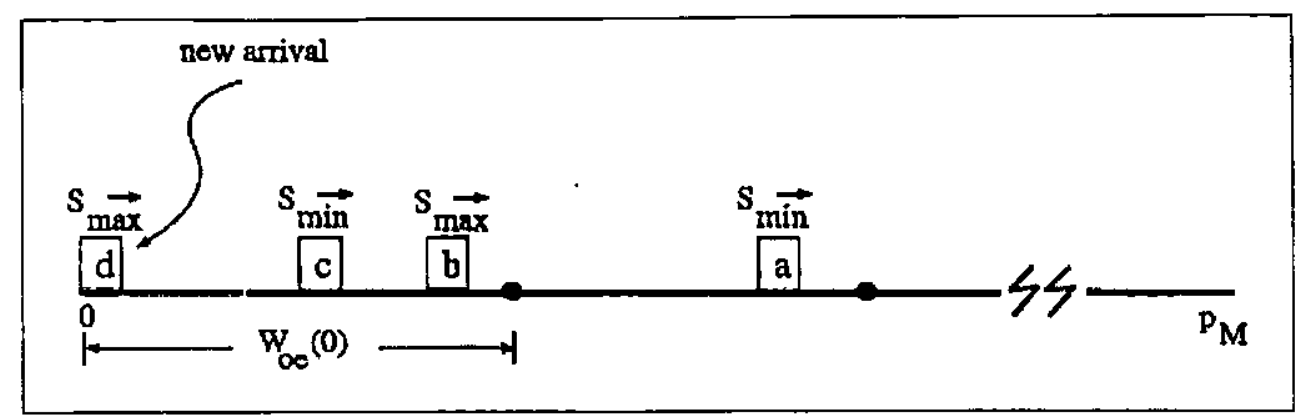

Figura 3.3: Estado do Sistema (do ponto de visão de um único objeto).

Figura 3.3 ilustra um possível cenário desta política. Quando o $\mathrm{I} / \mathrm{O}$ stream $d$ chegou ao sistema, I/O stream $c$ ainda estava na janela de mesclagem, $W_{o e}(0)$, "movendo-se" na velocidade $S_{\min }$; neste caso, a velocidade de transmissão da requisição $d$ é setado para $S_{\max }$. Do mesmo modo, quando stream $b$ chegou ao sistema, I/O stream $a$ estava dentro da janela de mesclagem $W_{o e}(0)$; por essa razão, a relocidade de transmissão de $b$ é setado para $S_{\max }$. Neste cenátio, I/O streams $a$ e $b$ mesclarão em um único I/O stream, e streams $c$ e $d$ também mesclarão em um único I/O stream.

\subsubsection{Política Simple Merging}

Define-se $W_{s m}(0)$ a ser a janela de mesclagem para a política Simple Merging, medida relativamente ao começo do primeiro stream da janela (veja Figura 3.4). Em adição, define-se $W_{s m}^{m}(0)$ como sendo o tamanho máximo da janela de mesclagem para a política simple merging, também medida relativamente ao início de um stream. $W_{s m}^{m}(0)$ indica a última posição possível onde a mesclagem de dois streams poderá ocorrer, por exemplo, se $i$ chegar ao sistema e encontrar $j, W_{s m}(0)$ quadros a sua frente, logo $i$ e $j$ poderão mesclar-se, e além disso, eles irão mesclar-se no limite da $W_{s m}^{m}(0)$ (veja Figura 3.4). A idéia básica que envolve a política simple merging é associar streams à "grupos de mesclagens", onde uma stream, por exemplo, stream $i$, inicia o grupo, e todas as streams que chegarem ao sistema enquanto a stream $i$ estiver dentro da $W_{s m}(0)$, eventualmente irão mesclar-se com a stream $i$; a última stream irá mesclar-se "dentro do grupo" antes que $W_{s m}^{m}(0)$ expire. O algoritmo para a política de mesclagem é: 
Algoritmo 3.1: Politica Simple Merging

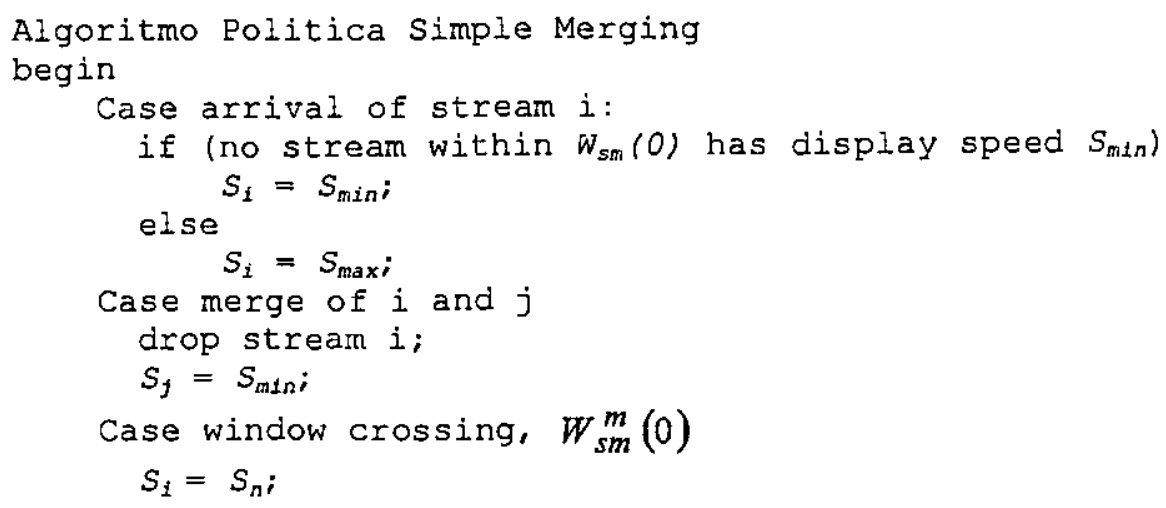

Note que a idéia de manter a taxa de transmissão à $S_{\min }$ até ultrapassar o limite de $W_{s m}^{m}(0)$, é permitir que todos os streams do grupo de mesclagem possam mesclar-se.

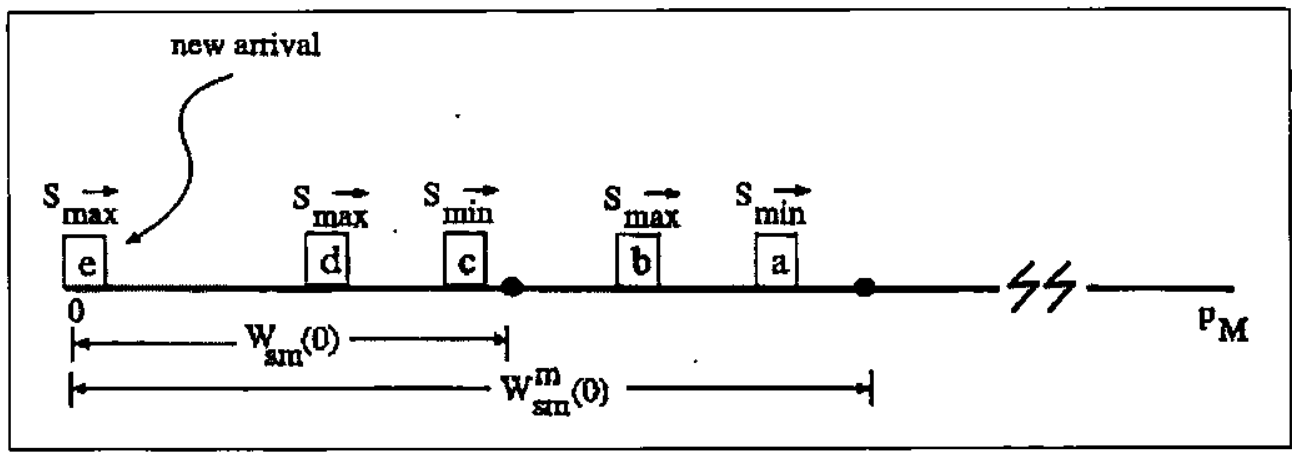

Figura 3.4: Cenário da Política Simple Merging.

Figura 3.4 ilustra um possível cenário desta política. Quando o I/O stream $c$ chegou ao sistema, I/O stream $a$ já havia ultrapassado a janela de mesclagem $W_{s m}(0)$; por essa razão, a velocidade de apresentação do I/O stream $c$ foi setado para $S_{\min }$. Quando o stream $b$ (streams $d$ e $e$ ) chegou ao sistema, stream a (stream $c$ ) estava dentro da janela de mesclagem $W_{s m}(0)$; logo, as velocidades de transmissão foram configuradas para $S_{\max }$. Neste cenátio, stream $b$ eventualmente mescla com stream $a$, e streams $d$ e $e$ irão mesclar com o stream $c$ (todas mesclagens ocorrem dentro da janela $W_{s m}^{m}(0)$ ). A Figura 3.5 ilustra esta situação, o eixo x representando (aumento) tempo e o eixo y representando a posição do vídeo em quadros. ( $O$ tamanho da janela e o tamanho $\mathrm{L}$ do vídeo também é apresentado.) Note que há sempre um único stream lento associado com cada janela distinta. Por outro lado pode haver qualquer número de streams rápidos, incluindo zero. 


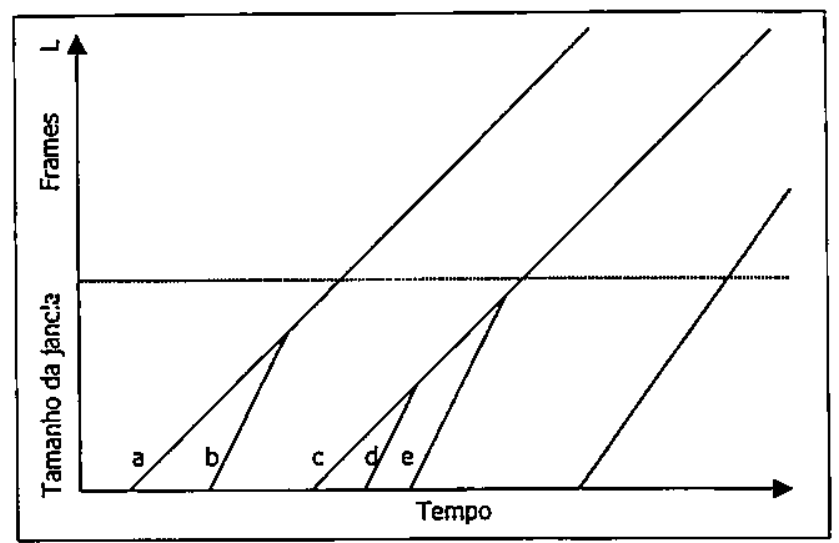

Figura 3.5: Politica Simple Merging

$W_{s m}(0)$ e $W_{s m}^{m}(0)$, podem ambos serem computados usando a equação (7). Os valores de $d_{1} \mathrm{e}$ $d_{2}$ podem ser encontrados (usando equações (5) e (6), respectivamente) simplesmente aplicando $p_{i}=0, C_{i}=C_{\max }, S_{i}=S_{\max }, C_{j}=C_{\min }, S_{j}=S_{\min }, C_{i}^{\prime}=C_{j}^{\prime}=C_{n}, S_{i}^{\prime}=S_{j}^{\prime}=S_{n}$, $C_{i}^{*}=C_{n}, S_{i}^{*}=S_{n}$. Então, tem-se:

$$
\begin{gathered}
d_{1}=\frac{\left[\frac{p_{M} C_{n}}{S_{n}}\right]}{\left[\left(\frac{C_{\max }}{S_{\max }}\right)+\left(\frac{S_{\min }}{S_{\max }-S_{\min }}\right)\left(\frac{C_{\max }}{S_{\max }}+\frac{C_{\min }}{S_{\min }}-\frac{C_{n}}{S_{n}}\right)\right]} \\
d 2=\frac{p_{M}\left(S_{\max -S_{\min }}\right)}{S_{\max }} \\
W_{s m}(0)=\min \left(d_{1}, d_{2}\right) \\
W_{s m}^{m}(0)=W_{s m}(0)+d_{m} \\
=W_{s m}(0)\left(1+\frac{S_{\min }}{S_{\max }-S_{\min }}\right)=W_{s m}(0)\left(\frac{S_{\min }}{S_{\max }-S_{\min }}\right)
\end{gathered}
$$




\subsubsection{Simple Merging generalizada}

De forma a aumentar a performance da política simple merging original, o tamanho de $W_{s m}$ é otimizado em função da previsão da taxa de requisições. Assuma, para simplicidade, que requisições para o vídeo são modeladas por um processo de Poisson com parâmetro $\lambda$. (Esta suposição não proporcionará resultados precisos.)

As contrapartidas para diferentes tamanhos de $W_{s m}$ são as seguintes:

(1) Quando o tamanho da janela é gtande, ocorterá um número maior de mesclagens. Porém estas tendem a ocorrer nos últimos estágios da exibição do vídeo, resultando em poucos beneficios.

(2) Quando o tamanho da janela é pequeno, mesclagens tendem a ocorrer em estágios mais próximos do início do vídeo. Porém ocorrerão poucas mesclagens.

De forma a quantificar as economias proporcionadas pelo piggybacking, recordando que sempre que uma stream lenta mescla-se com uma stream rápida, ambas streams irão combinar-se em uma stream lenta. Por efeito, assume-se que o stream rápido existe somente até aquele momento. Logo necessita-se do stream rápido até o ponto de mesclagem.

Primeiramente, considere o modelo que expressa o número esperado de quadros para um stream aleatoriamente escolhido como uma função do tamanho da janela $W_{s m}$. Considere a chegada de uma nova requisição, a probabilidade da velocidade do respectivo stream ser rápida é $P_{\text {fast }}$ ou lenta $P_{\text {slow }}=1$ $P_{\text {fast }}$. O número esperado $E[F]$ de quadros lidos por um stream aleatório é a média ponderada do número esperado de quadros $E\left[F_{\text {fass }}\right]$ se o stream é rápido e o número esperado de quadros $E\left[F_{\text {stas }}\right]$, se o stream for lento. Em outras palavras,

$$
E[F]=P_{\text {fast }} . E\left[F_{\text {fost }}\right]+P_{\text {slow }} \cdot E\left[F_{\text {sloas }}\right]
$$

De acordo com as regras assumidas, $F_{\text {slom }}$ é deterministicamente igual a $p_{M}$, e então $E\left[F_{\text {slow }}\right]=p_{M}$. Para calcular o número de quadros, considerando que o stream é rápido, suponha que o stream lento mais próximo esteja $p$ quadros à frente. O número de quadros requerido por este stream rápido para mesclar-se com o stream lento é dado por

$$
F_{\text {fast }}=\frac{p \cdot S_{\max }}{S_{\max }-S_{\min }}
$$

Note que o algoritmo é projetado de modo a garantir que $p \leq W_{s m}$. Desde que a taxa de chegada de requisições seja uniforme, segue pela simetria que $p$ é uniformemente distribuido entre zero e $W_{s m}$. Logo 


$$
E\left[F_{\text {fast }}\right]=\frac{W_{s m} / 2 \cdot S_{\max }}{S_{\max }-S_{\min }}
$$

Para calcular a probabilidade que um stream aleatoriamente escolhido será rápido. Note que todos os streams os quais estejam distantes de no máximo $W_{s m}$ quadros de um stream lento (ou, equivalentemente, estão dentro de $W_{s m} / S_{\min }$ unidades de tempo de um stream lento) são rápidos. Logo para cada stream lento, o número esperado de streams rápidos que o segue é consecutivamente igual a $\lambda . W_{s m} / S_{\min }$. Consecutivamente, a fração de streams rápidos no sistema é aproximadamente igual a

$$
P_{\text {fast }}=\frac{\lambda W_{s m} / S_{\min }}{\lambda W_{s m} / S_{\min }+1}
$$

Substituindo os valores acima na equação 12 , obtém-se a seguinte relação:

$$
E[F]=\frac{\lambda W_{s m}}{\lambda W_{s m}+S_{\min }} \cdot \frac{W_{s m} S_{\max }}{2\left(S_{\max }-S_{\min }\right)}+\frac{S_{\min }}{\lambda W_{s m}+S_{\min }} \cdot p_{M}
$$

Minimizando esta equação as restrições que um novo stream rápido deve sempre ser capaz de mesclar com um stream lento se o stream lento estiver no máximo $W_{s m}$ quadros a sua frente. Esta restrição resulta em:

$$
W_{s m} \cdot \frac{S_{\max }}{S_{\max }-S_{\min }} \leq p_{M}
$$

Ignorando a restrição por enquanto, aplica-se:

$$
\frac{d E[F]}{d W}=0
$$

Expandindo a equação resultante para $W_{s m}$ e simplificando, obtêm-se:

$$
W_{s m}^{2}+\frac{2 S_{\min }}{\lambda} \cdot W_{s m}-\frac{p_{M} S_{\min }\left(S_{\max }-S_{\min }\right)}{\lambda S_{\max }}=0
$$

Resolvendo a equação quadrática para $W_{s m}$ (e ignorando a raiz negativa), obtêm-se:

$$
W_{s m}^{*}=-\frac{S_{\min }}{\lambda}+\sqrt{\left(\frac{S_{\min }}{\lambda}\right)^{2}+2 \frac{p_{M} S_{\min }\left(S_{\max }-S_{\min }\right)}{\lambda S_{\max }}}
$$

A Segunda derivada é positiva e satisfaz a restrição 17 . Conseqüentemente, $W_{s m}^{*}$ é o tamanho janela de mesclagem ótima. A utilização janela de mesclagem ótima apresenta melhores resultados, tanto analiticamente quanto empiricamente, que o uso da janela de mesclagem máxima, aproximando- 
se dos resultados da política Greedy, o algoritmo que apresenta os melhores resultados em [Gol95], com a vantagem de ainda permanecer elementar.

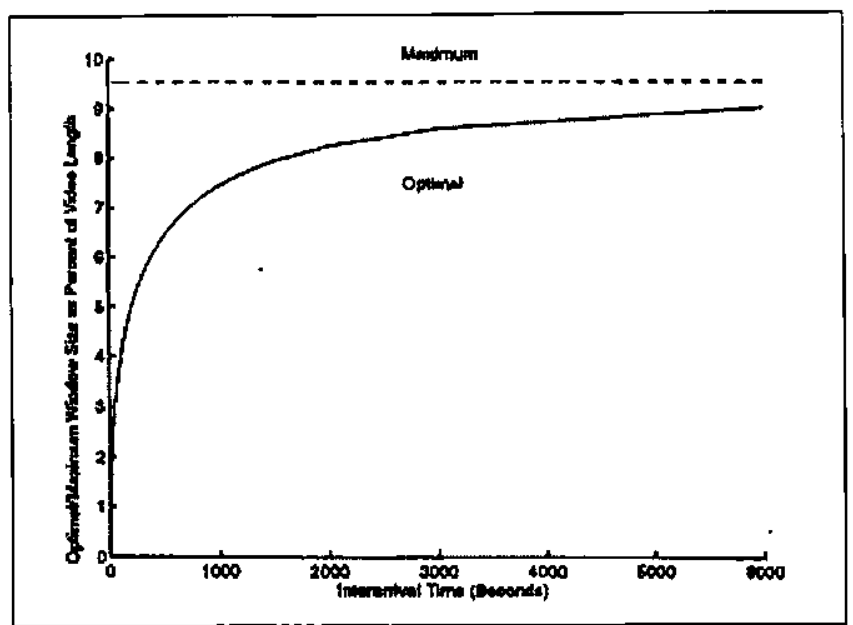

Figura 3.6: Tamanhos das janelas de mesclagem ótima e máxima

Figura 3.6 ilustra os valores relativos de $W_{s m}$ e $W_{s m}^{*}$ em função do intervalo entre as requisições (o recíproco de $\lambda$ ). (Estes são normalizados como uma porcentagem do total de númetos de quadros no vídeo). Estes números foram avaliados para um vídeo de duas horas com $S_{\min }=28.5$ e $S_{\max }=31.5$. Note que o tamanho da janela ótima é sempre menor que o tamanho da janela máxima de mesclagem, algumas vezes esta diferença é bastante significativa. Entretanto, $W_{s m}^{*}$ assintoticamente aproxima-se da $W_{s m}$ assim que o intervalo entre as requisições aumenta.

\subsubsection{Política Greedy.}

Se a taxa de requisições para o sistema for moderada pata alta, logo é vantajoso mesclar as requisiçōes quanto mais rápido possível (reduzindo a demanda de I/O mais cedo). Ambas políticas oddeven e simple merging tentam realizar isto. A política greedy tenta mesclar quantas vezes forem possíveis, durante toda apresentação do objeto. Por essa razão, em adição a janela de mesclagem inicial, $W_{g}\left(p_{i}\right)$, uma janela de mesclagem medida relativamente a posição $p_{i}$ na apresentação do objeto. Esta janela é usada pela política greedy (descrita abaixo) como uma possibilidade de ocorrerem mais mesclagens.

A política Greedy funciona da seguinte forma. No momento que chega uma requisição para um objeto, o ajuste de velocidade é realizado como na política odd-even. Se na travessia da janela de mesclagem, uma análise do stream determinar que este não está "cotado" para mesclagem, então checa $W_{g}\left(W_{g}(0)\right)$, para a possibilidade de mesclagem com alguma stream à frente. Quando a mesclagem ocorre na posição $p_{i}$, uma nova janela de mesclagem $W_{g}\left(p_{i}\right)$ é calculada. Se não há uma stream 
dentro desta janela, a velocidade de transmissão para requisição é configurada para $S_{n}$. Se houver alguma requisição dentro da janela de mesclagem $W_{g}\left(p_{i}\right)$ e a stream imediatamente a frente estiver com a velocidade $S_{n}$, logo a velocidade desta requisição será configurada para $S_{\min }$ e a velocidade da stream na posição $p_{i}$ será configurada para $S_{\max }$.

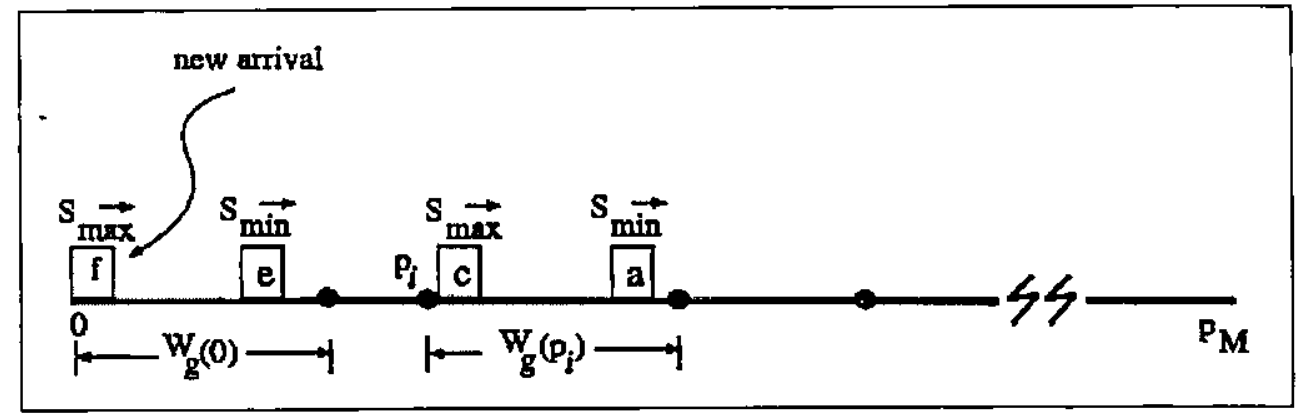

Figura 3.7: Cenário da Política de Mesclagem Greedy.

Figura 3.7 ilustra um possível cenário desta política. I/O streams $b$ e $d$ (não ilustrado) já foram mesclados com os streams $a$ e $c$, respectivamente; isto ocorre na primeira janela de mesclagem $W_{g}(0)$. Depois da mesclagem dos I/O streams $d$ e $c, \mathrm{I} / \mathrm{O}$ stream $c$ tenta mesclar com o I/O stream $a$, na janela de mesclagem $W_{g}\left(p_{i}\right)$. No mesmo tempo, um novo I/O stream, $f$, tenta mesclar com o $\mathrm{I} / \mathrm{O}$ stream $e$, o qual está dentro da janela de mesclagem $W_{g}(0)$.

$W_{g}\left(p_{i}\right)$, pode ser derivada da Equação (7). Os valores de $d_{1}$ e $d_{2}$ (agora ambas funções calculadas com relação a posição $i$ ) podem ser encontrados simplesmente aplicando $C_{i}=C_{\max }$, $S_{i}=S_{\max }, C_{j}=C_{\min }, S_{j}=S_{\min }, C_{i}^{\prime}=C_{j}^{\prime}=C_{n}, S_{i}^{\prime}=S_{j}^{\prime}=S_{n}, C_{i}^{*}=C_{n}, S_{i}^{*}=S_{n}$. Então, tem-se:

$$
\begin{gathered}
d_{1}=\frac{\left[2 \frac{\left(p_{M}-p_{i}\right) C_{n}}{S_{n}}+\frac{p_{M} C_{n}}{S_{n}}\right]}{\left[\left(\frac{C_{\max }}{S_{\max }}\right)+\left(\frac{S_{\min }}{S_{\max }-S_{\min }}\right)\left(\frac{C_{\max }}{S_{\max }}+\frac{C_{\min }}{S_{\min }}-\frac{C_{n}}{S_{n}}\right)\right]} \\
d_{2}=\frac{p_{M}\left(S_{\max }-S_{\min }\right)}{S_{\max }}
\end{gathered}
$$




\subsubsection{Merging Limitado}

Neste ponto remove-se a hipótese que a mesclagem possam ocorrer a qualquer momento. Se a replicação de dados for necessária de forma a executar a alteração da taxa de transmissão, então deve-se considerar outro parâmetro, denominado, a quantidade de espaço em disco adicional necessário para armazenar os dados duplicados. Há uma desvantagem entre a quantidade de armazenamento adicional, necessário para replicar dados, e a redução na demanda de I/O. Pode-se analisar a diferença considerando uma restrição adicional nas políticas de mesclagens, a restrição de um ponto máximo de mesclagem (na apresentação de um objeto). Em outras palavras, pode-se controlar a quantidade de dados que deve ser replicada permitindo o merging somente se este puder ocorrer dentro de uma intervalo de tempo ou dentro de uma determinada distância (em quadros), do começo da apresentação do objeto; esta distância é referida como $p_{m}^{\max }$. Considere novamente a Figura 3.2 e as equações (2) (4) as quais descrevem as restrições com relação à distância e ao custo que devem ser satisfeitas na tentativa de mesclagem de dois streams. Para controlar a quantidade de dados armazenados, é adicionada a restrição de que a mesclagem deve ocorrer antes de $p_{m}^{\max }$ ao invés de $p_{M}$, sendo $p_{m} \leq p_{m}^{\max }$. Logo, as equações (3) e (6) são repostas pelas equações (23) e (24), respectivamente, como segue:

$$
\begin{array}{r}
p_{i}+d+d_{m} \leq p_{m}^{\max } \\
d_{2}=\frac{\left(p_{m}^{\max }-p_{i}\right)\left(S_{i}-S_{j}\right)}{S_{i}}
\end{array}
$$

Todas as outras equações permanecem iguais (todas as modificações são válidas para as políticas de piggybacking discutidas acima).

\subsubsection{Algoritmo Snapshot}

Considere novamente um único vídeo consistindo de $p_{M}$ quadros. Suponha que em um ponto fixo no tempo $T$ haja um total de $n$ streams do mesmo vídeo sendo transmitido. Considere as posições destes streams, medidos em termos dos quadros, por $f_{1}, \ldots, f_{n}$, respectivamente. Sem perda da generalidade, pode-se assumir que $f_{1} \geq \ldots \geq f_{n}$. Ignore, por enquanto, as outras requisições para este vídeo que poderá aparecer mais tarde, e a maneira como os streams atingiram as suas atuais posiçōes. 
Este cenário é inteiramente determinístico, e por essa razão é significativo encontrar uma estratégia, a qual minimize o número total de quadros requeridos adiante do tempo $T$. Resolve-se este problema de otimização através do algoritmo de programação dinâmica[Gol96].

Como antes, as duas velocidades são denotadas por $S_{\max }$ e $S_{\text {min }}$ Não se pode assumir em uma solução ótima que o stream mais afastado possui sua velocidade configurada para $S_{\text {min }}$ (neste caso o correspondente a $f_{l}$ ), enquanto o último stream possui velocidade máxima $S_{\max }$ (o correspondente a $\left.f_{n}\right) . O$ algoritmo de programação dinâmica têm por objetivos gerar árvores binárias de mesclagens com seus respectivos custos. Cada nó folha destas árvores corresponde aos streams originais, enquanto os nós interiores correspondem as mesclagens. O nó raiz corresponde a mesclagem final de todas as $n$ streams originais. Os arcos à esquerda correspondem aos streams rápidos, e os arcos à direita correspondem aos lentos. Adiante do nó raiz há somente um stream, o qual pode prosseguir a qualquer velocidade. Algumas mesclagens próximas ao nó raiz podem não ocorrer. Isto depende se ou não estas ocorrerem depois da posição $p_{M}$.

Visto por este modo, há uma correspondência de um-para-um entre o conjunto de árvores binárias com os $n$ nós folhas e os $n$ streams.

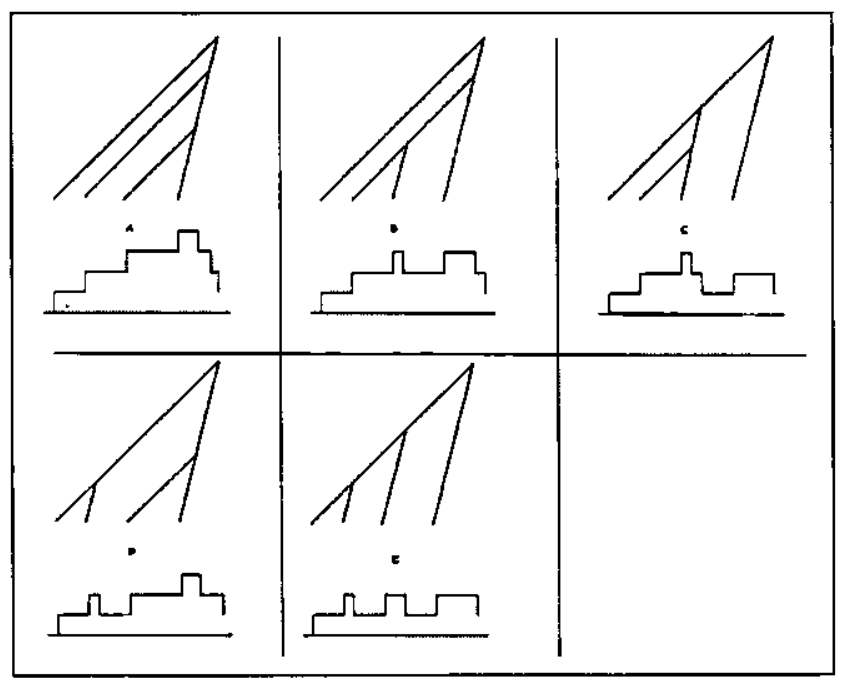

Figura 3.8: Árvores binárias alternativas e seus custos.

A figura 3.8 ilustra as 5 possíveis árvores binárias para um cenário no qual $n=4$ streams. Nesta o eixo x representa a posição e o eixo y corresponde ao tempo. A área do histograma abaixo de cada árvore binária ilustra o custo, em quadros, da implementação da determinada estratégia, assumindo que a mesclagem final, o nó raiz, ocorre antes de $p_{M}$. Note que a raiz ocorre sempre na mesma posição, e o custo restante é a diferença entre esta posição e $p_{M}$. Como é uma constante, o stream restante não foi ilustrado. Sendo uma constante, este termo é também irrelevante para o problema de otimização. Se $p_{M}$ ocorre antes da mesclagem final, o custo real corresponderia a integração da curva até $p_{M}$. 
Analisando-se a política odd-even descrita em [Gol95], emparelha streams sucessivos os quais não possuem uma diferença maior do que o tamanho da janela de mesclagem. A política greedy desenvolvida em [Gol95] repete este processo recursivamente com sucessivas mesclagens. Logo, a grosso modo, a política greedy resulta em árvores binárias da forma ilustrada na figura (d).

O número de árvores binárias pelo número de nós folhas (streams) é dado pelo (n-1) número de Catalan:

$$
b(n-1)=\frac{1}{n}\left(\begin{array}{c}
2 n-2 \\
n-1
\end{array}\right)
$$

O número de Catalan $b(n)$ pode ser aproximado através da aproximação de Stirling como:

$$
b(n) \approx \frac{4^{n}}{n^{3 / 2} \sqrt{\pi}}
$$

Logo o número de Catalan cresce muito rapidamente, e procurar todas as árvores binárias para qualquer valor moderado de n é impraticável. Felizmente, a seguir é descrita uma melhor maneira.

Considere $i$ e $j$ dois streams entre 1 e $n$, com $i \leq j$ e $P(i, j)$ representando a hipotética posição em quadros na qual os streams $i$ e $j$ poderiam mesclar considerando somente a chegada dos streams $i, \ldots, j$. Este valor poderia ser maior que $p_{M}$, e seria também o valor no qual os streams $i$ e $j$ mesclaria se estes fossem os únicos streams. O ponto é que $P(i, j)$ é bem definido porque a política ótima envolveria stream $i$ movendo-se na velocidade mínima e stream $j$ movendo-se na velocidade máxima. Logo obtemos:

$$
P(i, j)=f_{i}+\frac{S_{\min } \cdot\left(f_{i}-f_{j}\right)}{S_{\max }-S_{\min }}
$$

para $i<j$, e

$$
P(i, i)=f_{i}
$$

Este valor pode então ser computado para cada par $i$ e $j$ relevante e é independente de todas as outras streams. Agora, considere $C(i, j)$ denotando o custo de uma política ótima na qual somente as chegadas $i, \ldots, j$ ocorrem e $\tau(i, j)$ correspondendo a árvore binária. É fácil ver que

$$
C(i, i)=L-f_{i}
$$

para cada $i$. De forma a computar $C(i, j)$ para $i<j$ observa-se que: para uma política ótima existirá um stream $K \operatorname{com} i \leq k<j$ de modo que a sub-árvore esquerda conterá os nós folhas correspondentes aos streams $i, \ldots, k$ e a sub-árvore a direita conterá os nós folhas correspondentes aos streams $K+1, \ldots, j$. Além disso, ambas as sub-árvores da esquerda e da direita serão ótimas. Ou seja, serão $\tau(i, k)$ e $\tau(k+1, j)$, respectivamente. Esta árvore binária possui o custo $C(i, k)+C(k+1, j)-\max (L-P(i, j), 0)$, 。 último termo indicando a economia da mesclagem final na posição $P(i, j)$. Por essa razão a política 
ótima na qual somente chegadas $i, \ldots, j$ ocorrem possuem uma sub-árvore a esquerda com os nós folhas correspondendo a $i, \ldots, k^{*}$ e a sub-árvore a direita com os nós correspondentes a $k^{*}+1, \ldots, j$, onde

$$
k^{*}=\arg \min _{i \leq k<j}\left\{C(i, k)+C(k+1, j)-(L-P(i, j))^{+}\right.
$$

O custo total $C(1, n)$ e sua correspondente política piggybacking pode conseqüentemente ser calculada de forma bottom up (de baixo para cima) pelo algoritmo de programação dinâmicắ: iniciando com as árvores iniciais $\tau(i, i)$ e os custos $C(i, i)$, calcule todas as árvores $\tau(i, i+1)$ e custos $C(i, i+1)$, e então todas as árvores $\tau(i, i+2)$ e custo $C(i, i+2)$, assim por diante. Por último, calcula-se a árvore ótima $\tau(1, n)$ e seu custo $C(1, n)$.

O pseudocódigo para a programação dinâmica é o seguinte:

Algoritmo 3.2: Algoritmo de Programaçăo Dinâmica (Dynamic Programming)

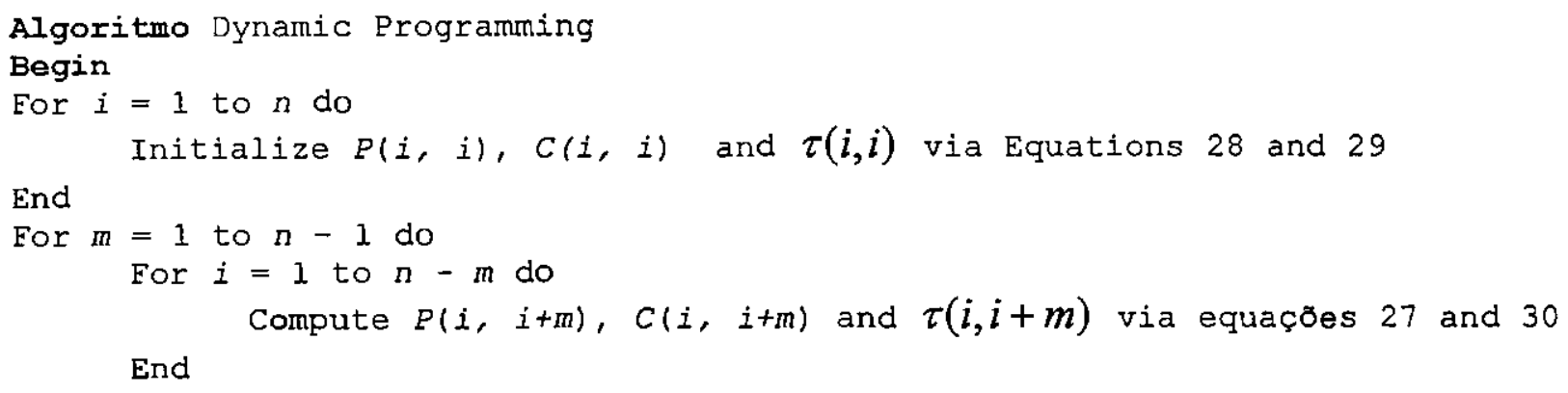

Incorporando-se a técnica determinística da programação dinâmica discutida acima em uma política de piggybacking conhecida como algoritmo snapshot [Agg96b]. Assumindo-se novamente que não há comandos VCR como pauses, resumes, fast-forwards ou rewinds. $\mathrm{O}$ algoritmo é baseado na idéia de coleta de posições das streams instantaneamente em intervalos pré-fixados, ou seja, com I unidades cada. Chama-se estes intervalos de intervalos snapbot. $O$ primeiro stream chegando dentro de um intervalo snapshot terá sua velocidade configurada para mínima, $S_{\text {min }}$. Todos os outros streams dentro do mesmo intervalo terão suas velocidades configuradas para máxima, $S_{\text {max }}$ Suponha que haja $n$ destes streams, com o stream 1 sendo lento e stream $2, \ldots, n$ sendo rápido. Isto é similar a política de simple merging generalizada descrita em [Gol95] e na seção anterior. Note que todas as $n$ streams irão estar dentro de uma janela, medida em quadros, de tamanho $W=I . S_{\max }$ Deve-se referenciar a $W$ como o tamanho da janela. Escolhe-se $I$ de um modo que garantirá que o tamanho da janela é menor ou igual ao tamanho máximo da janela de mesclagem, $W_{m}$. No final do intervalo snapsbot alguns dos streams originais poderão ter sido mesclados. Deve-se usar o algoritmo de programação dinâmica de forma a modificar as velocidades de todos os streams restantes que foram inicializados no intervalo. As velocidades dos streams pertencentes ao intervalo snapshot anterior não são afetadas. 
Realmente, muitas variantes do algoritmo snapshot são possiveis. Uma poderia, por exemplo, resolver todo o problema da programação dinâmica para todos os atuais streams, não somente para aqueles dentro da janela de mesclagem mais recente. Esta abordagem poderia aparecer ser muito dispendiosa, dada a complexidade do algoritmı de programação dinâmica. É claro que a efetividade do algoritmo por si, irá diminuir o número de strams significativamente relativo ao número original das requisiçōes dos usuários. Inversamente, a razão entre os streams restante relativos as requisições originais deverá diminuir durante a transmissão do vídeo. Logo é mais importante desenvolver o algoritmo de programação dinâmica mais cedo. Uma segunda variante do algoritmo agruparia as streams de acordo com o intervalo snapshot correspondente a chegada das requisições, e resolver o problema da programação dinâmica para cada um destes grupos no final de cada intervalo snapshot. Estes agrupamentos seriam plausíveis no sentido que o último stream de um intervalo snapshot e o primeiro stream do próximo intervalo snapshot estão naturalmente distanciando-se entre si. Todas as soluções subseqüentes serão idênticas a original. Logo o algoritmo snapshot apresentado parece representar a melhor solução dentre as várias alternativas.

Pseudocódigo para o algoritmo snapshot é o seguinte:

Algoritmo 3.3: Algoritmo Snapshot

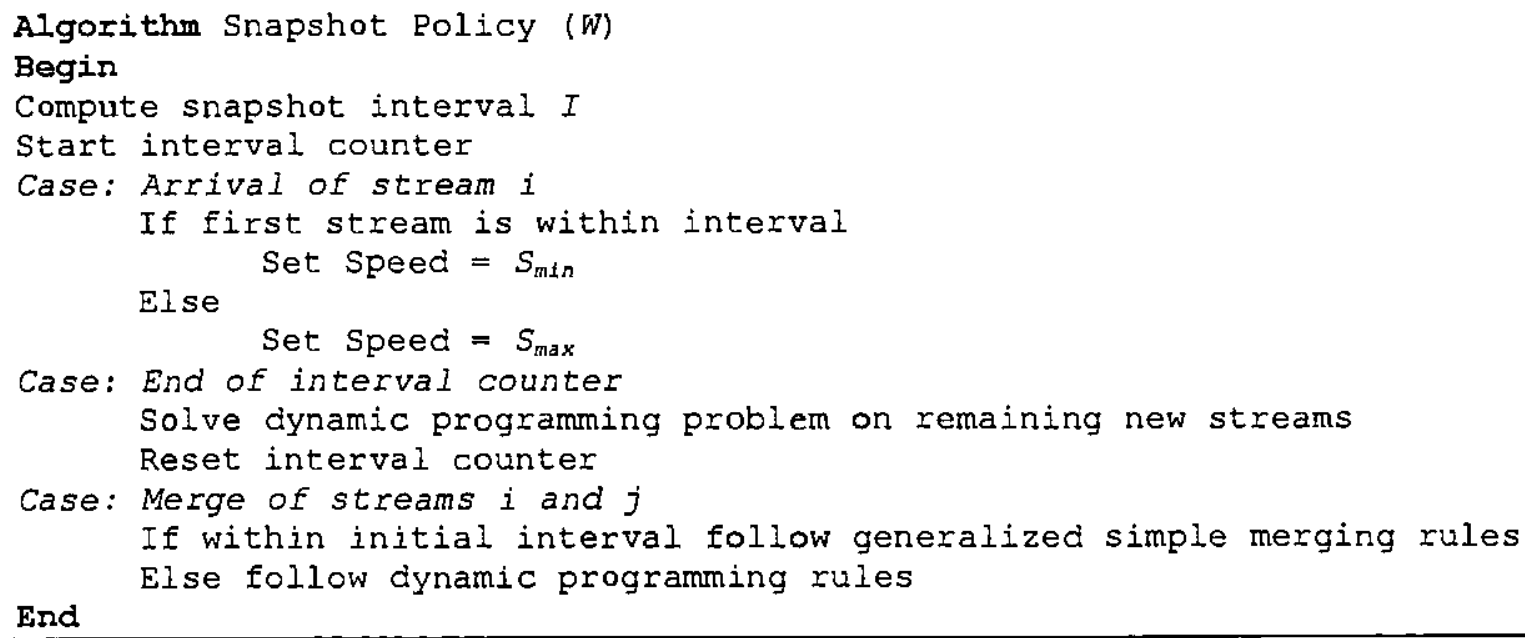

A política de programação dinâmica é ótima para streams os quais prosseguem após o intervalo snapshot. Devido ao fato da utilização da política simple merging generalizada para tratar com as chegadas não determinísticas até o final do intervalo pode não ser ótimo durante este período de tempo. Mas se o intervalo snapsbot é pequeno relativamente a duração do vídeo (ou, equivalentemente, se $W$ é pequeno relativamente a $p_{M}$ ), então pode-se ignorar este efeito. Em outras palavras, nenhuma política baseada em janelas irá superar o algoritmo do snapshot sob estas condições. Comprovou-se através de 
experimentos que o algoritmo snapsbot apresenta os melhores resultados em comparação com as políticas de piggybacking testadas.

Não existe um método analítico para derivação do tamanho da janela snapshot, logo foi adotado o tamanho da janela de mesclagem ótima da política simple merging. Felizmente, é mostrado experimentalmente que a performance do algoritmo snapsbot é razoavelmente insensível a escolha do tamanho da janela de mesclagem.

\subsubsection{A Política $S^{2}$}

Propõe-se a política $S^{2}$ [Agg96b] que busca otimizar o número de quadros exibidos por um conjunto de fluxos disparados pelo sistema numa janela máxima alterada de mesclagem, $W_{m}^{\prime}$, $\left(W_{m}^{\prime} \leq W_{m}\right)$ e não somente no intervalo $I$. A janela máxima alterada é constituída por um número inteiro de janelas ótimas, ou seja, a janela máxima alterada possui $\left[W_{m} / W\right\rfloor$ janelas ótimas. Em outras palavras, a política $S^{2}$ introduz um segundo nível de mesclagens, isto é, a mesclagem das resultantes dos intervalos I da política Snapsbot.

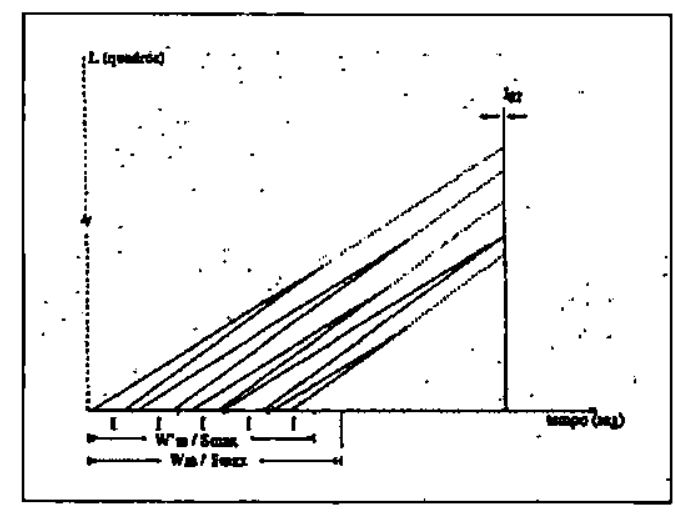

Figura 3.9: Possivel situação da política S2.

O funcionamento da política $S^{2}$ é como se segue: aplica-se primeiramente o algoritmo Snapshot sobre os fluxos que chegam ao sistema nos intervalos Snapsbot (como proposto originalmente) e em seguida, aplica-se novamente o Snapsbot sobre os fluxos resultantes dos fluxos dos intervalos ótimos. É interessante enfatizar que, de acordo com a definição da própria política Snapsbot, atribui-se a velocidade $S_{\max }$ a estes fluxos resultantes com exceção daquele gerado pela primeira janela ótima contida em $W_{m}^{\prime}$. Outro aspecto importante é que ao contrário do que ocorre com o primeiro nível de otimização, o ponto de aplicação do procedimento de otimização não ocorre ao final de intervalos de duração fixa. Estes intervalos são denotados por $I_{S^{2}}$ e sua duração é determinada pelo padrão das requisições por vídeos em cada janela $W_{m}^{\prime}$ (Figura 3.9). 
Uma generalização natural da política $S^{2}$ seria considerar $n$ níveis de otimização. No entanto, os ganhos obtidos com a implantação destes níveis seriam praticamente nulos dado que os fluxos nestes níveis estariam separados por valores bem próximos a $W_{m}$ quadros (ou ainda maiores) o que implica em mesclagens próximas do final do vídeo. Portanto, a introduçào de níveis extras de mesclagens não proporciona reduçōes efetivas de banda passante.

Para avaliar o impacto da introdução de um segundo nível de otimização, foi realizado um estudo comparativo através de simulação entre as políticas $S^{2}$, Snapshot original e a política Snapshot Global, que considera todas as requisições de um mesmo filme sem dividir o tempo em intervalos Snapshot. A função objetivo utilizada neste estudo difere da considerada em [Agg96a], a qual contabiliza apenas o número de quadros exibidos após o intervalo I. A função objetivo utilizada neste artigo contabiliza o número total de quadros apresentados por um conjunto de fluxos, ou seja, reflete a otimização realizada no intervalo $I$, assim como a realizada posteriormente ao intervalo. A função objetivo é dada por: $C(i, i)=L$ para um fluxo $i$ e para um conjunto de fluxos $1, \ldots, n$.

$$
C(1, n)=\text { Quadros }_{I}+\sum_{K=\operatorname{argin}}(C(i, k)+C(k+1, j)-\max (L-P(i, j), 0))
$$

em que Quadros I é o somatório dos quadros apresentados pelos $m$ fluxos descartados, $Q(b)$, para $l=$

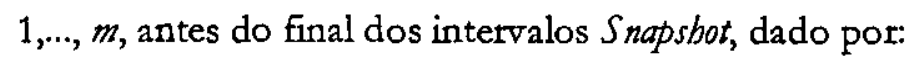

$$
\text { Quadros }_{I}=\sum_{l=1}^{m} Q(l)
$$

\subsection{Análise de Performance}

Esta seção apresenta soluções analíticas para cálculo da demanda de I/O em um servidor o qual usa políticas em conjunto com batching. Define-se a seguinte notação (veja Figura 3.10) usado na derivação desta seção. Todo cálculo é feito com respeito a um objeto multimídia ${ }^{12}$ em particular $j$. Exceto para maiores esclarecimentos, oculta-se o símbolo $j$ para maior simplicidade.

$p_{M}=$ número de quadros em um filme

$T=$ tempo de espera do batcbing (determinístico)

$\lambda=$ taxa de chegada

$t_{e}=$ tempo entre o final de um intervalo de batching e o começo do próximo (veja Figura 3.10)

$t_{a}=$ o tempo de chegada entre duas requisições no servidor

\footnotetext{
${ }^{12}$ Multimídia refere a utilização simultânea de vários tipos de mídia (texto, sons, imagens, gráficos, videos e animações).
} 
$W_{p}\left(p_{i}\right)=$ janela de mesclagem para a política $p$, relativa a posição $p_{i}$

$W_{p}^{m}\left(p_{i}\right)=$ janela máxima de mesclagem para a política $p$, telativa a posição $p_{i}$

$B W_{p}=$ significa a demanda total de I/O (sob a política $\left.p\right)($ bits $/ \mathrm{seg})$

Note que, abaixo não é dada equações tanto para $W_{p}\left(p_{i}\right)$ quanto $W_{p}^{m}\left(p_{i}\right)$, onde $p$ poderia ser a política odd-even (oe), simple (sm), ou greedy (g).

Primeiramente é derivada a função de densidade, $t_{a}$. Sendo que a taxa de requisição segue a distribuição de Poisson com taxa $\lambda$, isto implica que $t_{e}=\frac{1}{\lambda}$. Logo, a função de densidade, $t_{a}$, é:

$$
f_{t a}(x)=\lambda e^{-\lambda(x-T)} \quad \text { para } x \geq T
$$

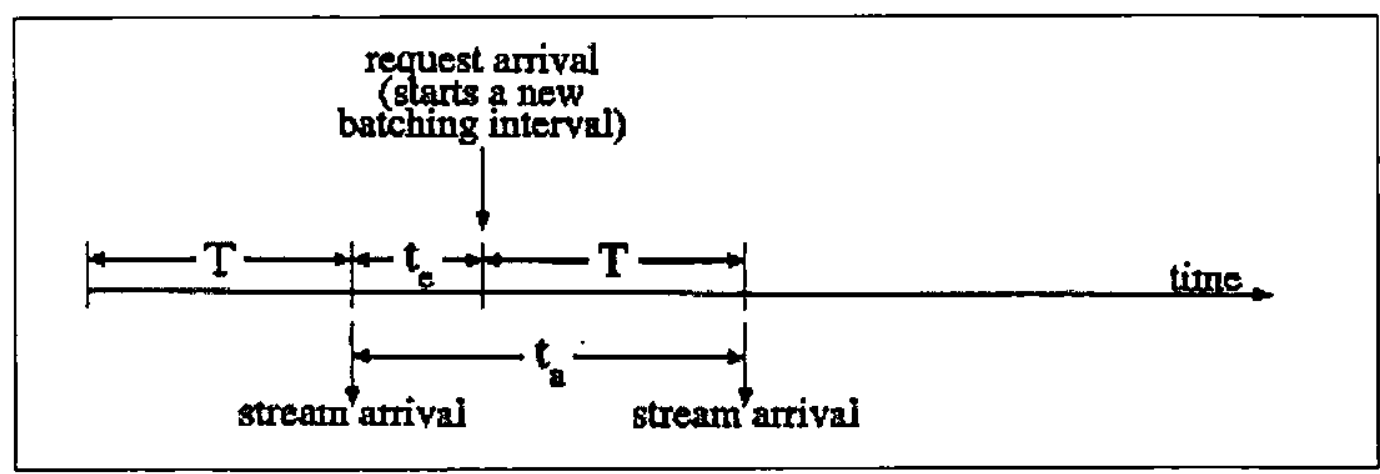

Figura 3.10: Chegada dos VO streams depois de um delay

Desde que uma duração normal de um filme é $p_{M} / S_{n}, N$, o número esperado de I/O streams que o servidor têm que suportar:

$$
N=\left(\frac{p_{M}}{S_{n}}\right)\left(\frac{1}{\int_{T}^{\infty} f_{t a}(x) d x}\right)=\frac{p_{M} / S_{n}}{1 / \lambda+T}
$$




\subsubsection{Análise da política Simple Merging}

A análise da política simple merging é similar à política odd-even, exceto que ao invés de olhar pares de streams, considera-se "grupos de mesclagem" de streams, ou seja, grupos de streams que eventualmente mesclarão entre si (veja seção 3.4). Similarmente a política odd-even, nota-se que todos os "grupos de mesclagens" são estaticamente idênticos, e por essa razão, pode-se analisar a demanda para um destes grupos e calcular a demanda de I/O média multiplicando a taxa de intensidade destes grupos pela demanda de I/O de cada grupo. Pela política simple merging, a mesclagem só é possível se além da stream que inicializou a janela, existir outra stream dentro da janela de mesclagem, $W_{s m}$, o qual está movendo na velocidade $S_{\min }$. Considere $\beta$ como sendo o número de streams, dentro da janela de mesclagem $W_{s m}(0)$, que pode (eventualmente) serem mesclados; chama-se este conjunto de streams de "grupo de mesclagem". Aproxima-se $\beta$ por:

$$
\beta=\max \left\{\left\lfloor\frac{W_{s m}(0) / S_{\min }}{T+1 / \lambda}+1\right\rfloor, 2\right\}
$$

O primeiro componente corresponde ao número de streams que podem cair dentro da janela $W_{s m}(0)$; configurando $\beta \geq 2$, considera-se a mesclagem quando ao menos 2 streams estão disponiveis para mesclagem.

Assume-se que todas streams em um grupo de mesclagem estão separadas por um tempo $x$ e que há $\beta$ streams dentro da janela de mesclagem $W_{s m}(0)$. A segunda stream precisa $t_{m}$ $\left(\right.$ ou $\left.\frac{x S_{\min }}{S_{\max }-S_{\min }}\right)$ unidades de tempo para alcançar o primeiro stream (ou seja, o primeiro stream no grupo), o terceiro stream precisa $2 t_{m}$ unidades de tempo para mesclar, e assim por diante. $O$ primeiro stream irá manter a velocidade mínima $S_{\text {min }}$ até alcançar a posição $W_{s m}^{m}(0)$, então a velocidade de transmissão será reestabelecida para $S_{n}$ :

$$
t_{f}=\frac{p_{M}-W_{s m}^{m}(0)}{S_{n}}
$$

A demanda de I/O para o grupo de mesclagem, dado que estes estão separados por $x$ unidades de tempo, pode ser expressa por: 


$$
B W_{s m}^{m}=\left(W_{s m}^{m}(0) / S_{\min }\right) C_{\min }+C(\beta) t_{m} C_{\max }+t_{f} C_{n}
$$

onde $C(\beta)=\beta(\beta-1) / 2$. Os termos de custo correspondem ao custo do primeito stream movendose à $S_{\min }$ e outros streams, originalmente dentro da janela de mesclagem $W_{s m}(0)$, movendo-se na velocidade $S_{\max }$. O último termo representa o tempo restante depois da última mesclagem, quando a velocidade do primeiro stream for estabelecida para $S_{n}$.

Se, por outro lado, a mesclagem não for possível para um dado intervalo de requisições, $x$, então a demanda de I/O para o grupo de mesclagem é:

$$
B W_{s m}^{n m}=\beta^{*}\left[\left(\frac{W_{s m}^{m}(0)}{S_{\min }}\right) C_{\min }+\left[\frac{p_{M}-W_{s m}^{m}(0)}{S_{n}}\right] C_{n}\right]
$$

A demanda esperada para a política simple merging é:

$$
\begin{aligned}
& \int_{T}^{W_{s m}(0)} S_{\min }\left(B W_{s m}^{m} * \frac{N}{\beta} * f_{t a}(x)\right) d x+\int_{W_{s m}(0)}^{\infty}\left(B W_{s m}^{n m} * \frac{N}{\beta} * f_{t a}(x)\right) d x \\
& B W_{s m}= \\
& S_{\min }
\end{aligned}
$$

\subsubsection{Validação do Resultado Analítico}

Para concluir este capítulo, é apresentado um resultado comparativo, obtido por simulação, da política simple merging em combinação com a política de batching por timeout.

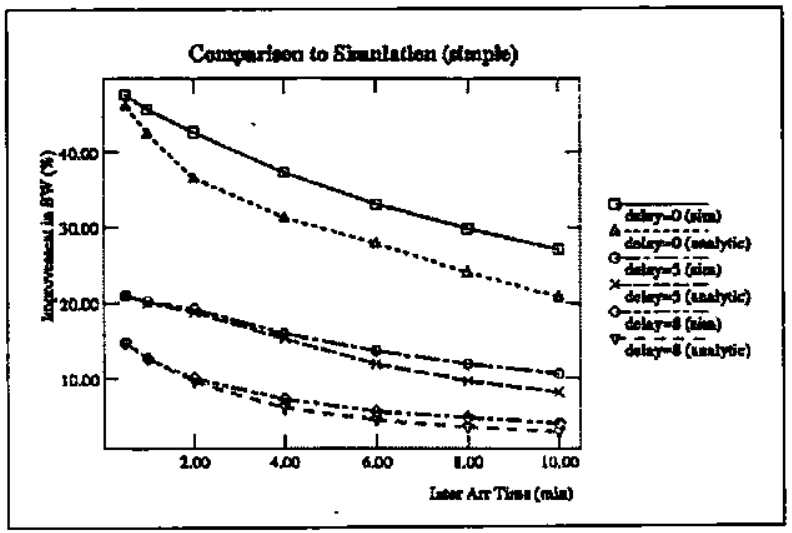

Figura 3.11: Política Simple Merging

Esta comparação ilustrada na Figura 3.11, onde o "delay" refere-se ao intervalo batching (em minutos) e cada curva tepresenta o aumento da porcentagem na demanda de $\mathrm{I} / \mathrm{O}$, em comparação com a política baseline. De acordo com a figura, as divergências aumentam quando a taxa de requisição é baixa; em taxas moderadas à alta, o resultado analítico iguala-se ao da simulação. 


\subsubsection{Resultados Experimentais}

Esta seção discute os resultados de simulações nas quais compara-se o resultado de várias políticas de piggybacking. Nenhuma abordagem da política de batcbing ou bridging foi considerada em nenhum dos experimentos, de forma a isolar os benefícios das políticas de piggybacking. Em todos os experimentos assumiu-se que a velocidade máxima igual a $S_{\max }=31,5$ quadros/segundos e a velocidade minima igual $S_{\min }=28,5$ quadros/segundos. Toda simulação foi desenvolvida assumindo que as chegadas são modeladas por um processo de Poisson com parâmetro $\lambda$. Cada gráfico discutido nesta seção ilustra a percentagem de quadros economizados pela política de piggybacking.

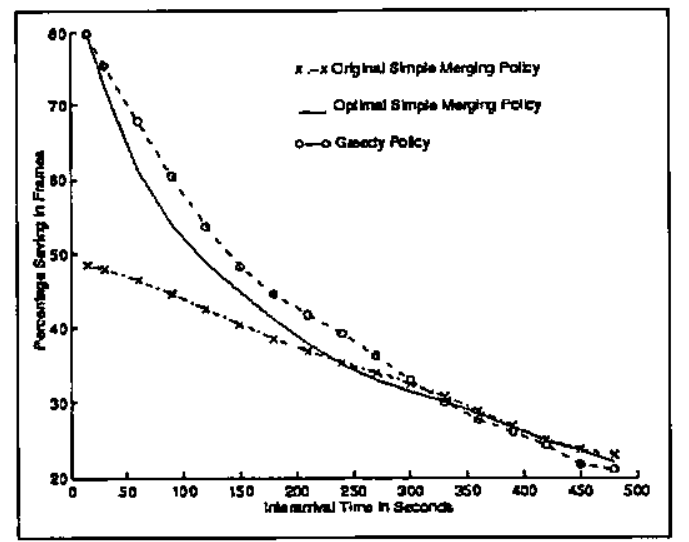

Figura 3.12: Comparação variando as taxas de chegada

Figura 3.12 ilustra a performance da simple merging original e políticas Greedy [Gol95] e a política simple merging otimizada (generalizada). Fixou-se o tamanho do video para 2 horas de duração, e variouse $o$ intervalo de chegada $\gamma=1 / \lambda$ entre 15 e 500 segundos. Verifica-se que aplicando o tamanho otimizado para janela de mesclagem, ao invés do tamanho da janela máximo, tesulta em grandes efeitos na performance da política simple menging generalizada, pelo menos quando o intervalo de chegadas é pequeno (ou equivalentemente, quando a taxa de chegada é expressiva). Ademais, a política simple merging generalizada agora parece tornar-se competitiva em relação à política Greedy. Lembrando que o simple merging é um algoritmo elementar, sendo que o algoritmo Greedy não. Para grandes intervalos de chegada todos os três algoritmos têm essencialmente igual performance. Como esperado, a performance de cada algoritmo diminui em função do aumento do intervalo de chegada. 


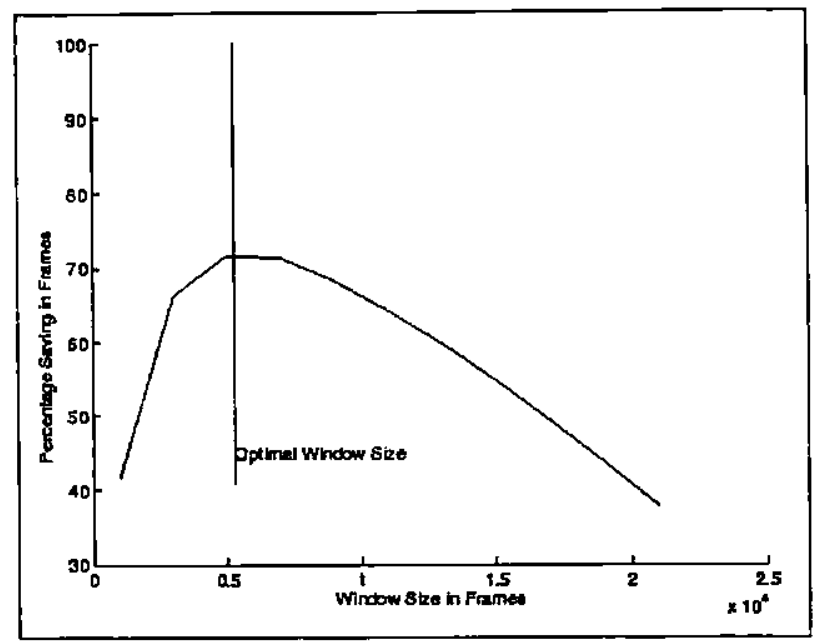

Figura 3.13: Performance da política Simple Merging com tamanho da janela variável.

Figura 3.13 ilustra a performance da política simple merging em função do tamanho da janela de mesclagem $W$. Fixou-se a duração do vídeo para 2 horas, e o intervalo de chegada para 30 segundos. $O$ tamanho ótimo da janela de mesclagem $\mathbb{W}^{*}$ é também ilustrado, e combina com a melhor performance da política simple merging generalizada. Diferenciando muito do tamanho da janela de mesclagem ótima em qualquer direção causa uma degradação na performance. Note que nossa o tamanho ótimo da janela de mesclagem é calculado em termos da taxa de chegada $\lambda$, a qual é obtido por previsão. Felizmente a figura ilustra relativamente uma performance estável para valores de W próximos ao ótimo, logo erros na previsão não irão provavelmente ocasionar um grande efeito negativo na política ótima.

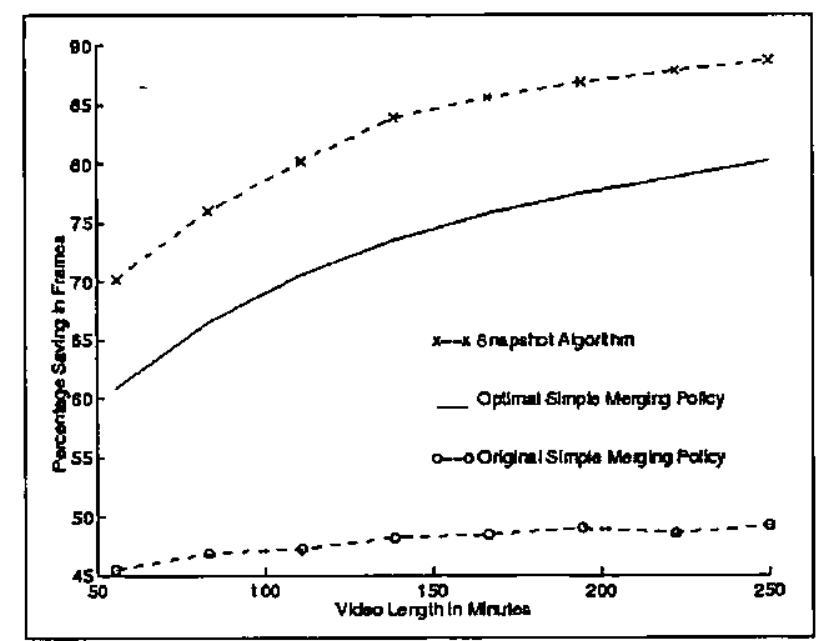

Figura 3.14: Comparação variando o tamanho do vídeo

Figura 3.14 ilustra a performance política simple merging original e ótima e o algoritmo snapshot em função do tamanho do vídeo. Fixou-se o intervalo de chegada de 30 segundos. Nota-se que a política simple merging otimizada sempre supera a política original, e progresso aumenta à medida que aumenta o tamanho do video. De fato, a performance do simple merging original é relativamente plana. O algoritmo 
snapshot supera ambas as políticas, e o progtesso relativo à política simple merging otimizada permanece praticamente constante.

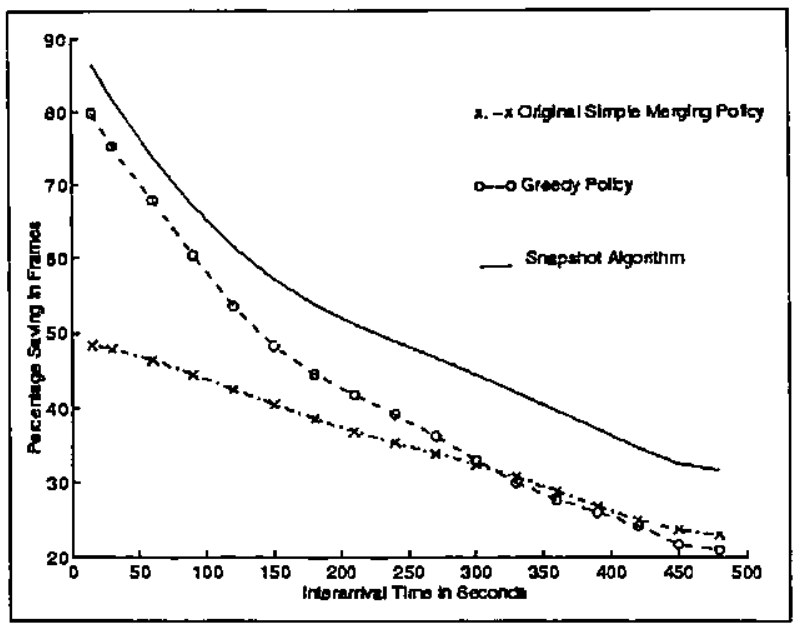

Figura 3.15: Comparação variando o tempo de chegada

Figura 3.15 ilustra a performance do simple merging original, política greedy e o algoritmo snapshot. Novamente fixou-se a duração do vídeo para 2 horas, e variou-se o intervalo de chegada $\gamma$ entre 15 e 500 segundos. Note que o snapshot é clatamente melhor que o algoritmo Greedy, e esta diferença é ainda mais acentuada para intervalo de requisições maiores.

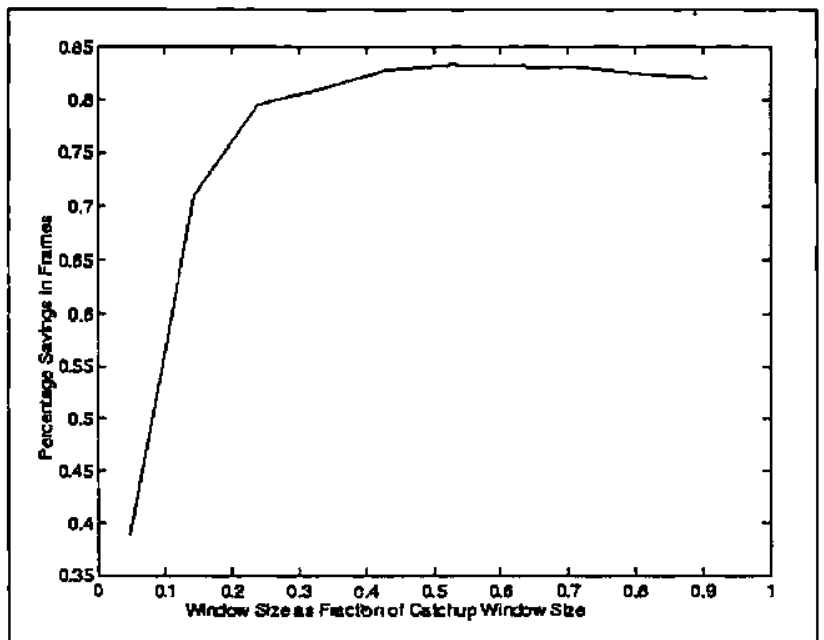

Figura 3.16: Performance do Snapshot variando o tamanho da janela

Figura 3.16 ilustra a performance do algoritmo snapsbot como uma função do tamanho da janela $W$, a qual foi normalizada como uma fração do tamanho da janela máxima de mesclagem. Novamente foi fixado o tamanho do vídeo para 2 horas, e o intervalo de requisições para 30 segundos. Lembrando que isto é importante porque não há um método para determinar o valor ótimo de $W$ para snapshot. Felizmente, a curva é quase plana nos limites nos quais há um maior interesse. 


\subsection{Avaliação das Técnicas}

Os servidores de vídeo-sob-demanda apresentam alguns problemas de performance interessantes. Parte do esforço é somente para entender as restrições e objetivos aceitáveis para avaliar com precisão o que é possivel. Neste capitulo, foram considerados somente métodos de redução da demanda de I/O requerida, enquanto ao mesmo tempo garantir uma latência máxima. Foi explorado o fato de que pequenas variações nas taxas de vídeo não trazem perceptíveis degradações a qualidade do vídeo. Os resultados provaram que pequenas variações na velocidade do vídeo possibilita mesclagens que resultam em significantes reduções na demanda de I/O. Foram analisadas muitas políticas heurísticas com destaque para três algoritmos de piggybacking para sistemas de vídeo-sob-demanda.

O primeiro refere-se a uma versão da política simple merging original (generalizada), para a qual calculou-se o tamanho otimizado para a janela de mesclagem. O segundo é um algoritmo snapshot baseado na progtamaçào dinâmica. $O$ algoritmo snapshot aparentemente supera todas as políticas existentes, enquanto a performance da política simple merging otimizada é aproximadamente igual à política greedy. O terceiro trata-se de uma introdução a política $S^{2}$, a qual acrescenta um nível de otimizaçäo em relação à política Snapshot e uma heurística aproximada, que busca a redução da complexidade da construção da árvore de mesclagens dos fluxos disparados num intervalo Snapshot.

\subsection{Considerações Finais}

Este capitulo tratou das políticas de gerenciamento, destacando principalmente as políticas conhecidas como adaptive piggybacking. Foram focalizadas ainda três técnicas são essenciais para este projeto, a saber: simple merging, simple menging generalizada e o Snapshot, apresentando uma análise e avaliação de performance das mesmas.

A mesclagem é um elemento teórico que na prática ocorre via multicasting. Ou seja, vários clientes recebendo a mesma transmissão de dados (pacotes). O processo de transmissão por multicast é dependente do protocolo utilizado pela rede. O próximo capítulo, é tratado o multicast em redes IP. 


\section{Capítulo 4 - IP Multicast}

\subsection{Considerações Iniciais}

Este capítulo fornece algumas informações interessantes para compreensão dos protocolos multicast e implementações, podendo ser úteis para evitar erros comuns. Este capitulo segue a seguinte organização: na próxima seção apresenta são apresentados conceitos introdutórios do multicast, na seção 4.3 trata de detalhes do multicast; na seção 4.4 refere-se ao Internet Group Management Protocol (IGMP); a seção 4.5 aborda uma breve introdução aos protocolos de roteamento multicast, na seção 4.6 é introduzido o multicast no IP versão 6 (IPv6).

\subsection{Conceitos do multicast}

Unicast é corresponde ao cenário onde há somente um processo transmissor ou remetente e somente um processo receptor ou destinatário. TCP é, por natureza, orientado a conexões unicast. UDP suporta outros paradigmas, embora se houver apenas um processo transmitindo pacotes UDP e apenas um processo receptor, logo é caracterizado o unicast.

No começo das redes IP, um pacote poderia ser enviado tanto para um receptor (unicast) ou para todos os receptores (broadcast). Uma única transmissão, a qual poderia alcançar um grupo específico de receptores, não era possível. Por anos as transmissões unicast provaram ser suficientes para a Internet. A idéia do multicasting IP foi desenvolvida em 1988 por Steve Deering na Universidade de Stanford, promovida pelo deseja de proporcionar transmissões de áudio e vídeo, em tempo real, das reuniões do Internet Engineering Task Forces (IETF) através da Internet. Os dados de áudio e vídeo devem ser transmitidos somente para um endereço multicast IP, mas deve ser recebido por qualquer usuário que queira assistir a transmissão.

IP Multicast é uma extensão do protocolo IP padrão. RFC 1112, Host Extensions for IP Multicasting, de autoria de Steve Deering em 1989, descreve IP Multicasting como: "A transmissão de um datagrama IP para um 'grupo de host', um conjunto de zero ou mais hosts identificados por um único 
endereço IP de destino. Um datagrama multicast é entregue para muitos membros deste grupo com a mesma confiabilidade 'best-effort' dos datagramas unicast. $O$ número de membros de um grupo é dinâmico; ou seja, bosts poderão associar-se e deixar os grupos a qualquer momento. Um bost pode ser membro de mais de um grupo ao mesmo tempo"[Dee89]. Adicionalmente, a nível da aplicação, urn único endereço de grupo pode ter múltiplos dúta streams em diferentes portas, em diferentes sockets, em uma ou mais aplicações. Múltiplas aplicações podem compartilhar um único endereço de grupo em um bost.

A primeira transmissão multicast que funcionou neste caso, foi realizada em 1992. Para sincronizar os pacotes de áudio e vídeo nas transmissões foi desenvolvido o Real-time Transport Protocol (RTP). Em 1993 uma implementação multicast foi desenvolvida no 4.4 BSD. Quais eram os problemas endereçados ao multicast?

A Internet mudou muito deste os tempos primórdios. Particularmente, a aparência da Web transformou fortemente a situação: as pessoas não somente querem conexões com bosts remotos, correios e FTP. Primeiramente, satisfazia-se visualizando as fotos nas bome pages, mas posteriormente desejou-se ver e ouvir as pessoas.

Com a tecnologia atual é possível satisfazer o custo de ter uma conexão unicast com qualquer um que queira ver uma bome page. Entretanto, se houver uma transmissão de áudio ou vídeo, a qual necessita de uma grande quantidade de largura de banda compatada as aplicações web, havia duas opções: estabelecer uma conexão unicast separado com cada um dos receptores, ou usar o broadcast. A primeira solução não era disponível: pois se uma conexão transmitindo áudio/vídeo consume uma largura de banda muito grande, um número maior de conexões seria ainda mais inviável para ambos o computador transmissor e a rede.

Se o objetivo é transmitir para todos os bosts da LAN, por exemplo para atender a uma conferência, pode-se utilizar o broadcast. Os pacotes serão enviados apenas uma vez e cada bost irá recebê-los assim que estes forem enviados para o endereço broadcast. O problema é que talvez somente uma pequena parcela destes hosts, e não todos, estejam interessados nestes dados. Além disso: talvez alguns bosts estejam realmente interessados na conferência, mas estes bosts encontram-se fora da LAN, distante alguns roteadores. O broadcast funciona perfeitamente dentro da LAN, mas os problemas aumentam quando os pacotes broadcast são roteados sobre LANs diferentes.

Uma melhor solução é transmitir pacotes para endereços especiais (análogo a certas freqüências de transmissão de rádio/TV). Logo, todos os bosts que decidirem associar-se à conferência estarão atentos aos pacotes com o endereço de destino, lendo-os quando estes atravessar a rede, e serem passados para a camada IP para serem demultiplexados. Isto é similar ao broadcasting pelo fato de que é transmitido somente um pacote broadcast e todos os bosts na rede o reconhece; entretanto, é diferente, 
no fato que nem todos os pacotes multicast são lidos e processados, mas somente aqueles que foram previamente registrados no kernel ${ }^{3}$ como sendo de "interesse".

\subsection{Detalhes do Multicast}

\subsubsection{Endereços Multicast}

O limite dos endereços IP é dividido em "classes" baseadas nos bits de alta ordem de um endereço de 32 bits:

Tabela 4.1: Classes dos Endereços IP

\begin{tabular}{|c|c|c|}
\hline 0 & Endereço da Classe A & $0.0 .0 .0-127.255 .255 .255$ \\
\hline 1 & 0 Endereço da Classe B & $128.0 .0 .0-191.255 .255 .255$ \\
\hline 1 & 0 Endereço da Classe C & $192.0 .0 .0-233.255 .255 .255$ \\
\hline 1 & 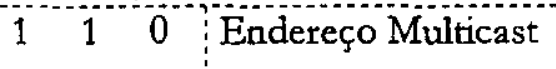 & $224.0 .0 .0-239.255 .255 .255$ \\
\hline 1 & $\begin{array}{llllll}1 & 1 & 1 & 0 & \text { Reservado }\end{array}$ & $240.0 .0 .0-247.255 .255 .255$ \\
\hline
\end{tabular}

O limite de interesse é a "classe de endereço D". Todo datagrama IP cujo endereço de destino inicia com "1110" é um datagrama IP multicast. Endereços IP da classe E, no exemplo, aqueles com "1111" como seus quatro bits de alta prioridade, são reservados para endereçamentos futuros.

Os 28 bits restantes identificam o grupo multicast que o datagrama está sendo enviado, ou seja, seguindo a analogia ao rádio/TV, o kernel estará sintonizado para receber pacotes enviados para um grupo multicast específico. Quando isto é feito, é dito que o bost associou-se a este determinado grupo em uma interface especificada. Mais adiante este assunto será tratado em maiores detalhes.

Os endereços IP Multicast reservados estão listados no RFC1700, "Assign Numbers" (Números Associados). Para cada endereço multicast há um conjunto de zero ou mais bosts que estão escutando-o. Este conjunto é chamado de grupo de bost. Um bost que envia para um grupo pode não ser um membro deste grupo. Há dois tipos de grupos de bosts.

${ }^{13}$ Corresponde ao núcleo do sistema operacional, fomecendo serviços necessários para a ultilização de um computador. 


\section{Permanente}

Endereços IP permanente são especificados pela "Internet Assigned Numbers Autbority (LANA)". Um grupo permanente existe mesmo se não há membros. A lista de endereços IP associados aos grupos de bosts permanentes é incluída no STD 2 - Números Internet Associados (RFC 1700).

\section{Transiente}

Qualquer grupo que não é permanente é transiente e está disponível para uma associação dinâmica assim se fizer necessário. Grupos transientes deixam de existir quando o número de associados chega a zero.

Multicasting em uma única rede física que suporta o uso de multicast é simples. Para associar-se a um grupo, um processo sendo executado em um bost deve de alguma forma informar aos drivers ${ }^{14}$ das placas de rede que deseja ser um membro de um grupo especificado. $O$ driver deve mapear o endereço IP multicast para o endereço multicast fisico e possibilitar a recepção de pacotes deste endereço. $O$ driver da placa deve também garantir que o processo de recepção não receba datagramas falsos checando o endereço de destino no cabeçalho do pacote IP antes de passá-lo para a camada IP.

\subsubsection{Niveis de conformidade}

Hosts podem estar em três diferentes níveis de conformidade com a especificação multicast, de acordo com os requerimentos que satisfazem.

Nível 0: nenhum suporte para IP multicasting

Há, neste momento, nenhum requetimento que todas as implementações IP suportem o multicasting. Muitos dos bosts e roteadotes na Internet incluem-se neste estado, como o suporte para multicast não é obrigatório no IPv4 (entretanto é obrigatório no IPv6). Conseqüentemente, bost neste nível não poderá nem transmitir ou receber pacotes multicast. Hosts de nível 0 , em geral, não são afetados pela atividade multicast. A única exceção surge em alguns tipos de redes locais, onde a presença de bosts de níveis 1 ou 2 pode causar erro entregando datagramas multicast para bosts de nível 0. Estes datagramas podem ser facilmente identificados pela presença de um endereço da classe D no campo de endereço de destino; estes datagramas devem ser descartados pelos bosts que não suportam IP multicasting. Endereços da classe D são descritos na seção 4.3.1 deste capítulo.

\footnotetext{
${ }^{1+}$ Driver é um software utilizado para permitir a interoperabilidade entre diferentes sistemas ou dispositivos.
} 
Nível 1: suporta a transmissão mas não recepção dos datagramas IP multicasting

Nível 1 permite que um host participe de alguns serviços baseados no multicasting, como localizar serviços ou reportar status, mas não permite que um host associe-se a qualquer grupo de bost. Uma implementação IP poderia ser atualizada do nivel 0 para o nível 1 muito facilmente e com pouco códigc novo.

Nível 2: suporte completo para o multicasting IP (capazes de transmitir e receber tráfego multicast)

Nivel 2 permite a um host associar (join) e deixar (leave) grupos de host, bem como enviar datagramas IP para grupos de host. Requer a implementação do Internet Group Management Protocol (IGMP) na pilha TCP/IP, a extensão do IP e interfaces dos serviços de redes locais no host. Todas as seções seguintes deste capítulo são aplicáveis as implementações do nível 2.

\subsubsection{Transmitindo datagramas IP multicast}

Está claro que o tráfego multicast é manipulado na camada de transporte com UDP, como TCP fornece conexões ponto-a-ponto, não factível para o tráfego multicast. (Pesquisas estão sendo realizadas com o objetivo de definir e implementar novos protocolos de transporte multicast orientado).

Em princípio, uma aplicação precisa somente abrir um socket UDP e preencher com um endereço multicast da classe D, o endereço do destinatário para onde se quer enviar o pacote. Entretanto, há muitas operações que um processo transmissor deve ser capaz de controlar.

\section{TTL}

O campo TTL (Time To Live) no cabeçalho IP tem um significado duplo no multicast. Como sempre, controla o tempo de vida do datagrama para impedir que este entre em loop infinito devido a erros de roteamento. Roteadores decrementa o TTL a todo datagrama que é passado de uma rede para outra e quando o valor alcança o zero, o pacote é eliminado. O TTL no IPv4 multicasting tem também o significado do "threshold". Por exemplo: suponha que foi configurada uma vídeo conferência entre todos os hosts pertencentes ao departamento. Deseja-se que o tráfego permaneça dentro da LAN. Talvez o departamento seja grande o suficiente para abrigar várias LANs. Neste caso é fundamental que os hosts pertencentes a diferentes LANs assistam a conferência, sendo necessário limitar a distância de expansão do tráfego multicast acerca dos roteadores, para isso é utilizado o TTL. Roteadores têm um TTL threshold associado com cada uma de suas interfaces, e somente datagramas com TTL maior do que o threshold da interface é retransmitido. Note que quando um datagrama atravessa um roteador com um certo threshold associado, o TTL do datagrama não é decrementado pelo valor do threshold. Somente uma comparação é feita. (como anteriormente, o TTL é decrementado por 1 cada vez que um datagrama passar por um roteador). 
Uma lista dos TIL thresholds e seus escopos associados segue:

Tabela 4.2: Lista dos TTL thresholds e seus escopos

\begin{tabular}{ll}
\hline TTL & Escopo \\
\hline 0 & Restrito ao mesmo bost. Não será enviado por nenhurna interface \\
1 & Restrito a mesma sub-rede. Não será retransmitido pelo roteador \\
$<32$ & Restrito ao mesmo site, organização ou departamento \\
$<64$ & Restrito a mesma região \\
$<128$ & Restrito ao mesmo continente \\
$<255$ & Não está restrito ao escopo. Global \\
\hline
\end{tabular}

Os limites do "site" e "região" ainda não são exatos. É de responsabilidade do administrador decidir estes limites.

O artificio do TIL não é sempre flexível o suficiente para todas as necessidades, especialmente quando se trata de encobrir regiões ou tentando estabelecer limites geográficos, topológicos e de largura de banda simultaneamente. Para resolver estes problemas, o escopo administrativo das regiões IPv4 multicast foi estabelecido em 1994. (veja D. Meyer's "Administrative Scoped IP Multicast" Internet draft). Isto baseado nos endereços multicast ao invés de TTLs. O limite 239.0.0.0 a 239.255.255.255 é reservado para o escopo administrativo.

\section{Loopback}

Quando o bost transmissor é de nível 2 e também é membro do grupo de datagramas ao qual datagramas estão sendo transmitidos, uma cópia é retornada por default (padtão). Isto não significa que a placa de interface com a rede lê a própria transmissão, reconhece como pertencente a um gxupo ao qual a interface faz parte, e lê o datagrama da rede. Pelo contrário, é a camada IP a qual, por padtão, reconhece o datagrama a ser enviado e o copia para uma fila IP de entrada antes de transmití-lo. $O$ processo transmissor pode ativar ou não o loopback.

\section{Seleção da interface}

Hosts vinculados a mais de uma rede deve fornecer um caminho para as aplicações decidirem qual interface de rede será usada para a saída das transmissões. Se não especificada, o kernel escolhe um padtão baseado na configuração do administrador do sistema. 


\subsubsection{Recebendo datagramas IP multicast}

\section{Associando-se a um grupo multicast}

Broadcast é (em comparação) mais fácil de implementar do que o multicast. Não tequer que os processos dêem ao kernel algumas regras referentes sobre o que fazer com os pacotes broadcast. O kernel sabe o que fazer: ler e transmitir todos os pacotes para as aplicações apropriadas.

Com o multicast, entretanto, é necessário avisat ao kernel quais grupos multicast são de interesse. Ou seja, deve-se requisitar ao kernel para "associar" (join) a estes grupos multicast. Dependendo do hardware da subcamada, os datagramas multicast são filtrados pelo hardware ou pela camada IP (e, em alguns casos, por ambos). Somente aqueles com um grupo de destino previamente registrados via um join são aceitos.

Essencialmente quando se associa a um grupo, está sendo dito ao kernel "para ler e cntregar (a todo processo com interesse nestes dados) qualquer datagrama que for tecebido pela interface de rede com este grupo multicast no campo de destino."

Algumas considerações: primeiro, note que não somente associa-se a um grupo. Associa-se a um grupo em uma interface de tede em particular. É claro que é possível associar-se ao mesmo grupo em mais de uma interface. Se não for especificada uma interface concreta, o kernel escolherá uma baseada em suas tabelas de roteamento quando os datagramas forem ser enviados. É também possível que mais de um processo associe-se ao mesmo grupo multicast na mesma interface. Todos receberão os datagramas enviados para este grupo multicast via esta interface. Todos os hosts deverão estar associados ao grupo 224.0.0.1, logo como dito, uma operação de "ping" neste grupo retorna todos os bosts na tede que possuem capacidade multicast.

Finalmente, considere que para um processo receber datagramas multicast, este tem que requisitar ao kernel pata associar ao grupo e bind (ligar) a porta para a qual os datagramas serão transmitidos. A camada UDP usa ambos, o endereço e porta de destino, para demultiplexar os pacotes e decidir a quais sockets entregar.

\section{Deixando um grupo multicast}

Quando um processo não está mais interessado em um grupo multicast, este informa ao kernel que deseja sair daquele grupo. É importante entender que isso não significa que o kernel não irá aceitar datagramas multicast destinados para aquele grupo. O kernel continuará a aceitar se houver mais processos ainda interessados neste grupo. Neste caso, o bost permanece membro do grupo, até que todos os processos decidam deixar o grupo. 
A idéia é que para associar-se a um grupo basta requisitar para a camada IP e a camada de enlace de dados (a qual transmite para o hardware) para aceitar os datagramas multicast destinados para aquele grupo. Isto não é feito por processo, mas por host.

\section{Mapeamento de endereços multicast para endereços Ethernet/FDDI}

O binding dos endereços de grupos a hosts físicos pode ser considerado uma generalização do binding dos endereços unicast. Um endereço unicast é estaticamente associado a uma única interface de rede local em uma única rede. Um endereço de grupo é dinamicamente associado a um conjunto de interfaces de rede local em um conjunto de redes IP.

Ambos frames Ethernet e FDDI possuem um campo de endereçamento de destino de 48 bits. De forma a evitar um tipo de multicast ARP que mapeia endereços IP para endereços ethernet/FDDI, o LANA reservou um limite de endereços para o multicast: Cada frame ethernet/FDDI com seus destinos variando de 01-00-5e-00-00-00 a 01-00-5e-ff-ff-ff (hexadecimal) contém dados para grupos multicast. O prefixo 01-00-5e identifica o frame como multicast, o próximo bit é sempre zero e logo somente 23 bits são deixados para o endereço multicast. Como grupos IP multicast possuem comprimento de 28 bits, o mapeamento não poderá ser de um-para-um. Somente os 23 bits menos significantes do endereço grupo multicast são posicionados no frame. Os cinco bits de alta ordem restantes são ignorados, resultando em 32 grupos multicast diferentes sendo mapeados no mesmo endereço ethernet/FDDI. Isto significa que a camada ethernet age como um filtro imperfeito, e a camada IP irá decidir se aceitará os datagramas passados pela camada de enlace de dados. A camada IP age como um definitivamente como um filtro perfeito.

Figura 4.1 ilustra o mapeamento de um grupo de endereços multicast para um endereço Ethernet multicast.

Endereço da Classe D: 224.11.9.7

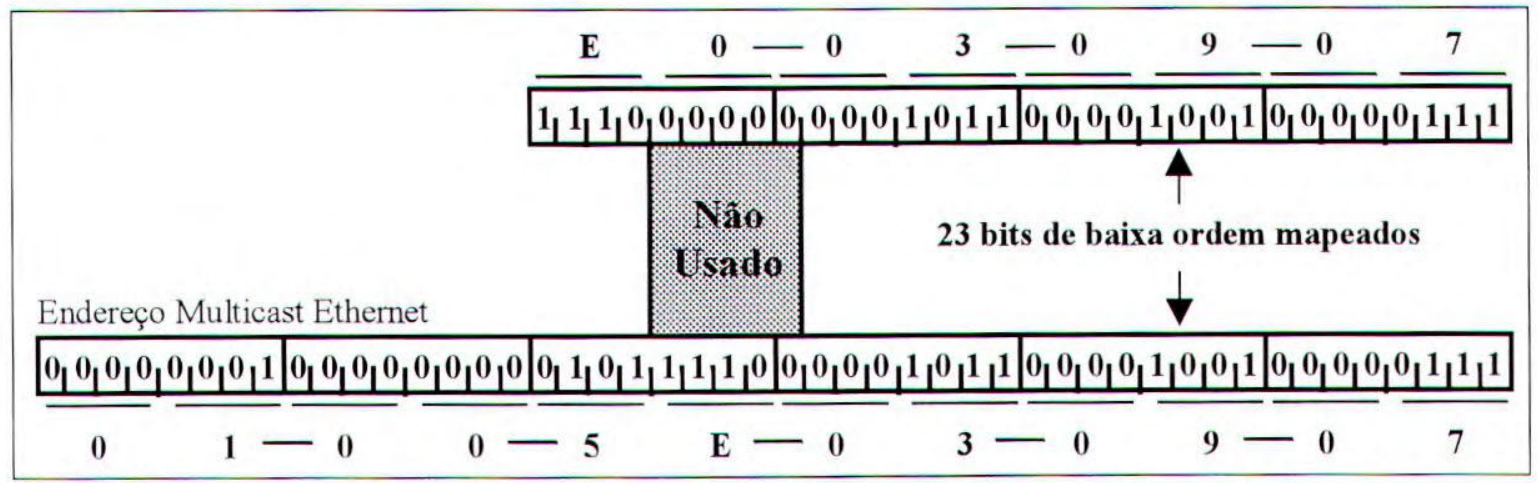

Figura 4.1: Mapeando endereços IP da Classe D para endereços Ethernet IEEE802.3 


\subsection{Internet Group Management Protocol (IGMP)}

O Internet Group Management Protocol (IGMP) é usado pelos bosts para reportar os memberships para qualquer roteador muiticast imediatamente vizinho[Fen97]. As requisições para associação aos grupos sào reportadas de um host diretamente para o roteador multicast mais próximo. O status do IGMP é recomendado e descrito no RFC 1112.

Quando um bost associa-se "join" ou sai "leave" a um grupo multicast, é dito que a informação fornecida por estes "comandos" é usada pelo kernel para escolher quais dos datagramas multicast aceitar ou descartar. O que ocorre é que os hosts instruem seus toteadores dizendo quais grupos são de interesse; então, estes roteadores irão comunicat a outros toteadores, o interesse pelo determinado grupo, este processo é tepetido pelos roteadores ao longo do caminho. Algoritmos empregados para tomar a decisão de quando requisitar pelo tráfego de um grupo ou comunicar que não deseja receber um determinado tráfego, varia muito. Há porém há uma coisa que nunca modifica: como esta informação é transmitida. IGMP é usado para isto.

IGMP versão 0 é especificado no RFC-988 o qual é agora obsoleto. Quase nenhum usa a versão 0 agota. O IGMP versão 1 é descrito no RFC-1112 e, embora tenha sido atualizado pelo RFC-2236 (IGMP versão 2).

Como ICMP, IGMP é uma parte integral do IP [Dee89]. É necessário que seja implementado por todos os hosts de nível 2 da especificação multicast. No IPv6, IGMP é integrado no ICMPv6 considerando o fato de que todos os hosts IPv6 suportam multicasting (visto na seção 4.6). No IPv4, o suporte é opcional, logo diferente do IP e ICMC, IGMP não é requerido.

Para as discussōes seguintes é importante que os roteadores multicast recebam todos datagramas multicast.

\subsubsection{Operação IGMP}

Roteadores multicast envia mensagens Host Membership Query (em seguida chamada Queries) para descobrit quais grupos de bosts possuem membros em suas redes locais. Queries são endereçados para o grupo "todos-bosts" (endereço 224.0.0.1), e transportam um Time-To-Live igual a 1.

Hosts respondem a Query gerando Host Membership Reports (em seguida chamada Reports), reportando cada grupo de bost aos quais pertencem à interface de rede na qual a Query foi recebida. De forma a impedit uma "explosão" de Reports concorrentes e reduzir o número total de número de Reports transmitidos, duas técnicas são usadas:

1. Quando um bost tecebe uma Query, ao invés de transmitir Reports imediatamente, inicia-se um report delay timer para cada um dos group membership na interface de rede por onde chegou a Query. Cada timer é 
configurado para um valor diferente, randomicamente escolhido entre zero e D segundos. Quando um timer expira, um report é gerado para o grupo de bost correspondente. Então, Reports são espalhados por um intervalo de $\mathrm{D}$ segundos ao invés de ocorrerem todos no mesmo instante.

2. Um Report é enviado com um endereço de destino igual ao endereço do grupo sendo reportado, e com time-to-live igual a 1 , de modo que outros membros do mesmo grupo na mesma rede possa estar cientes do Report. Se um bost ouvir um Report para um grupo do qual ele faz parte naquela rede, o host pára seu timer para aquele grupo e não gera um Report para aquele grupo. Então, no caso normal, somente um Report irá ser gerado para cada grupo presente na rede, pelo membro cujo delay timer expira primeiro. Note que os roteadores multicast recebem todos os datagramas multicast, e portanto não precisam ser endereçados explicitamente. Além disso, note que os roteadores não precisam saber quais bosts pertencem a um grupo, somente aqueles com pelo menos um bost em uma rede em particular.

Há duas observações no comportamento descrito acima. Primeira, se um report delay timer já estiver rodando quando um Query for recebido, o timer não é reiniciado com um novo valor randômico, mas ao contrário, continua sendo executado com seu valor corrente. Segundo, um report delay timer nunca é configurado para um bost para o membership no grupo "todos-bosts" (224.0.0.1), e este membership nunca é reportado.

Se um bost usa um gerador de número pseudo-randômico para calcular os delays do report, o próprio endereço do bost deve ser usado como parte da semente para o gerador, para reduzir a chance de múltiplos bosts gerarem a mesma seqüência de delays.

Um bost deve confirmar que o endereço no campo de destino do Report recebido seja igual ao endereço do grupo multicast, para garantir que o report do bost, em questão, não seja cancelado por um report errado. Um bost deve descartar qualquer mensagem IGMP que não seja Host Membership Query ou Host Membership Report.

Quando um bost associa-se a um novo grupo, este deve imediatamente transmitir um Report para aquele grupo, ao invés de esperar por um Query, para o caso de ser o primeiro membro daquele grupo na rede. Para cobrir a possibilidade de um Report inicial ser perdido ou danificado, é recomendado que seja repetido uma ou duas vezes depois de delays curtos. (Um modo simples de realizar isto é agir como se um Query tivesse sido recebido somente pelo grupo, iniciando o delay randômico do grupo)

Roteadores multicast envia Queries periodicamente para atualizar seus conhecimentos sobre memberships presentes em uma rede em particular [Bak95]. Se nenhum Report for recebido por um grupo em particular depois de alguns números de Queries, os roteadores assume que o grupo não possui membros locais e não precisam retransmitir multicasts originados remotamente para o gtupo na rede local. Queries são normalmente não são enviadas freqüentemente (não mais de uma vez por minuto) 
para manter o overbead IGMP nos bosts e na rede baixo. Entretanto, quando um roteador multicast inicia, este emite muitos Queries em pouco espaço de tempo de forma a construir a base de dados sobre os membersbips locais rapidamente.

Desde que o IGMP somente desenvolve a comunicação entre os bosts receptores e o último roteador multicast na árvore de entrega, o roteamento de pacotes entre roteadores multicast deve ser gerenciado por um protocolo de roteamento multicast. Há muitos algoritmos para o roteamento de pacotes entre os roteadores multicast. A figura 4.2 ilustra um multicast routing protocol (protocolo de roteamento multicast) e o group membersbip protocol (protocolo de associação ao grupo) funcionando em diferentes seções da árvore de entrega multicast durante uma transmissão multicast [Bra93].

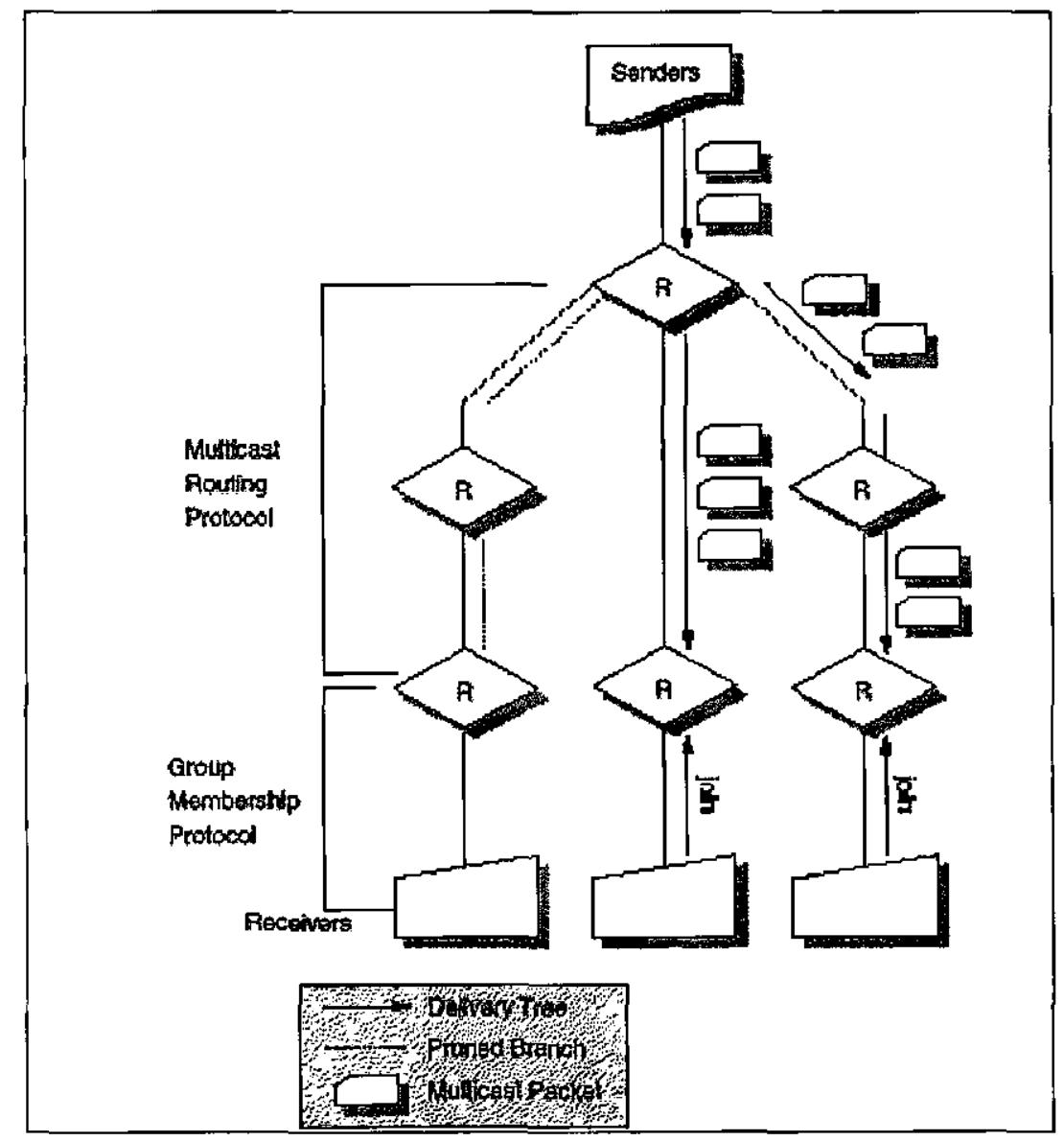

Figura 4.2: Protocolo de roteamento multicast

A Figura 4.2 ilustra que os pacotes multicast são transmitidos de um transmissor através de uma árvore de entrega para os receptores. Se nenhum dos bosts conectados diretamente a um roteador multicast estiver associado a um grupo multicast específico, nenhum pacote é distribuído no ramo da árvore que leva aos bosts não associados.

Quando um bost ou um roteador multicast recebe um datagrama multicast, a ação é dependente do valor do TTL e do endereço IP de destino. 


\subsection{Roteamento IP multicasting}

O tráfego multicast para um particular par (origem, grupo de destino) é transmitido da origem para receptores via uma spanning tree que conecta todos os bosts no grupo. Diferentes protocolos de roteamento IP usam técnicas diferentes para construir estas spanning trees, uma vez que uma árvore é construida, todo o tráfego é distribuído por sob a mesma.

Os protocolos multicast de roteamento IP geralmente seguem uma de duas abordagens básicas, dependendo da distribuição esperada dos membros do grupo multicast através da rede. A primeira abordagem é baseada em suposições que os membros do grupo multicast estão densamente distribuídas através da rede (por exemplo, muitas das sub-redes contêm ao menos um membro do grupo) e que a largura de banda é abundante. Então chamados protocolos de roteamento de "modo denso" contam com uma técnica chamado flooding para propagar a informação para todos os roteadores da rede. Protocolos de roteamento de modo denso incluem Distance Vector Multicast Routing Protocol (DVMRP) [Wai88], Multicast Open Sbortest Path First (MOSPF) [Moy94], e Protocol-Independent Multicast - Dense Mode (PIM-DM).

Uma segunda abordagem para o roteamento multicast basicamente assume que o grupo de membros multicast está disperso acerca da rede e a largura de banda não está necessariamente totalmente disponível, por exemplo, acerca de algumas regiões da Internet. Sparse-Mode "modo disperso" não significa que o grupo possui poucos membros, somente que estes estão amplamente espalhados. Neste caso, flooding poderia desperdiçar desnecessariamente a largura de banda e conseqüentemente poderia causar sérios problemas de performance. Conseqüentemente, protocolos de roteamento "sparse-mode" devem contar com técnicas mais seletivas para configurar e manter as redes multicast. Protocolos de roteamento "sparse mode" inclui Core Based Trees (CBT) [Bal97] e Protocol-Independent Multicast - Sparse Mode (PIM-SM) [Est97].

\subsection{Multicast no IPv6}

\subsubsection{Resumo do IPv6}

IPv6 oferece as seguintes características significantes:

- Um maior espaço de endereçamento, dito como suficiente para os próximos 30 anos.

- Endereçamento único e hierárquico, baseado nos prefixos ao invés das classes de endereço, para manter as tabelas de roteamento pequenas e o roteamento do backbone eficiente.

- Um mecanismo para auto-configuração das interfaces de rede. 
- Suporte para o próprio encapsulamento e outros protocolos

- Classe de serviço para distinguir tipos de dados

- Suporte aperfeiçoado para o roteamento multicast

- Autenticação e encriptação embutido

- Métodos de transição para migrar do IPv4

- Métodos compatíveis para coexistir e comunicar com IPv4

\subsubsection{Endereço multicast}

Um endereço multicast é um identificador associado a um conjunto de interfaces em múltiplos bosts. Pacotes ${ }^{15}$ enviados para este endereço serão transmitidos para todas interfaces correspondentes a este endereço (veja seção 4.4, "Internet Group Management Protocol- IGMP"). Não há en dereços broadcast no IPv6. A figura 4.3 ilustra o formato do endereço IPv6 multicast.

\begin{tabular}{|l|l|l|l|l|}
\hline 0 & \multicolumn{1}{|c|}{8} & 12 & 16 & 127 \\
\hline FP & Flags & Scopo & Group 10 & \\
\hline
\end{tabular}

Figura 4.3: Formato do endereço IPv6 multicast

FP Format Prefix - 11111111.

Flags Conjunto de quatro bits. Somente o bit de baixa ordem possui significado, como segue:

0000 Indica um endereço multicast permanentemente associado ("bem conhecido"), associado pelo global internet numbering autbority.

0001 Endereço transiente. Endereços deste tipo pode ser estabelecido pelas aplicações quando requerido. Quando as aplicações terminam, o endereço será liberado pela aplicação e poderá ser reutilizado.

Scope é o valor de 4 bits do escopo multicast usado para limitar o escopo do grupo multicast.

\section{Group ID}

O group ID identifica o grupo multicast, tanto permanente quanto transiente, dentro do dado escopo. O significado do endereço multicast permanentemente associado é independente do valor do

${ }^{15}$ Nota: IPv6 usa o termo pacote ao invés de datagrama. O significado é o mesmo, embora os formatos sejam diferentes. 
escopo. Por exemplo se o grupo de servidores NTP está associado a um endereço multicast permanente, com um grupo ID de X'101, então:

FF01:0:0:0:0:0:0:101 representa todos servidores NTP no mesmo nó transmissor FF02:0:0:0:0:0:0:101 representa todos servidores NTP no mesmo link transmissor FF05:0:0:0:0:0:0:101 tepresenta todos servidores NTP no mesmo site do transmissor FF0E:0:0:0:0:0:0:101 representa todos servidores NTP na internet

Endereços multicast não permanentemente associados possui um significado somente dentro um dado escopo. Por exemplo, um grupo identificado como não permanente, o endereço multicast FF15:0:0:0:0:0:0:101 em um site não possui nenhuma telação com um grupo usando o mesmo endereço em um site diferente, nem com um grupo não permanente usando o mesmo grupo ID com escopo diferente, nem com um grupo permanente com o mesmo grupo ID.

Endereços multicast não devem ser usados como endereços de origem nos pacotes IPv6 ou aparecer no cabeçalho de roteamento.

Endereços multicast de propósito especial são pré-definidos como segue:

Endereços multicast reservados: FF0X:0:0:0:0:0:0:0, com X=0..F

Os endereços multicast acima são reservados e nunca deverão associados a qualquer grupo multicast.

FF01::1 todas interfaces do nó local - Define todas interfaces no bost

FF02::1 Todos nós locais - Define todos sistemas da rede local.

FF01::2 Todos os roteadores do nó-local - Define todos roteadores local ao bost.

FF02::2 Todos roteadores do link local - Define todos roteadores no mesmo link do bost.

FF05::2 Todos roteadores do site local - Define todos roteadores no mesmo site do bost.

FF02::B Agentes Móveis link local.

FF02::1:2 Todos agentes DHCP link-local.

FF05::1:3 Todos servidores DHCP site-local.

Uma listagem completa dos endereços multicast pode ser encontrada no RFC 2375 - IPv6 Multicast Address Assignments.

Endereço do nó solicitado: $\quad$ FF02:0:0:0:0:1:FFXX:XXXX

$O$ endereço multicast dado é calculado como uma função dos endereços unicast ou anycast. $\mathrm{O}$ endereço do nó multicast solicitado é formado tomando-se os 24 bits de baixa-ordem do endereço 
(unicast ou anycast) e anexando aqueles bits para o prefixo FF02:0:0:0:0:1:FF00::/104 resultando em um endereço multicast variando entre: FF02:0:0:0:0:1:FF00:0000 a FF02:0:0:0:0:1:FFFF:FFFF.

Por exemplo, o nó multicast solicitado correspondente ao endereço IPv6 4037::01:800:200E:8C6C é FF02::1:FF0E:8C6C. Endereços IPv6 que diferem somente nos bits de alta-ordem, por exemplo, devido a múltiplos prefixos de alta-ordem associados com diferentes agregações, irá ser mapeado para o mesmo endereço do nó solicitado logo teduzindo o número de endereços multicast que um nó possa associar-se.

É necessário que um nó calcule e associe-se aos endereços multicast solicitados para cada endereço unicast e anycast que este é associado.

\subsection{Considerações Finais}

Este capítulo abordou algumas informações interessantes para compreensão dos protocolos multicast e implementações.

Como o processo de transmissão por multicast é dependente do protocolo utilizado pela rede, o multicast em redes ATM é realizado de uma forma. Para completar o assunto sobre o multicast, o próximo capítulo trata do multicast em redes ATM, apresentando as diferenças em relação ao IP multicast. 


\section{Capítulo 5 - ATM Multicast}

\subsection{Considerações Iniciais}

Há algumas diferenças combinatórias entre como é realizado o multicast em redes ATM e em redes IP. Este capítulo aborda questões referentes ao multicast em redes ATM, sendo organizado da seguinte maneira: a próxima seção trata de uma descrição do serviço, introduzindo a tecnologia ATM; a seção 5.3 aborda os mecanismos para possibilitar o IP multicast, descrevendo brevemente como ocorre o estabelecimento de uma conexão multicast, a seção 5.4 descreve um mecanismo de distribuição que permite redes baseadas no UNI 3.0 suporte o serviço multicast de protocolos como IP, através do uso do Multicast Address Resolution Server (MARS).

\subsection{ATM (Asynchronous Transfer Mode)}

ATM é uma tecnologia de roteamento de células. Switches (comutadores) tomam o lugar de roteadores nas redes ATM. ATM é muitas vezes usado como um backbone de alta velocidade pelas operadoras, por exemplo T3 e frame relay sendo muitas vezes são executadas no topo do ATM. A velocidade mais comum das redes ATM é de $155 \mathrm{Mbps}$; algumas são de $622 \mathrm{Mbps}$ (quatro canais de $155 \mathrm{Mbps}$ ). A tecnologia é escalável e pode suportar velocidades de gigabits via o uso de múltiplos canais [Pry95].

Redes ATM são orientadas a conexão[Hän94]. Uma conexão deve ser configurada antes que mensagens possam ser enviadas. Conexões são configuradas usando tanto circuitos virtuais permanentes (PVCs) ou circuitos virtuais conectados (SVCs). Quando um PVC ou SVC é estabelecido, uma rota física específica é selecionada da origem para o destino, e todas as switches acerca deste caminho constroem entradas na tabela de modo que possam rotear corretamente os pacotes[Pis98]. Veja Figura 5.1. Depois que uma conexão PVC ou SVC estiver configurada, todas as mensagens para aquela conexão seguem o mesmo caminho para o destino. PVCs são planejados para serem relativamente permanentes (por exemplo, permanecendo por meses ou anos), enquanto SVCs são 
dinamicamente construidos quando se fizer necessário e são imediatamente desabilitados quando não são mais necessários.

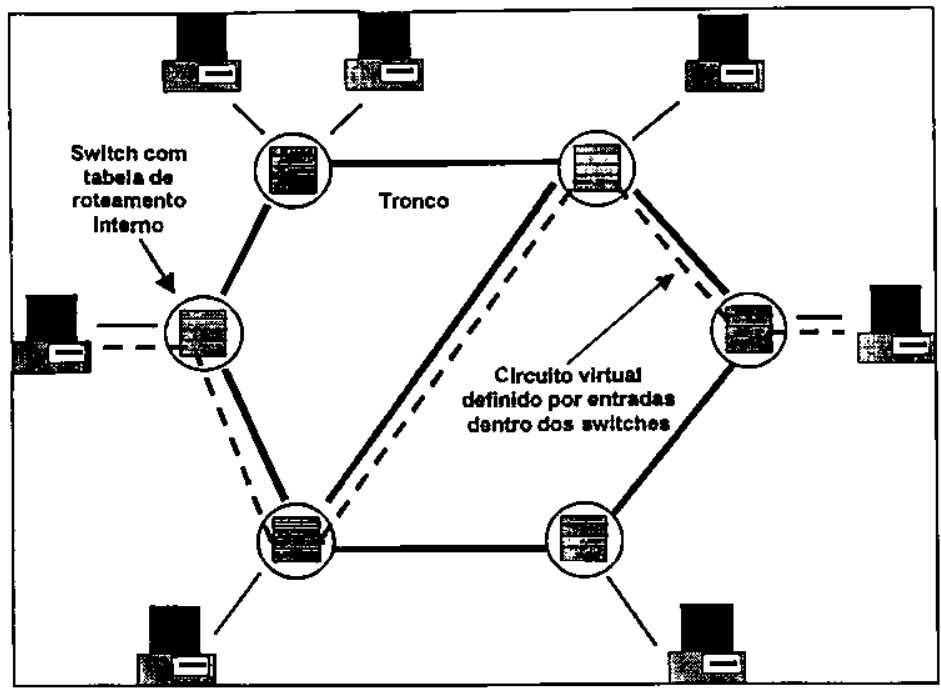

Figura 5.1: Uma conexão em uma rede ATM

\subsection{Mecanismos para possibilitar o IP Multicast}

ATM suporta multicast na camada de enlace de dados. Há um esforço para padronizar a possibilidade do estabelecimento de um switched virtual circuit (SVC) ponto-a-multiponto entre o transmissor e um conjunto de teceptores conhecidos (grupo multicast), via mecanismos de sinalização UNI 3.0/3.1[ATM94]. Estes serviços poderiam possibilitar IP Multicast a ser rodado no topo do ATM, usando circuitos virtuais ponto-a-multiponto como uma árvore de entrega. A próxima seção aborda o multicast em redes ATM.

\subsubsection{Considerações Especiais}

Há muitas difetenças combinatórias entre o conceito do ATM multicast apresentado acima, e o conceito tradicional de IP multicast.

De acordo com o cenário acima, o transmissor possui completo controle sobre o circuito virtual multicast. Seria inconveniente para o receptor, iniciar associando-se ao grupo (levando-se em conta o algoritmo do Snapshot); uma mensagem contendo esta requisição teria que ser enviada para o transmissor. Também, este cenátio funciona naturalmente para o multicast um-para-muitos, mas não para o multicast muitos-para-muitos, no qual um grupo poderá ter múltiplos transmissores.

Considerando o ATM, o multicast é inicializado pelo transmissor, desde que o transmissor configure o SVC ponto-a-multiponto. Por outro lado, IP Multicast é orientado ao receptor; um receptor 
pode tornar-se um membro de um grupo de multicast sem que o transmissor tome conhecimento da sua existência.

Grupos de Trabalho dentro do ATM Forum, assim como IETF, estão trabalhando no desenvolvimento de um padrão para implementar IP Multicast sobre o ATM. Dentro do ATM Forum, o Grupo de Trabalho Multiprotocol Over ATM iMPOA) está resolvendo esta questão; o correspondente Grupo de Trabalho IETF é o Grupo de Trabalho IP-over-ATM[Per94].

\subsubsection{Estabelecimento da Conexão}

$O$ modelo ATM aceita os circuitos virtuais permanentes e os circuitos virtuais comutados. $O$ primeiro é encontrado em todas as situações e pode ser usado à vontade, assim como as linhas privadas. O outro tipo de circuito tem de ser definido sempre que for usado, exatamente como acontece com as chamadas telefônicas. Nesta seção, é apresentado como são estabelecidos os circuitos virtuais comutados.

Tecnicamente, o estabelecimento de conexão não pertence à camada ATM, mas é manipulada pelo plano de controle usando um protocolo ITU, denominado Q.2931 [Sti96].

É possível estabelecer uma conexão de diversas formas. A mais comum, no entanto, é adquirir um circuito virtual para sinalização e usá-lo[Sti96]. Para estabelecer um circuito desse tipo, as células contendo uma solicitação são enviadas em um caminho virtual 0 , circuito virtual 5 . Se não houver problemas, será estabelecido um novo circuito virtual, no qual as solicitações e respostas de estabelecimento de conexão podem ser enviadas e recebidas.

A razão para as duas etapas desse procedimento de estabelecimento é que, dessa forma, a largura de banda reservada para o circuito virtual 5 (que praticamente não é usado) pode ser mantida extremamente baixa. Outra alternativa também é oferecida para o estabelecimento de circuitos virtuais. Algumas concessionárias de comunicações podem permitir que os usuários tenham caminhos virtuais permanentes entre destinos predefinidos ou permitir que eles os definam dinamicamente. Quando um bost tem um caminho virtual para outro bost, ele pode alocar circuitos virtuais nele próprio, sem envolver os comutadores.

O estabelecimento de um circuito virtual utiliza os seis tipos de mensagem listados na tabela 5.1. Cada mensagem ocupa uma ou mais células e contém o tipo, o tamanho e os parâmetros da mensagem. As mensagens podem ser enviadas para a rede através de um bost ou podem ser enviadas pela rede para um bost (geralmente, em resposta a uma mensagem de outro bost). 
Tabela 5.1: Mensagens usadas para o estabelecimento e o encerramento da conexão

\begin{tabular}{|l|l|l|}
\hline \multicolumn{1}{|c|}{ Mensagem } & \multicolumn{1}{|c|}{$\begin{array}{c}\text { Significado quando } \\
\text { enviada pelo host }\end{array}$} & $\begin{array}{l}\text { Significado quando enviada } \\
\text { pela rede }\end{array}$ \\
\hline SETUP & Estabeleça um circuito & Chamada recebida \\
\hline CALL & Vi a chamada recebida & $\begin{array}{l}\text { A sua solicitação de chamada } \\
\text { será processada }\end{array}$ \\
\hline CONNECT & Aceito a chamada recebida & $\begin{array}{l}\text { A sua solicitação de chamada } \\
\text { foi aceita }\end{array}$ \\
\hline CONNECT ACK & Obrigado por aceitar & Obrigado por fazer a chamada \\
\hline RELEASE & Favor encerrar a chamada & $\begin{array}{l}\text { O outro lado já teve o } \\
\text { suficiente }\end{array}$ \\
\hline RELEASE COMPLETE & Confirmação de RELEASE & Confirmação de RELEASE \\
\hline
\end{tabular}

O procedimento normal para o estabelecimento de uma chamada, ilustrado na Figura 5.2, é fazer com que um bost envie a mensagem SETUP em um circuito virtual especial. Em seguida, a rede responde com CALL PROCEEDING para confirmar o recebimento da solicitação. Quando se propaga na direçào do destino, a mensagem SETUP é confirmada em cada bop por CALL PROCEEDING.

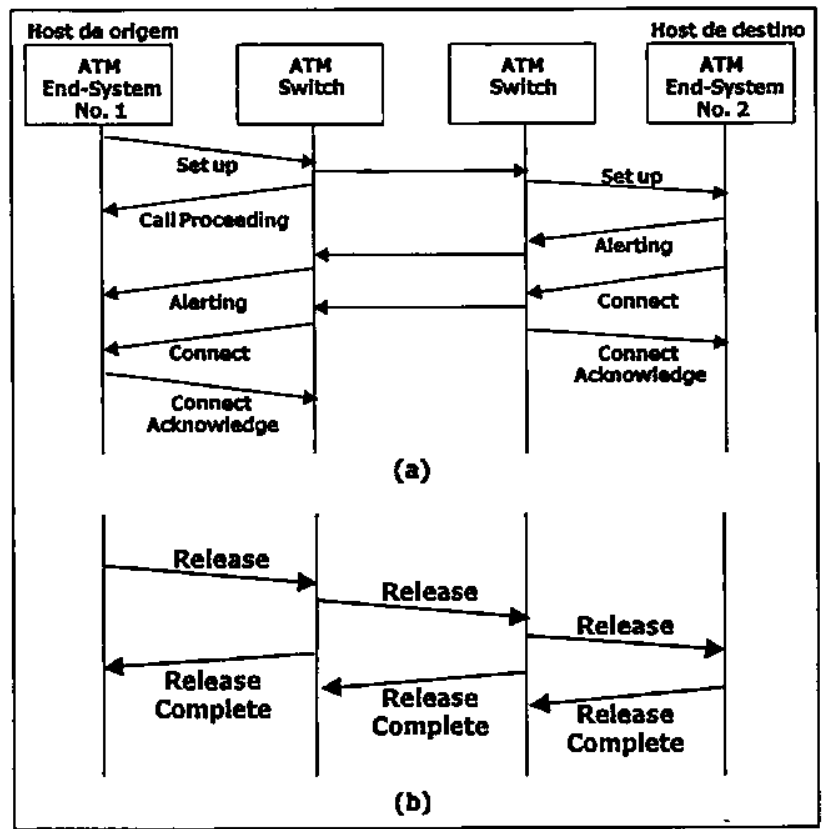

Figura 5.2: Seqüência de eventos para abrir/fechar uma conexão ATM

Quando a SETUP finalmente chega, o bost de destino pode responder com CONNECT para aceitar a chamada. Em seguida, a rede envia a mensagem CONNECT ACK para indicar que recebeu a 
mensagem CONNECT. Quando a mensagem CONNECT é propagada de volta na direção da origem, cada comutador que a receber deverá confirmá-la com uma mensagem CONNECT ACK. Tanto no "CALL PROCEEDING" ou na mensagem "CONNECT" o novo VPI/VCI alocado é determinado para o ATM End-system No. 1. Essa seqüência de evontos é mostrada na Figura 5.2(a).

A seqüência que encerra um circuito virtual é igualmente simples. $O$ bost que deseja desconectarse só precisa enviar a mensagem RELEASE, que se propaga até a outra extremidade e faz com que o circuito seja encerrado. A mensagem é confirmada em cada um dos bops ao longo do caminho, como mostra a Figura 5.2(b).

As redes $A T M$ permitem a configuração de canais de multicast. Um canal de multicast tem apenas um transmissor e mais de um receptor. Para criá-los, é necessário configurar uma conexão para um dos destinos da maneira tradicional. Em seguida, a mensagem ADD PARTY é enviada para anexar um segundo destino ao circuito virtual retornado pela chamada anterior. Em seguida, podem ser enviadas novas mensagens ADD PARTY a fim de aumentar o tamanho do grupo de multicast.

A seção seguinte define um registro de endereço e um mecanismo de distribuição que permite redes baseadas no UNI 3.0 suporte o serviço multicast de protocolos como IP, através do uso do Multicast Address Resolution Server (MARS).

\subsection{Suporte para Multicast em redes ATM - MARS}

ATM está sendo utilizado como uma tecnologia da camada de enlace de dados para suportar uma variedade de protocolos, incluindo IP. Com RFC 1483 [Hei93] o IETF definiu um mecanismo mutiprotocolo para o encapsulamento e transmissão de pacotes usando AAL 5 através de canais virtuais ATM (VCs). Porém, a publicação da especificação da sinalização ATM Forum (UNI 3.0 [A TM94], com adições para UNI 3.1 oficializado no final de 1994) não fornece a abstração do endereço multicast. Conexões unicast são suportadas por circuitos virtuais $(V C s)$ ponto a ponto e bidirecionais. $O$ multicasting é suportado attavés de circuitos virtuais ponto a multiponto. A principal limitação é que o transmissor deve ter conhecimento de cada receptor, e explicitamente estabelecer um VC tendo si próprio como raiz e os receptores como nós-folhas.

O Multicast Address Resolution Server (MARS), relativamente diferente do ATM ARP Server introduzido no RFC 1577 [Lau93], age como um registro dos multicast group memberships. As mensagens MARS, baseadas no formato ATM ARP, suporta a distribuição da informação do multicast group membership entre MARS e bosts ou endpoints ${ }^{16}$. As entidades de resolução de endereços de endpoints fazem

${ }^{16}$ Considere endpoints como hosts conectados a uma rede ATM. 
uma query (pergunta) para o MARS quando um endereço de grupo multicast precisar ser resolvido. $O$ mecanismo para enviar os pacotes por multicasting é através de uma rede (meshes) de VCs ponto a multiponto, ou o uso de servidores multicast. Para fornecer a notificação assíncrona das mudanças no group membership o MARS gerencia úois VCs ponto a multiponto - um direcionado para todos os endpoints que desejam o suporte multicast, e o outro para todos os servidores multicast registrados como fornecendo suporte para qualquer grupos multicast. A escolha da rede de VCs ou servidores multicast é configurável por grupo.

O número de grupos multicast ficará restrito pelos interesses práticos como o suporte limitado de VC nas interfaces ATM dos endpoints. Cada MARS gerencia um 'cluster' de endpoints ATM conectados. Um cluster é definido como um conjunto de endpoints disposto a ser agrupados juntos como membros de grupos multicast. Roteadores configurados são utilizados para passar o tráfego multicast entre clusters.

O mapeamento de clusters para outros conjuntos de endpoints (como Logical IP Subnets - "LIS") é deixado a cargo dos administradores de rede. Uma abordagem simples para cobrit ambientes IP poderia ser que cada LIS seja servido por um MARS separado, com o cluster construído por membros da LIS. Roteadores IP multicast poderia interconectar cada LIS como é feito nas redes convencionais. Entretanto, não há nenhum requerimento que um cluster seja limitado a uma única LIS.

\subsubsection{Suporte ao multicast através do UNI 3.1}

Esta seção irá descrever a operação em termos das funções 'genéricas' que devem estar disponiveis para os clientes de uma entidade de sinalização UNI $3.1 \mathrm{em}$ um dado endpoint ATM. O modelo ATM descreve ' $A A L$ Users' como qualquer entidade que estabelece e gerencia VCs e os serviços da camada inferior AAL para a troca de dados. Uma interface IP sobre ATM é uma forma de 'AAL User'.

As principais limitações do suporte multicast do UNI 3.1 são:

- Somente VCs ponto a multiponto, unidirecionais podem ser estabelecidos.

- Somente o nó raiz de um dado VC pode adicionar ou remover nós-follha.

Dentro destas restrições, membros dos grupos multicast podem comunicar através do uso de uma rede (meshes) de conexões multicast, ou servidores multicast. Em uma rede de conexões multicast, cada bost de transmissão é um nó-raiz de um VC ponto a multiponto que possui cada bost pertencente ao grupo como nó-folha. No modelo do servidor multicast, os membros do grupo enviam seus pacotes diretamente para o servidor ${ }^{17}$, o qual então retransmite cópias para todos os outros membros.

\footnotetext{
${ }_{17}$ Servidor é um host onde o MARS reside, sendo ainda diretamente endereçável pelos endpoints que este está servindo.
} 
Esta seção define a sinalização $M A R S$-Endpoint necessária para suportar ambos os mecanismos. As seguintes funções de sinalização, tabela 5.2, devem estar disponíveis para $A A L$ Users locais:

Tabela 5.2: Funções de Sinalização

\begin{tabular}{|l|l|}
\hline L_CALL_RQ & Estabelece um VC unicast pas a um endpoint especificado \\
\hline L_MULTI_RQ & Estabelece um VC multicast para um endpoint especificado \\
\hline L_MULTI_ADD & Adiciona um novo nó-folha ao VC já estabelecido \\
\hline L_MULTI_DROP & Remove um nó-folha específico VC já estabelecido \\
\hline L_RELEASE & Libera um VC unicast, ou todas as folhas em um VC multicast \\
\hline
\end{tabular}

As indicações, apresentadas na tabela 5.3, são assumidas para estarem disponíveis para AAI Users, geradas pela entidade de sinalização UNI 3.1 local:

Tabela 5.3: Indicações geradas pela rede

\begin{tabular}{|l|l|}
\hline L_ACK & Completo sucesso da requisição para a entidade de sinalização \\
\hline L_REMOTE_CALL & Um novo VC esta sendo estabelecido para o AAL User. \\
\hline ERR_L_RQFAILED & $\begin{array}{l}\text { Um endpoint ATM remoto rejeitou um L_CALL_RQ, L_MULTI_RQ, } \\
\text { ou L_MULTI_ADD }\end{array}$ \\
\hline ERR_L_RELEASE & Um endpoint preferiu terminar um VC pré-existente \\
\hline
\end{tabular}

UNI 3.1 define dois formatos de endereços - E.164 e ISO NSAP. Em UNI 3.1 um 'ATM number' é a identificaçào primária de um endpoint ATM, e este pode usar os dois formatos. Sob certas circunstâncias um ATM endpoint deve ser identificado por ambos endereços E.164 (identificando o ponto de uma rede privada com uma tede pública) e o ISO NSAP (ATM Subaddress') identificando o endpoint final dentro de uma rede privada. Para o restante da seção o termo 'ATM Address' irá ser usado para significar tanto um único 'ATM Number' ou um 'ATM Number' combinado com um 'ATM Subaddress'.

\subsubsection{Visão Geral do Multicast Address Resolution Server}

O MARS poderia residir dentro de qualquer ATM endpoint que é diretamente endereçável pelos endpoints que este está servindo. Endpoints desejando associar-se-a um multicast cluster deve ser configurado no bost no qual o MARS reside. Este é o cluster do MARS primário. Se um cluster é servido por um MARS de backup, endpoints são configurados pelo MARS secundário. Embora um MARS secundário é opcional, implementações endpoint devem ser capazes de utilizá-los. 
Arquiteturalmente o MARS é similar ao RFC 1577 ARP Server, embora há uma pequena diferença nas informaçōes manipuladas. Enquanto o ARP Server mantém uma tabela de pares de endereços \{IP, ATM \} para todos IP endpoints na LIS, o MARS mantém tabelas de mapeamentos extendidos \{endereço multicast, ATM.1, ATM.2, ..., ATM.n\}. Isto pode ser configurado utilizando determinados mapeamentos, ou dinamicamente através de mafeamentos "aprendidos".

O MARS distribui as informações das associações do grupo para os membros do cluster através de um VC ponto a multiponto, conhecido como ClusterControlVC. No suporte de múltiplos servidores dentro de um cluster, o MARS também estabelece um VC ponto a multiponto separado conhecido como ServerControlVC. Todos membros do cluster são nós-folha do ClusterControlvC. Todos os servidores multicast são nós-folha do ServerControlVC.

\subsubsection{Transmitindo para Grupos Multicast}

A seguinte descrição irá ser em termos de uma interface IP/ATM que é capaz de transmitir pacotes da classe $\mathrm{D}$ a qualquer momento, sem prévio aviso.

Quando um pacote chega para transmissão, e não há nenhum VC de saída para o endereço do grupo multicast de destino, o MARS é questionado em relação ao conjunto de endpoints que atualmente compõe o grupo multicast.

A busca é executada emitindo um MARS_REQUEST. A mensagem MARS_REQUEST é formatada como uma ATM ARP_REQUEST com código do tipo igual 11 (decimal). A resposta do MARS pode ter uma das duas formas:

$>$ MARS_MULTI - Seqüência de mensagens MARS_MULTI retornam um conjunto de endpoints em um grupo.

$>$ MARS_NAK - Nenhuma mapeamento encontrado, grupo está vazio

$\mathrm{O}$ tráfego de request/response deve ocorrer em um VC ponto a ponto estabelecido do host para o MARS. Onde o MARS e ARP Server são co-residente, este VC pode ser compartilhado entre o tráfego do ATM ARP e do MARS.

\section{Recuperando Group Memberships do MARS.}

Se o MARS não tivesse nenhum mapeamento para o endereço da classe $D$ desejado um MARS_NAK será retornado. Neste caso o pacote IP deve ser descartado. Se uma combinação for encontrada nas tabelas MARS, esta procede o retorno dos endereços de ATM.1 até ATM.n em uma seqüência de um ou mais MARS_MULTIs. Um simples mecanismo é usado para detectar e recuperar da perda das mensagens MARS_MULTI. 
Cada MARS_MULTI transporta um novo valor booleano (verdadeiro ou falso), e um campo inteiro y de 15 bits - expressado como MARS_MULTI(x,y). Campo y age como um número de seqüência, iniciando em $1 \mathrm{e}$ incrementado para cada MARS_MULTI enviado. Campo x age como um marcador de 'final da resposta'. Quando $\mathrm{x}=1$, a resposta do MARS é considerada como completí.

Em adição, cada MARS_MULTI podetia transportar múltiplos endereços ATM do conjunto \{ATM.1, ATM.2, ... ATM.n\}. Um MARS deve minimizar o número de MARS_MULTIs transmitidos agrupando, quanto possível, os endereços dos membros em um único MARS_MULTI. O limite da mensagem MARS_MULTI deve ser o MTU ${ }^{18}$ do VC.

Considere que deve ser retornado $\mathrm{n}$ endereços ATM, cada MARS_MULTI é limitado a somente $\mathrm{p}$ endereços ATM, e $\mathrm{p}<\mathrm{n}$. Isto necessitaria de uma seqüência de $\mathrm{k}$ mensagens MARS_MULTI (onde $\mathrm{k}=(\mathrm{n} / \mathrm{p})+1$, usando aritmética inteira), transmitida como segue:

MARS_MULTI $(0,1)$ transporta \{ATM.1 ... ATM.p\}

MARS_MULTI $(0,2)$ transporta $\{$ ATM. $(\mathrm{p}+1)$... ATM.(2p) $\}$

MARS_MULTI $(1, \mathrm{k})$ transporta $\{\ldots$ ATM.n $\}$

Se $k=1$ então somente MARS_MULTI $(1,1)$ é enviado.

Uma falha típica será a perda de uma ou mais mensagens MARS_MULTI $(0,1)$ até MARS_MULTI $(0, \mathrm{k}-1)$. Isto é detectado quando o y pula mais de um entre MARS_MULTIs. Uma outra categoria de falha seria a perda do MARS_MULTI $(1, k)$. Um timer deve ser implementado para mostrar a falha na chegada do último MARS_MULTI. Um valor padrão sugerido é de 10 segundos.

Se um timeout ocorrer, o bost deve descartar todos os resultados, e repetir o MARS_REQUEST.

Se o MARS estiver gerenciando um cluster de endpoints espalhados por diferentes redes ATM mas diretamente acessíveis, o MARS pode não set possível retornar todos os membros do grupo em um único MARS_MULTI. O formato da mensagem MARS_MULTI permite que tanto E.164, ISO NSAP, ou (E.164 + NSAP) seja retornado como endereço ATM. Entretanto, cada mensagem MARS_MULTI poderia somente retornar o endereço ATM do mesmo tipo. O endereço retornado deve ser agrupado de acordo com o tipo (E.164, ISO NSAP, ou ambos) e retornados em uma seqüência separada das partes MARS_MULTI .

${ }^{18}$ MTU sigla para Maximum Transfer Unit. Cada rede tem uma MTU, e cada segmento deve caber na MTU. Na prática, uma MTU tem alguns milhares de bytes e, portanto, define o limite superior em termos de tamanho de segmento. 


\subsection{Considerações Finais}

Neste capítulo foram apresentadas algumas diferenças combinatórias entre como é realizado o multicast em redes ATM e em redes IP. No próximo capítulo é apresentada a modelagem do algoritmo snapshot e como todos estes conceitos abordados são utilizados neste projeto. 


\section{Capítulo 6 - Modelagem da implementação do Servidor de Vídeo SNAPSHOT}

\subsection{Considerações Iniciais}

Há várias técnicas de sincronização de streams baseadas no adaptive piggybacking, cada qual com suas particularidades, mas semelhantes em relação aos princípios básicos da técnica do adaptive piggybacking. A técnica Snapsbot foi escolhida por conter estes princípios básicos do adaptive piggybacking, por exemplo, a alteração on-line da velocidade dos streams (quadros por segundo) de acordo com o resultado do algoritmo de programação dinâmica e a mesclagem das streams (que na prática é representada pelo multicast).

Este projeto propõe definir a modelagem de uma aplicação para a técnica SNAPSHOT, utilizando o $\mathrm{UML}^{19}[\mathrm{Rum} 99][$ Sch99], com finalidades de testes e avaliações servindo de base para a implementação de um software. Este capítulo está organizado da seguinte maneira: a próxima seção apresenta a metodologia utilizada para construir a modelagem; na seção 6.3 é apresentada a análise de requisitos, a seção 6.4 trata da funcionalidade do sistema; as seções 6.5 e 6.6 compreendem a análise dinâmica, sendo que a seção 6.5 trata dos diagramas de seqüência, abordando os diversos tipos de cenários que demonstram a funcionalidade do sistema e na seção 6.6 é apresentado o diagrama de estados; as seções 6.7 e 6.8 compreendem a análise estática, ou estrutural, sendo que na seção 6.7 é apresentado o diagrama de classes e na seção 6.8 é apresentado o diagrama de componentes.

19 Unifred Modeling Language (UML), introduzido em 1997, é considerado pela indústria do software como uma linguagem gráfica padrão para especificação, construção, visualização e documentação de sistemas de software, fornecendo a todos envolvidos na produção, desenvolvimento e manutenção do software, uma notação padrão para expressar o projeto do sistema. 


\subsection{Metodologia}

A modelagem da aplicação seguirá a disciplina de engenharia de software. $O$ atual trabalho irá realizar a análise da técnica SNAPSHOT a fim de criar um modelo implementável. O modelo será orientado por objetos. A linguagem de modelagem será a UML. A modelagerı da aplicação não pressupōe nenhuma linguagem, nenhum padrão, nenhum framework, nenhuma biblioteca de funções ou qualquer outro recurso de implementação específico. Entretanto, ele poderá servir de base para o modelo de implementação em qualquer linguagem, preferencialmente orientada a objeto. A construção do modelo se iniciará com a definição de requisitos que formatá a base para a análise dinâmica, estrutural e funcional do sistema. Logo, foram definidas as seguintes etapas:

- A análise de requisitos deverá apresentar as características necessárias para o aplicativo, especificando um ambiente de funcionamento. A técnica de especificação de requisitos será o estudo de caso de uso.

- A análise dinâmica especificará a interação de troca de mensagens entre os objetos do modelo. Ela será baseada no estudo dos cenários de caso de uso e utilizará os diagramas de seqüência e de transição de estados.

- A análise estática especificará as relações estruturais entre objetos. A análise estática, ou estrutural, e a análise dinâmica ocorrem simultaneamente. A modelagem da análise estrutural utilizará o diagrama de classes e o diagrama de componentes para especificar os processos paralelos.

\subsubsection{Estudos realizados}

Durante a análise de requisitos, foi feita uma busca por conhecimentos correlatos e artigos que tratavam da técrica em si. A partir de então, depois de dominado o conhecimento que envolve as técnicas de sincronização de vídeo iniciou-se a etapa de especulação dos recursos necessários para a realização do projeto, tanto a nível de hardware, considerando a infra-estrutura, quanto a nível do software (tanto bibliotecas de suporte para programação para cenátios de Video on Demand quanto protocolos de redes). Nesta especulação foi levada em conta a restrição, já mencionada, como a realização do multicast, a qual depende da rede, bem como as restrições para o tempo de processamento de cálculos e alteraçōes de velocidades de streams durante o progresso das mesmas.

Logo após, foi feita a análise de sistema. Nesta análise foi feita a modelagem do algoritmo, sem levar em conta detalhes de implementação, tais como qual biblioteca ou linguagem de programação, qual arquitetura de rede deveria ser utilizada, etc. Porém, esta modelagem é de fundamental importância para compreender o funcionamento, bem como os passos a serem tomados na próxima etapa que é a etapa de projeto, onde deverào ser definidos os passos para a codificação. 
Iniciando a etapa de projeto, foi feita uma busca por uma biblioteca que pudesse servir como uma base sólida para a implementação do proposto algoritmo. Dentre todas as encontradas, a que mais satisfazia ao perfil das necessidades foi o Java Media Framework (JMF) versão 2.0 [Sun99]. O JMF é uma rica biblioteca para tratamento de vídzo que pode servir de grande auxilio para a implementação, pois muitas das necessidades do programa, como uma busca por um determinado quadro dentro de um vídeo, os mecanismos necessários para transmissão das streams de vídeo, isto é, codificadores e decodificadores, pacotizadores e depacotizadores, estão contidos neste framework. Logo apresentando todos esses recursos, que na verdade excede o necessário a implementação, esta biblioteca surge como uma boa solução, além de ser multiplataforma. Pata que o JMF possa atender a todas exigências do algotitmo, é necessário tealizar alterações e adições de plug-ins $5^{20}$ Uma das exigências básicas é a alteração da velocidade dos stream em progresso. Para isso, o SureStream desenvolvido pela RealSystem( poderia servir como modelo, pois embora o roteamento seja impulsionado por razões diferentes, a idéia poderia ser aproveitada. Uma solução pata a implementação da plataforma de suporte para o algoritmo snapsbot ( $2^{\mathrm{a}}$ camada da arquitetura apresentada no capítulo 7) poderia ser, por exemplo, a re-escrita dos recursos implementados do Java e RealSystem adequando-os ao propósito do algoritmo Snapshot.

Como o multicast é dependente do protocolo utilizado pela rede, foi feito um estudo envolvendo as redes IP e ATM. O estudo do multicast nas redes ATM fazia parte da proposta inicial do trabalho, pois como já discutido, a forma como o multicast é realizado nas redes ATM proporciona a transparência do sistema para os clientes, o que fazia parte de uma restrição inicial do projeto. A utilização do ATM, também serviria ao propósito de utilizar as chaves ATM para obter os dados do tráfego que seriam roteados pela mesma e assim obter um maior detalhamento nos experimentos. Para realizar a implementação da camada de comunicação com a rede ATM, poder-se-ia utilizar a API da própria ForeSystem (B) ou a API do Winsock2, da Microsoft, que é uma biblioteca de suporte a programação para rede, que foi extendida com APIs para auxiliar a progtamação para redes ATM. Poder-se-ia ainda utilizar a API do XTI, para UNIX, a qual é baseada no X/Open (como dito, a ForeSystem implementou o ATM Service Providers para ambos WinSock2 e XTT). Estas alternativas seriam interessantes pois os equipamentos ATM da Fore Systems utilizados pelo laboratório do Intermídia, por exemplo, placa adaptadora e switches, suportam essas APIs.

\footnotetext{
${ }^{20}$ Software que pode ser instalado de forma a agir como se fizesse parte do sistema
} 


\subsection{Análise de requisitos}

$O$ ambiente de funcionamento de um sistema de video-on-demand é sempre uma rede de computadores, seja uma rede particular ou pública, rede local ou rede mundial, não importa.

A técnica de SNAPSHOT é fundamentada em 1) mesclagem de streams, 2) transmissão com velocidade alterável (rápida e lenta) e 3) o algoritmo de programação dinâmica (dynamic programming). Estes fundamentos já foram amplamente discutidos. Tais fundamentos devem ser trazidos para o modelo a fim de definir um modo de implementação.

Por ser uma aplicação distribuída em rede, deve ser adotada a arquitetura CLIENTE/SERVIDOR. Este projeto não impõe restrições em relação ao tipo de rede a ser utilizada, embora a modelagem tenha tratado o multicast nas redes IP e ATM.

Os tópicos abaixo é uma aplicação dos conhecimentos, descritos nos capítulos anteriores, voltada como suporte para a implementação do snapshot.

\subsubsection{A mesclagem}

A mesclagem é um elemento teórico que na prática ocorre via multicasting, ou seja, vários clientes recebendo a mesma transmissão de dados (pacotes). No protocolo IP, o multicast envolve o cliente, isto é, o servidor transmite os dados, através do transporte UDP, para um grupo multicast e os clientes que pertencerem a este grupo receberão os pacotes UDP. O servidor snapshot deve indicar para os seus clientes quando e a qual endereço e porta multicast, este deve se conectar quando ocorrer uma mesclagem. Para isso, o cliente poderia ter duas portas: uma unicast, por onde trafegariam as mensagens de controle entre o servidor e o cliente, tais como o novo endereço multicast por onde prosseguirá a transmissão, abandono da seção tanto pelo cliente quanto pelo servidor, etc. A outra porta seria uma porta multicast por trafegariam os dados da mídia.

Uma outra forma, é utilizar o multicast ATM, não sendo mais necessário que o cliente se associe a um grupo multicast. No capítulo 5, foi introduzido o assunto sobre Multicast Address Resolution Server (MARS). Utilizando este modelo, é possível simular o IP multicast de nível 2, tendo a máquina servidora, na qual o MARS reside, a função do roteador no IP multicast. Com isso, os cenátios apresentados neste capítulo para o IP multicast serviriam também para o ambiente de IP sob A'TM.

Em todas as formas de se obter o multicast, deve-se levar em conta que o tempo que envolve todo o processo, desde o momento que a stream envia uma mensagem para a outra stream com a qual esta irá se mesclar até o recebimento dos dados pelo cliente transmitidos pela nova stream, não deve ser superior ao intervalo entre o envio de um quadro e outro. 


\subsubsection{A transmissão}

Há pelo menos duas formas para obter as versões alteradas. $\mathrm{Na}$ primeira, quadros são adicionados ou retirados embora mantendo-se a mesma taxa de transmissão da versão original. A adição ou subtração é seguida pela técnica da interpolação de quadros, de forma a suavizar a alteração. Para diminuir a taxa de apresentação, quadros são acrescentados e vice-versa. Logo o número de quadros das versões alteradas difere do número de quadros da versão original, conseqüentemente, é necessária uma função de conversão no processo de alteração da velocidade.

$\mathrm{Na}$ segunda forma, o layout dos dados é "sintonizado" para uma determinada taxa de apresentação. Com isso, o número de quadros das versões alteradas não difere do número de quadros da versão original, dispensando-se assim, a função de conversão no processo de alteração.

Estas versões podem ser criadas on-line, embora com o intuito de diminuir a carga de processamento, é recomendável que as mesmas sejam criadas off-line e armazenadas em disco. A capacidade do servidor de alteração dinâmica na taxa de apresentação do vídeo enquanto o mesmo está em progresso, é de extrema importância para a viabilidade da técnica do piggybacking. Para o suporte a implementação desta tarefa pode ser utilizado o Surestream, da RealSystem ${ }^{\circledR}$.

O SureStream fornece um framework para codificação o qual permite que múltiplos streams de diferentes taxas sejam codificados simultaneamente e combinados em um único arquivo, sendo que mudanças na largura de banda são traduzidas em combinações de streams diferentes[Rea99].

Logo, o SureStream beneficia os usuários permitindo um fluxo confiável, sem interrupções, de acordo com a largura de banda disponível. SureStream permite aos provedores de conteúdo criar um arquivo para todos os ambientes, fornecendo alta qualidade para os usuários em diferentes taxas de dados. O diagrama (Figura 6.1) é um exemplo de um servidor enviando fluxo de áudio e vídeo projetados para emparelhar com as reais condições das taxas de throughput da conexão.

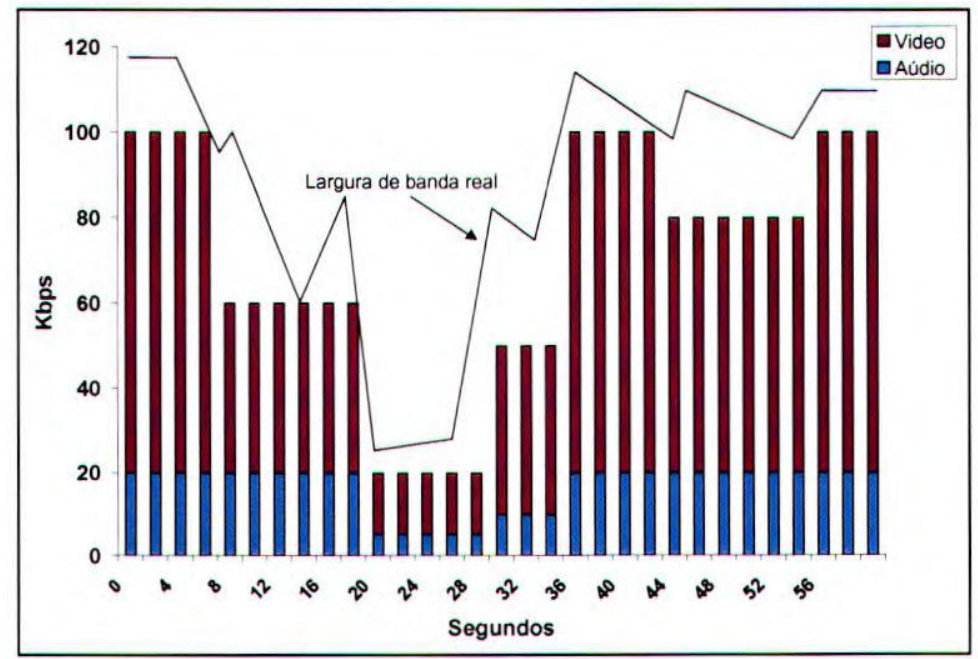

Figura 6.1: Exemplo de uma conexão ISDN 
Pelas razões apresentadas acima, o SureStream com sua capacidade de roteamento dinâmico e sem cortes (não é perceptível para o usuátio) entre os arquivos embutidos em um clip, mostra-se útil para a implementação do Snapshot. Como a capacidade de alteração on-line da taxa de transmissão dos streams é um pré-requisito básico para que o Snapsbot possa ser implementado, o SureStream poderia auxiliar como um modelo na realização desta tarefa.

\subsubsection{Dynamic Programming}

O Dynamic Programming (ou algoritmo de programação dinâmica) é o grande diferencial da técnica Snapshot. Através dele é obtido a melhor árvore de mesclagem, ou seja, a de menor custo. Para isso é necessária $\mathrm{O}\left(n^{3}\right)$ iterações, onde $n$ é o número de streams a serem mesclados.

Para que seja possível alcançar os resultados teóricos esperados, sendo essa uma aplicação de tempo-real, é necessário que o cálculo do dynamic programming, bem como o processo de alteração da velocidade apresentação dos streams de vídeo, seja inferior ao tempo de envio de um quadro. Esta restrição se faz necessária, de forma que os resultados decorrentes do algoritmo de programaçãodinâmica, quando forem postos na prática, reflitam todos os seus benefícios.

\subsection{Funcionalidades do Sistema}

\subsubsection{Interatividade entre o Administrador e o Sistema}

Retomando a especificação, este modelo irá apresentar apenas o servidor. Todo sistema cliente/servidor possui a figura do administrador que é responsável por iniciar, configurar e finalizar a execução do programa servidor, como ilustrado na Figura 6.2.

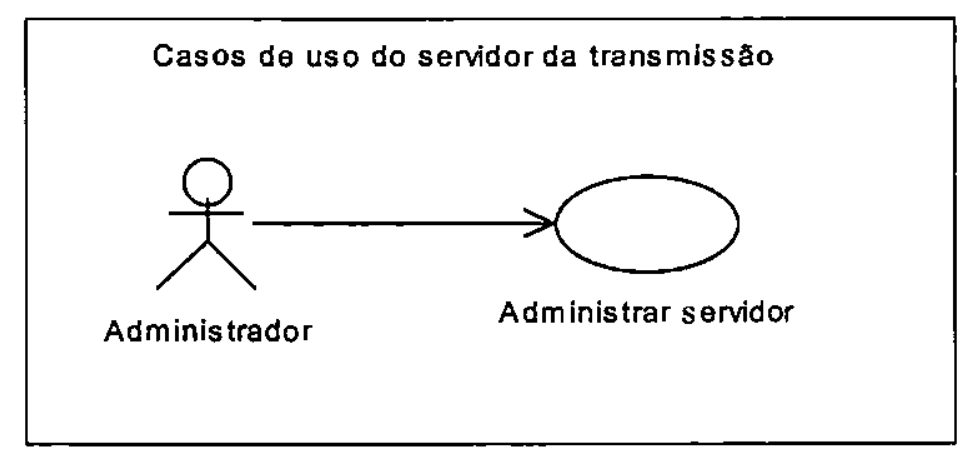

Figura 6.2 : Casos de uso do servidor de transmissão 
Tabela 6.1: Descrição da administraçăo do servidor

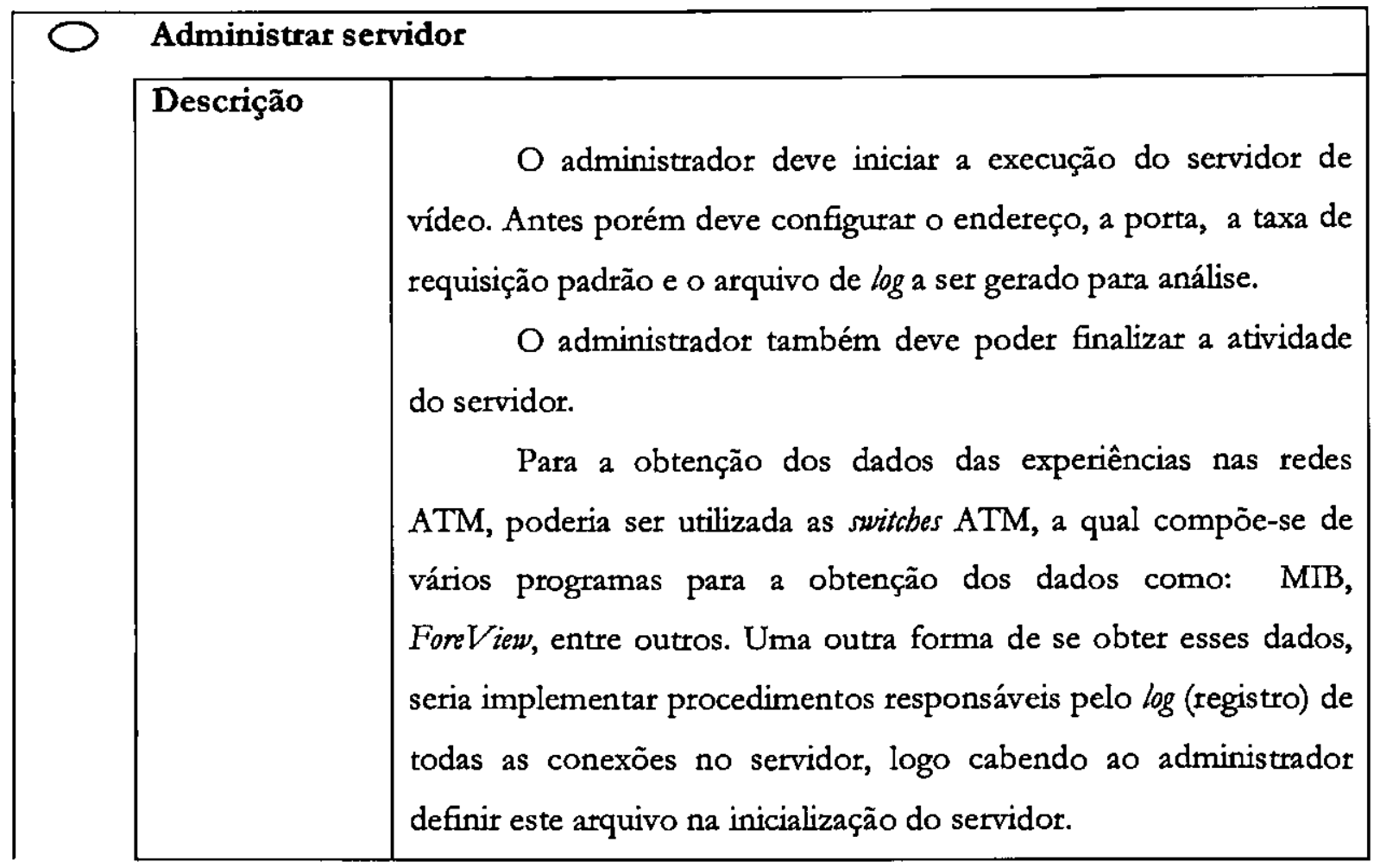

\subsubsection{Interatividade entre o Cliente Remoto e o Sistema}

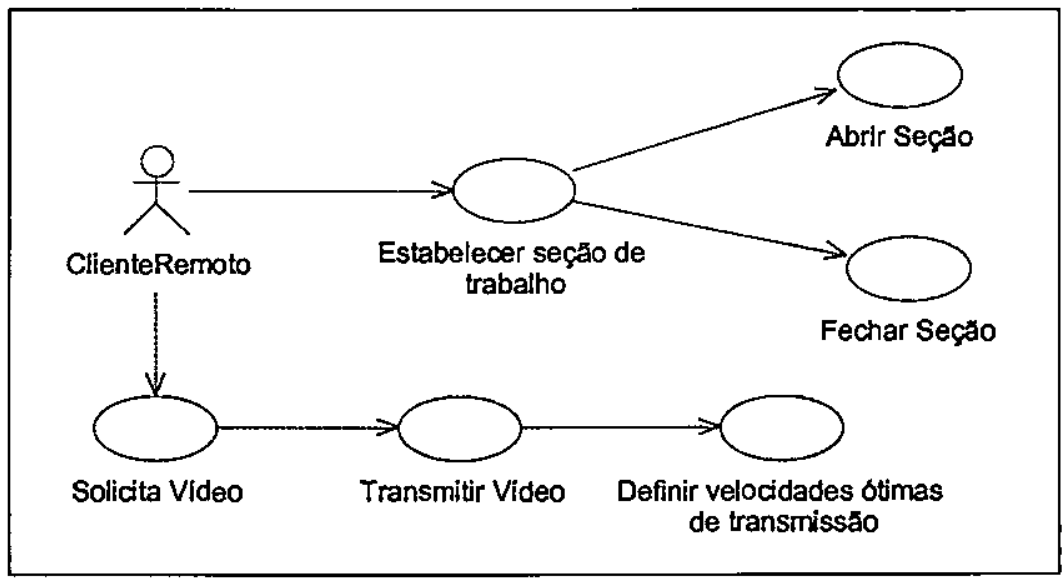

Figura 6.3: Casos de uso do cliente da transmissão de VOD utllizando Snapshot 
Tabela 6.2: Descrição do estabelecimento da seção de trabalho

\begin{tabular}{|l}
\hline Estabelecer seção de trabalho \\
\begin{tabular}{|l|l|}
\hline Descrição & O cliente remoto é responsável por estabelecer a seção de \\
trabalho e solicitar vídeos. O cliente somente poderá requisitar um \\
vídeo após ter aberto sua seção com o servidor, onde informações \\
do cliente serão registradas, como o endereço e a porta de \\
comunicação.
\end{tabular} \\
\hline
\end{tabular}

A próxima seção corresponde a análise dinâmica, a qual como dito no início do capítulo, especificará a interação de troca de mensagens entre os objetos do modelo, baseando-se no estudo dos cenários de caso de uso acima. Para isso será utilizado os diagramas de seqüência e de transição de estados.

\subsection{Diagrama de seqüência}

\subsubsection{Cenário de configuração do servidor}

O administrador é a figura responsável pela operação do servidor de vídeo snapshot. Durante a inicialização, como mostrado na Figura 6.4, o servidor obterá as informações de configuração.

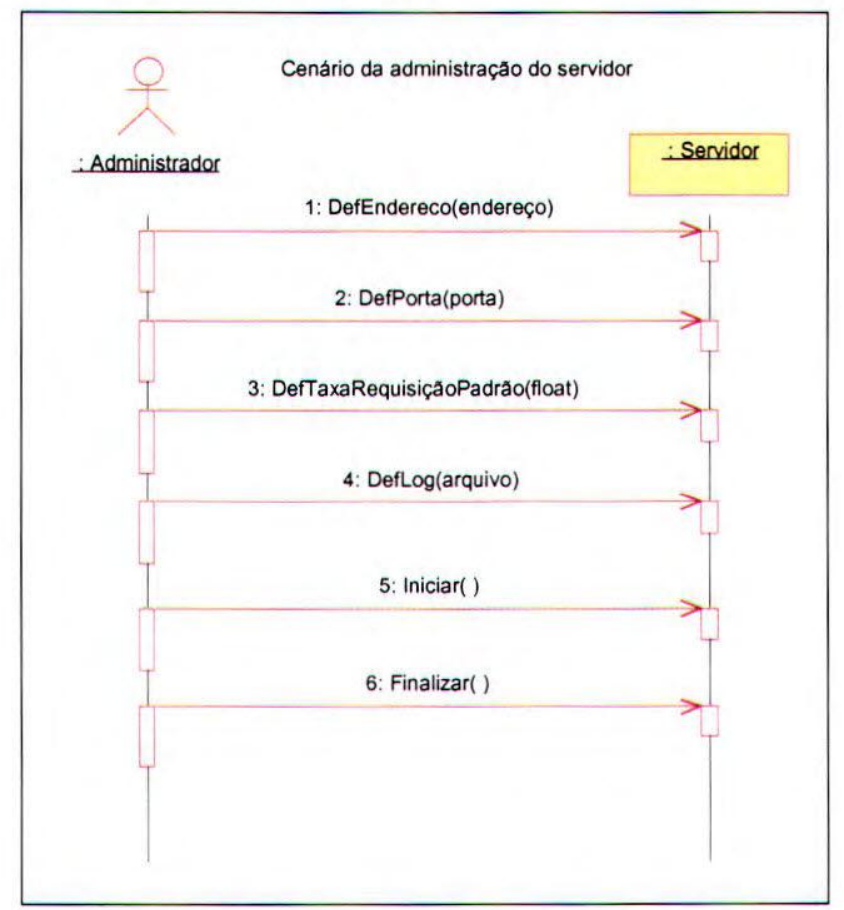

Figura 6.4: Cenário de configuração do servidor 
Estas informações poderão ser obtidas através de um arquivo gerenciado pelo administrador. Entre estas informações destaca-se a taxa de requisição padrão $\lambda$ (DefTaxaRequisiçãoPadrão()) que corresponde ao número de requisições por unidade de tempo. Esta taxa, como já mencionada, é utilizada pelo programa para o cálculo da janela de mesclagem ótima, utilizando a fórmula abaixo:

$$
W_{s m}^{*}=-\frac{S_{\min }}{\lambda}+\sqrt{\left(\frac{S_{\min }}{\lambda}\right)^{2}+2 \frac{p_{M} S_{\min }\left(S_{\max }-S_{\min }\right)}{\lambda S_{\max }}}
$$

Com isso, otimiza-se o número e a posição, relativamente ao tamanho do vídeo, em que mesclagens ocorrem; e, deste modo, diminui-se a demanda de banda passante. Após a entrada da taxa de requisição, o administrador poderá inicializar o servidor (Iniciar (), Figura 6.5), o que na prática significa colocá-lo á espera por conexões.

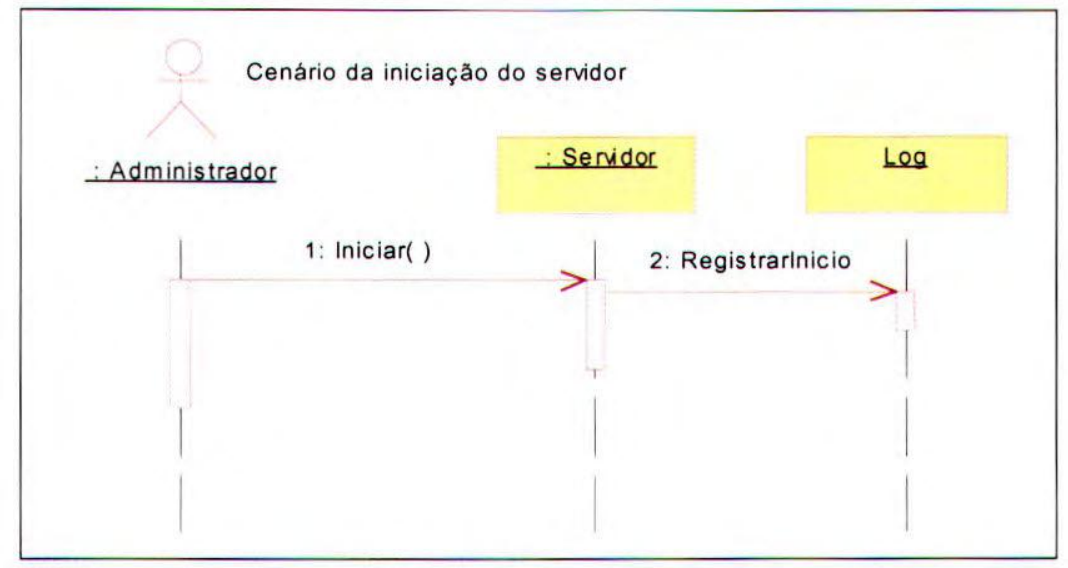

Figura 6.5: Cenário de iniciação do servidor

O processo de finalização do servidor (Finalizar(), Figura 6.6) consiste na destruição de todos os clientes que estiverem pendentes no momento do encerramento.

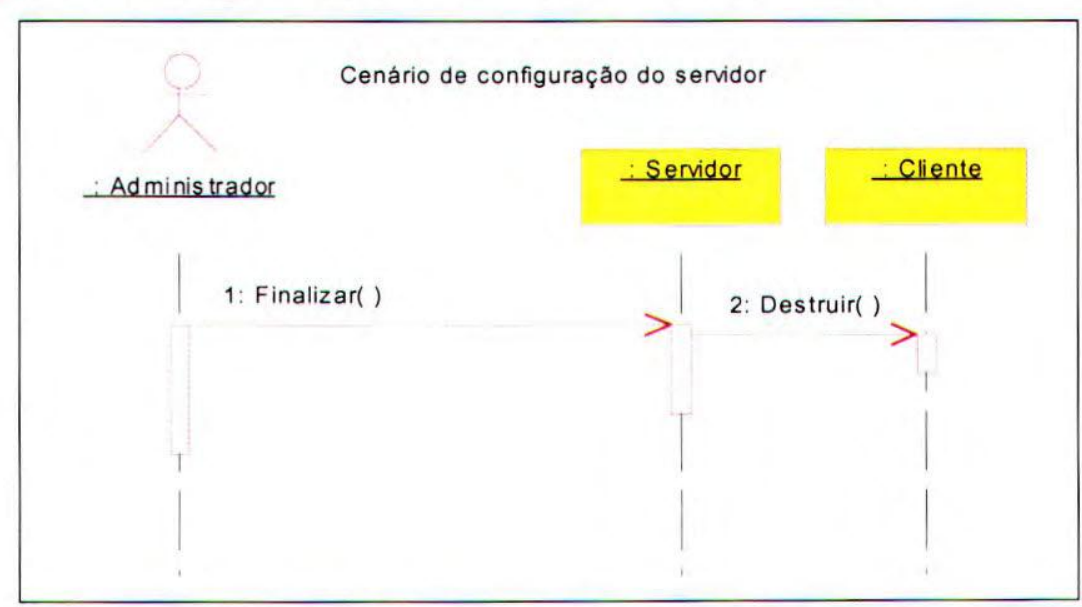

Figura 6.6: Cenário de configuração do servidor 


\subsubsection{Cenário do Estabelecimento de uma seção de trabalho}

O processo de estabelecimento de uma seção, Figura 6.7, é inicializado pelo cliente remoto, sendo composto por dois cenários: abrir e fechar seção. Na abertura de uma seção o cliente remoto invoca o método ConectarClienteRemoto() no servidor, o qual irá invocar o método Criar() na classe Cliente, o que criará uma instância da classe contendo o endereço do cliente.

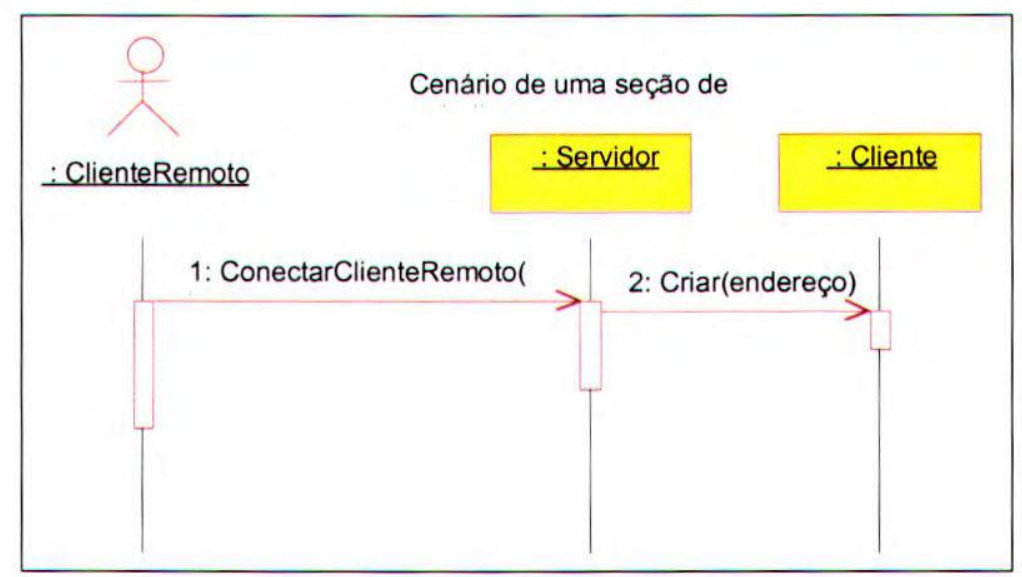

Figura 6.7: Cenário da abertura de uma seção de trabalho

O processo de desconectar o cliente, Figura 6.8, envolve mais comunicação entre as classes. Primeiramente, o cliente remoto invoca o método DesconectarClienteRemoto (), o qual gerará uma seqüência de chamadas de métodos que resultará no cancelamento de todas as referências alocadas para o cliente remoto, finalizando com a referência da stream no Controle de Mesclagem.

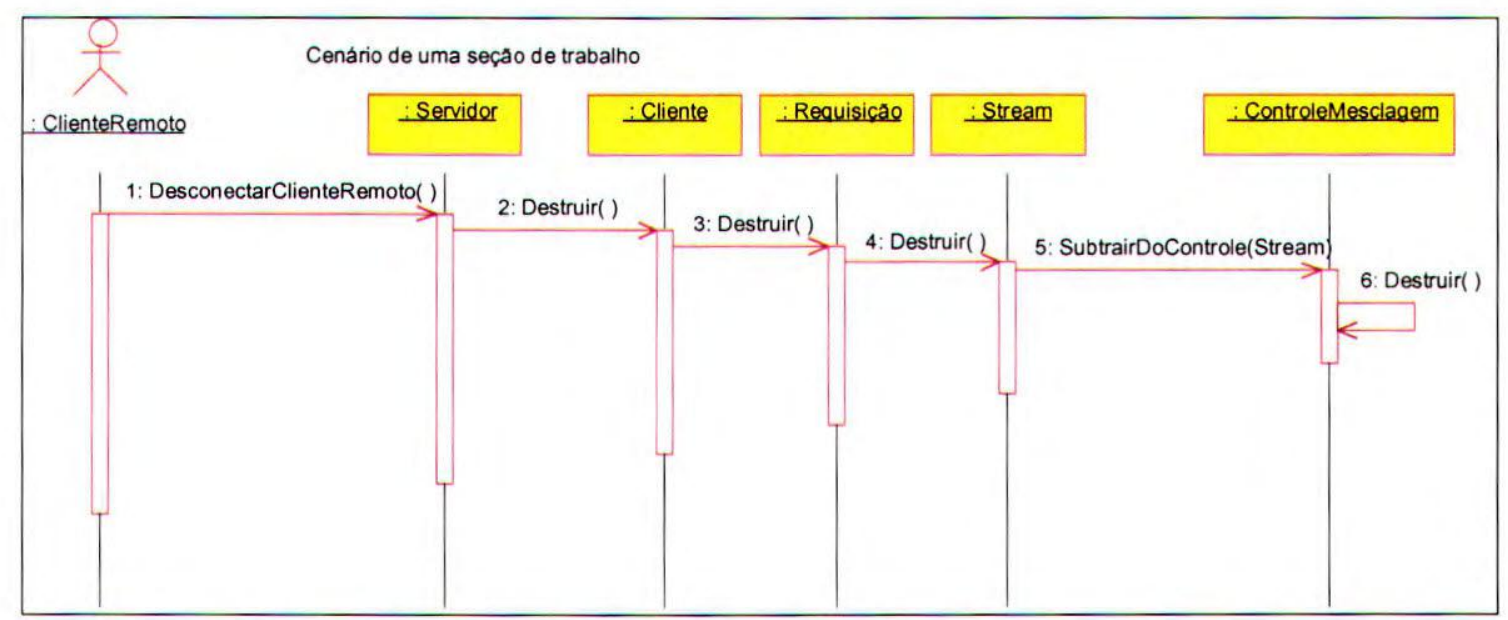

Figura 6.8: Cenário do encerramento de uma seção de trabalho 


\subsubsection{Cenário típico de envio por SNAPSHOT}

O cliente é responsável por solicitar o vídeo (Solicitar (nome), Figura 6.9). O servidor por sua vez, invocará o método criar(nome), gerando uma instância da classe Video. O servidor também criará uma instância da classe Requisição através da chamada Criar (Cliente, Video). De acordo com a técnica do Snapshot, a primeira stream da janela sempre será configurada com a velocidade mínima e as streams restantes terão velocidade máxima. Logo baseado neste fato, a classe Requisição invocará o método ExisteJanelaAberta (Video). Isto é necessário para saber se já existe alguma stream dentro intervalo snapshot. Se não existe, então cria-se a PrimeiraStream, que é uma subclasse da classe Stream, sendo tratada de um modo especial em relação às outras streams, por ser a primeira stream do intervalo. Em seguida, é criada uma instância do controle de mesclagem, de modo a controlar as streams do intervalo (Criar(PrimeirastreamdaJanela)). A seguir, o Controle de Mesclagem lê a taxa de Requisição para o determinado vídeo (LerTaxaRequisicao (Video)), logo calcula-se o tamanho da janela de mesclagem ótima, e em seguida, é definido o quadro que determina o fim da janela de mesclagem (DefFimJanela(Quadro)). Esta informação é muito importante pois a primeira stream ficará responsável por sinalizar para o controle de mesclagem o fim do intervalo snapshot quando exibir este quadro. Depois configura-se a velocidade mínima para a primeira stream. Por fim, inicia-se a transmissão da primeira stream.

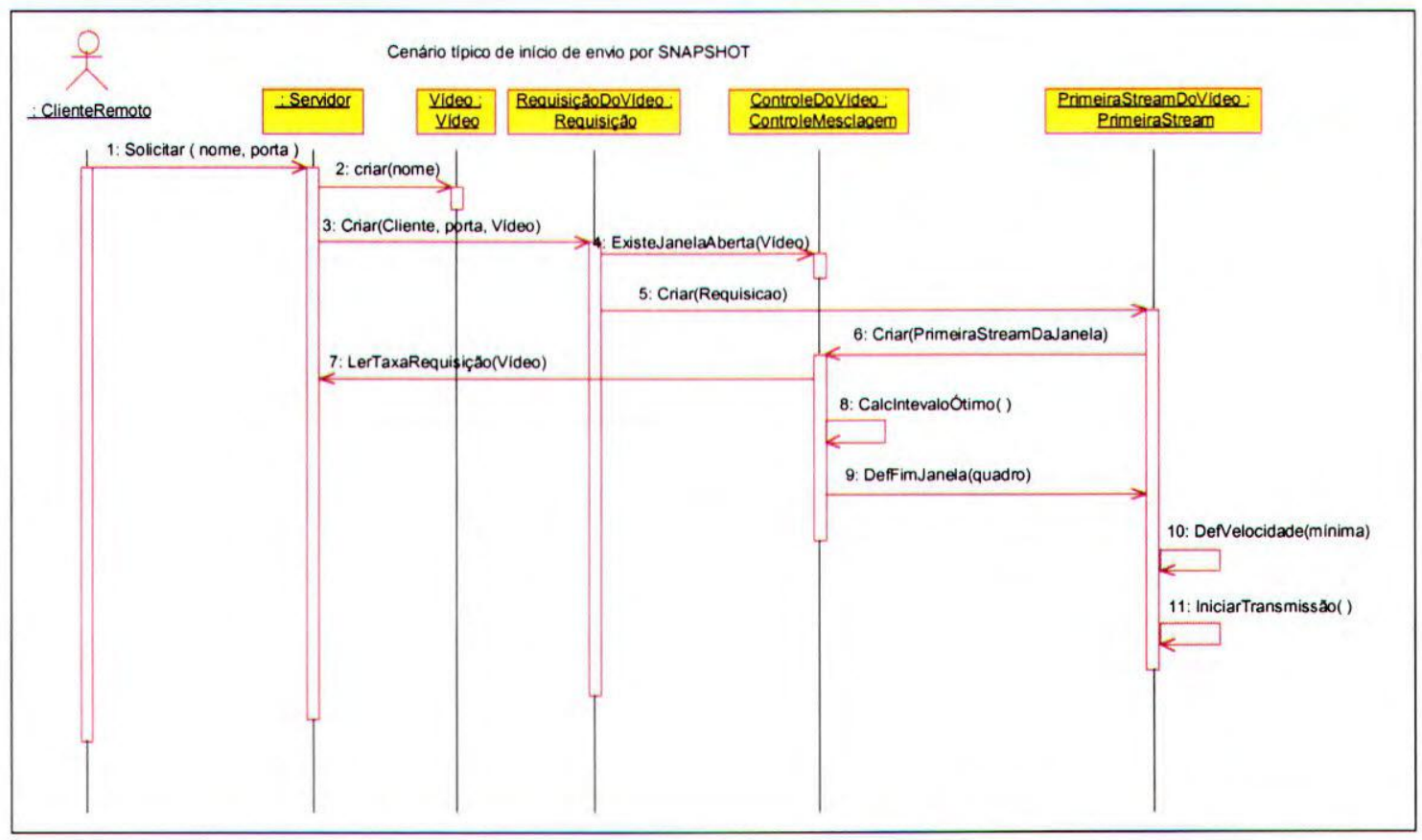

Figura 6.9: Cenário do envio da primeira stream do intervalo snapshot

Se já existir outra stream dentro do intervalo, então uma stream "comum" deverá ser gerada. Logo é definida a velocidade máxima (DefVelocidade (máxima)) e em seguida é adicionada ao controle (AdicionarAoControle (Stream)). O controle calcula o ponto de mesclagem das streams geradas 
com a primeira stream do intervalo (CalcPontoMesclagem(PrimeiraStream, Stream)) e envia para a stream o quadro de mesclagem. Por fim, a stream inicia a transmissão (IniciarTransmissão()), veja Figura 6.10.

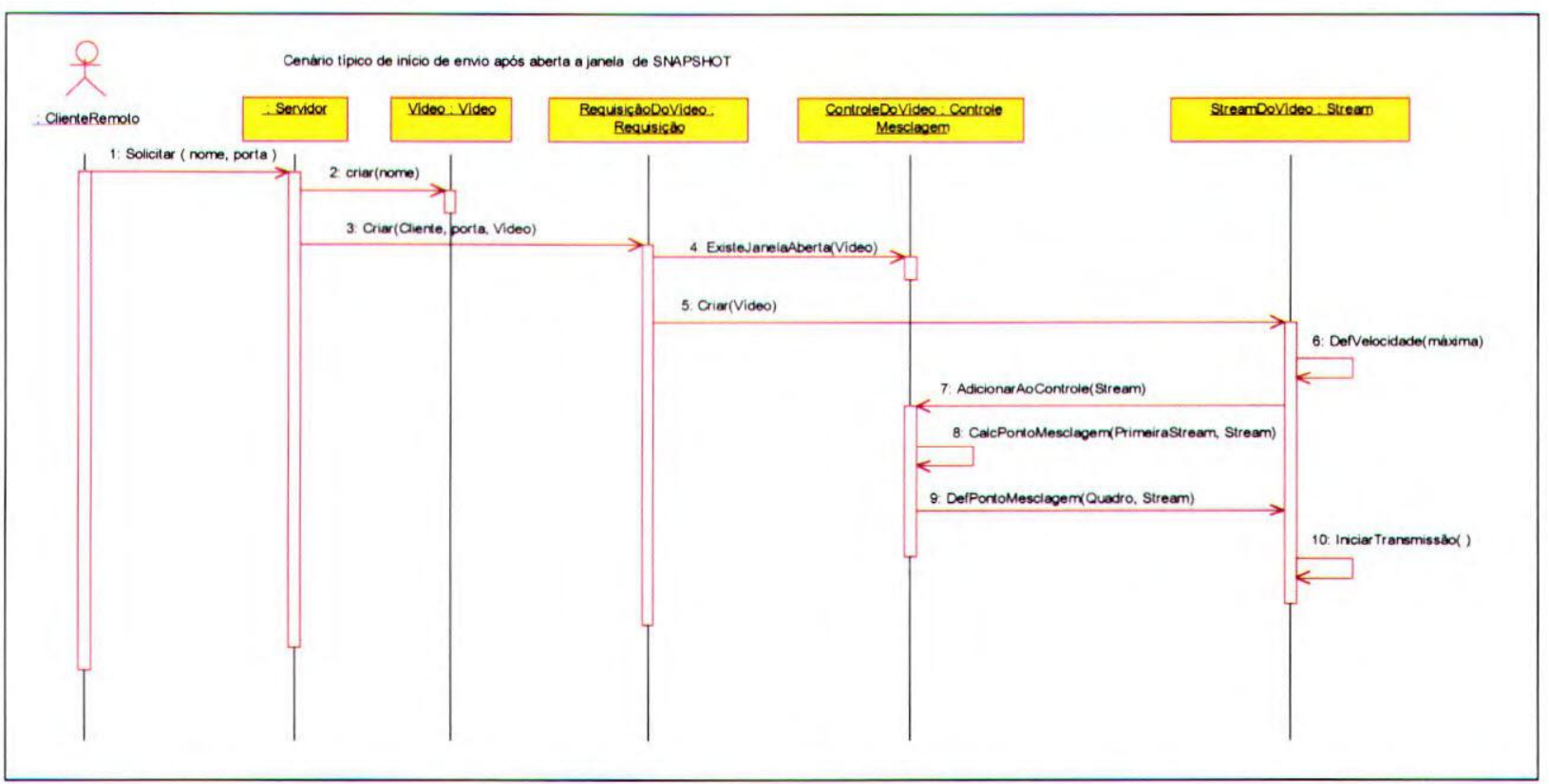

Figura 6.10: Cenário de envio das streams posteriores a primeira stream da janela

De acordo com o capítulo 4, o IP multicast ocorre de maneira diferente. Neste ambiente, o transmissor não necessita ter conhecimento dos receptores, a stream somente precisaria conhecer o endereço multicast. Para aplicá-lo na implementação do snapshot, poder-se-ia optar pela seguinte solução: Toda stream teria no momento da inicialização da transmissão um endereço e porta multicast associado, sendo este endereço determinado pelo objeto de controle de mesclagem. Tanto a stream quanto o cliente terão agora dois endereços para a manipulação: um endereço unicast e um endereço multicast. $\mathrm{O}$ endereço unicast é por onde trafegará os dados de controle para/do cliente, por exemplo, para qual endereço multicast DefEndMulticast (endereco, porta) este cliente deve se conectar para receber os dados da mídia, saída do cliente da sessão. E o endereço multicast, por onde trafegarão os dados da mídia. Este cenário é ilustrado na Figura 6.11: 


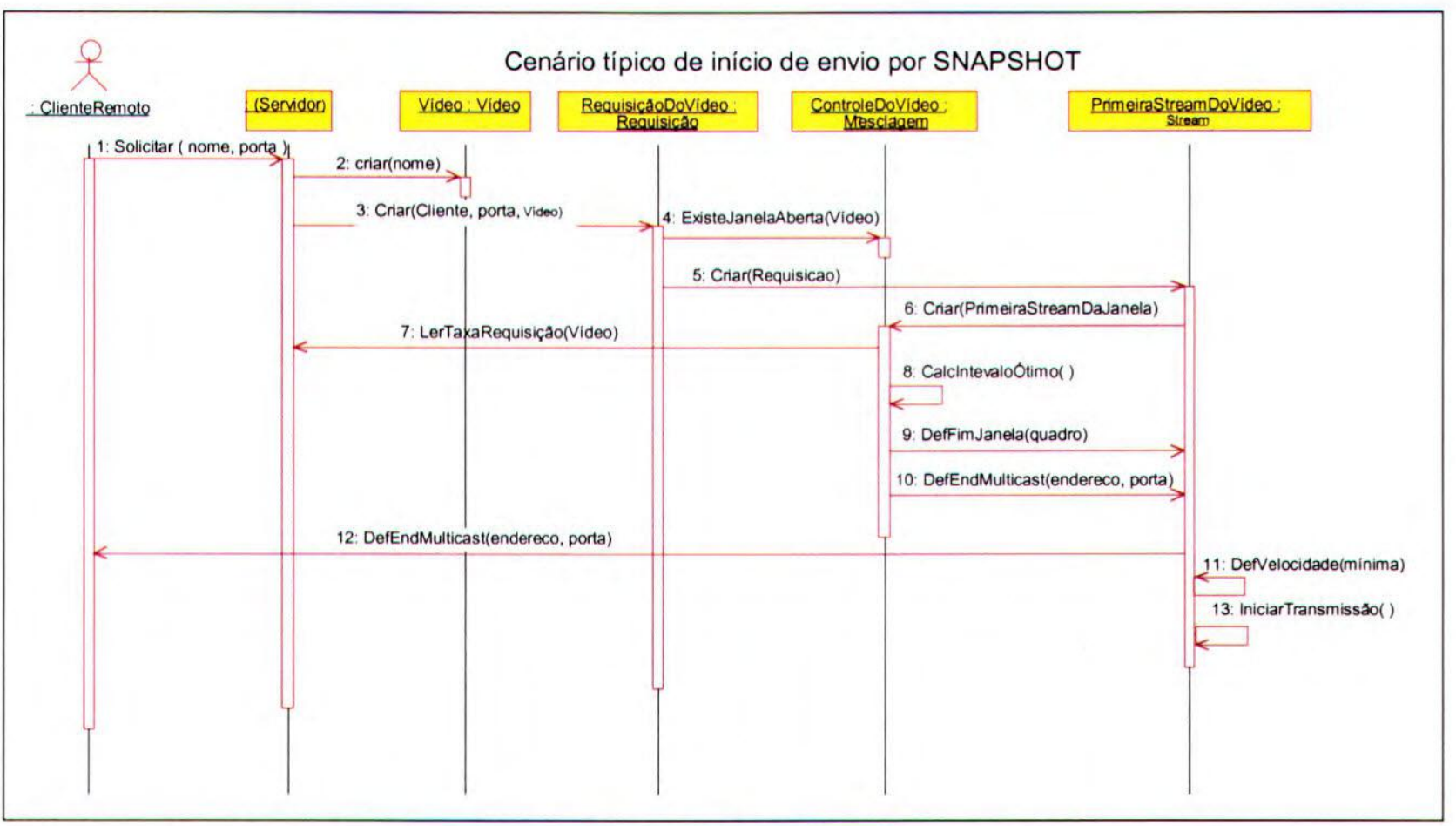

Figura 6.11: Cenário Típico de envio por Snapshot utilizando o IP multicast

O cenário para as outras requisições que ocorrerem após aberta a janela de mesclagem, Figura 6.12, é análogo ao cenário do IP multicast para a primeira requisição da janela de mesclagem.

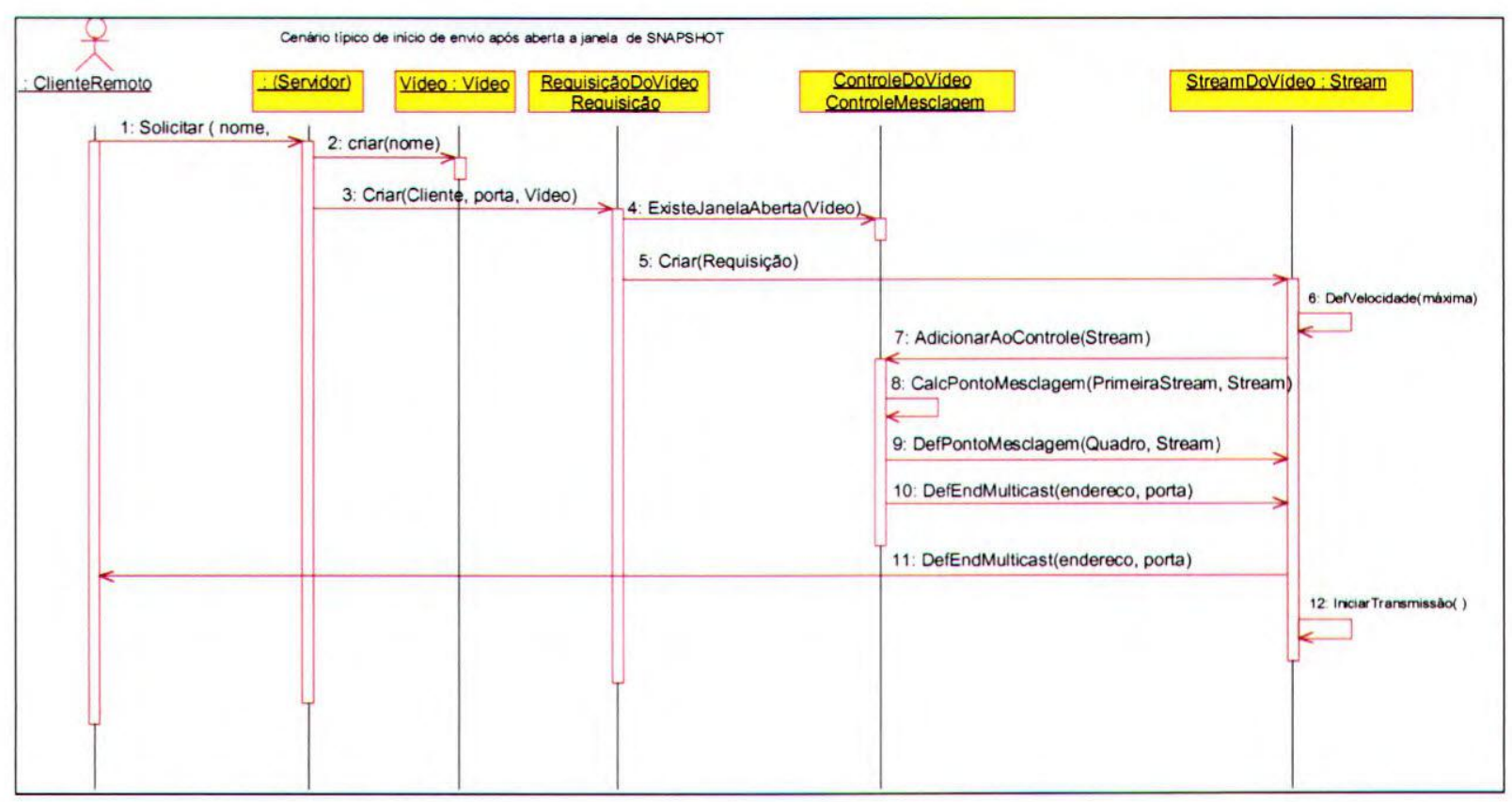

Figura 6.12: Cenário típico de envio após aberta a janela de Snapshot 


\subsubsection{Cenário do Encerramento da janela de mesclagem}

A primeira stream ao transmitir o quadro que marca o fechamento da janela, envia uma chamada (FecharJanela ( ) para o controle de mesclagem indicando o final do intervalo de mesclagem, como ilustrada na Figura 6.13.

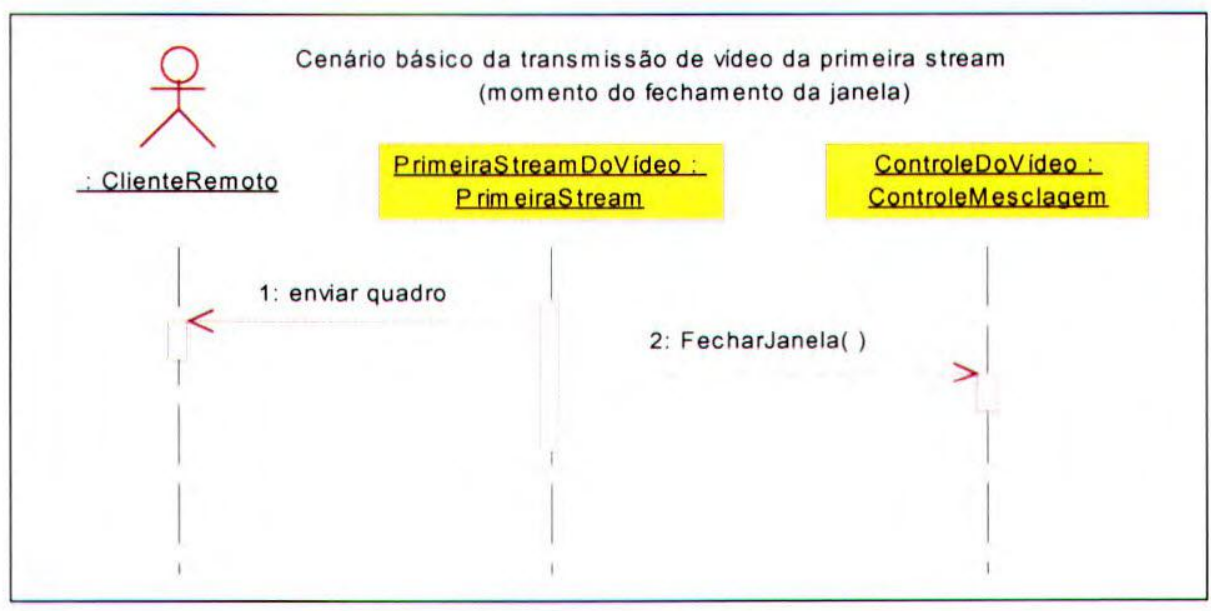

Figura 6.13: Cenário da finalização do intervalo Snapshot

\subsubsection{Cenário da mesclagem de streams}

Como dito no início do capítulo, a mesclagem é um elemento teórico que na prática ocorre via multicasting, ou seja, vários clientes recebendo a mesma transmissão de dados (pacotes). Na rede ATM, o multicasting ocorre no lado do servidor que envia um pacote para vários clientes, sendo o multicast transparente para o cliente. Para isso, o servidor poderá utilizar os canais multicast ATM.

Considerando que as streams possuem já previamente definida o seu quadro de mesclagem e a stream com a qual irá mesclar-se, o seguinte cenário retrata o procedimento de mesclagem. A stream envia uma mensagem para a outra stream com a qual esta irá mesclar-se, contendo o endereço do cliente, para que a stream possa também começar a transmitir para este cliente via multicast. A seguir, a stream a ser destruída envia uma mensagem para o controle de mesclagem para que este apague as referências da stream (SubtrairDoControle(Stream)). Depois a stream autodestrói ${ }^{21}$, veja Figura 6.14 .

\footnotetext{
${ }^{21}$ A autodestruição de objetos indica que a alocação de memória do objeto deve ser liberada e suas referências (associações) devem ser anuladas. Algumas linguagens não suportam a destruição dentro de métodos do próprio objeto. A forma que foi apresentado no modelo é apenas uma indicação que o objeto deve ser destruído.
} 


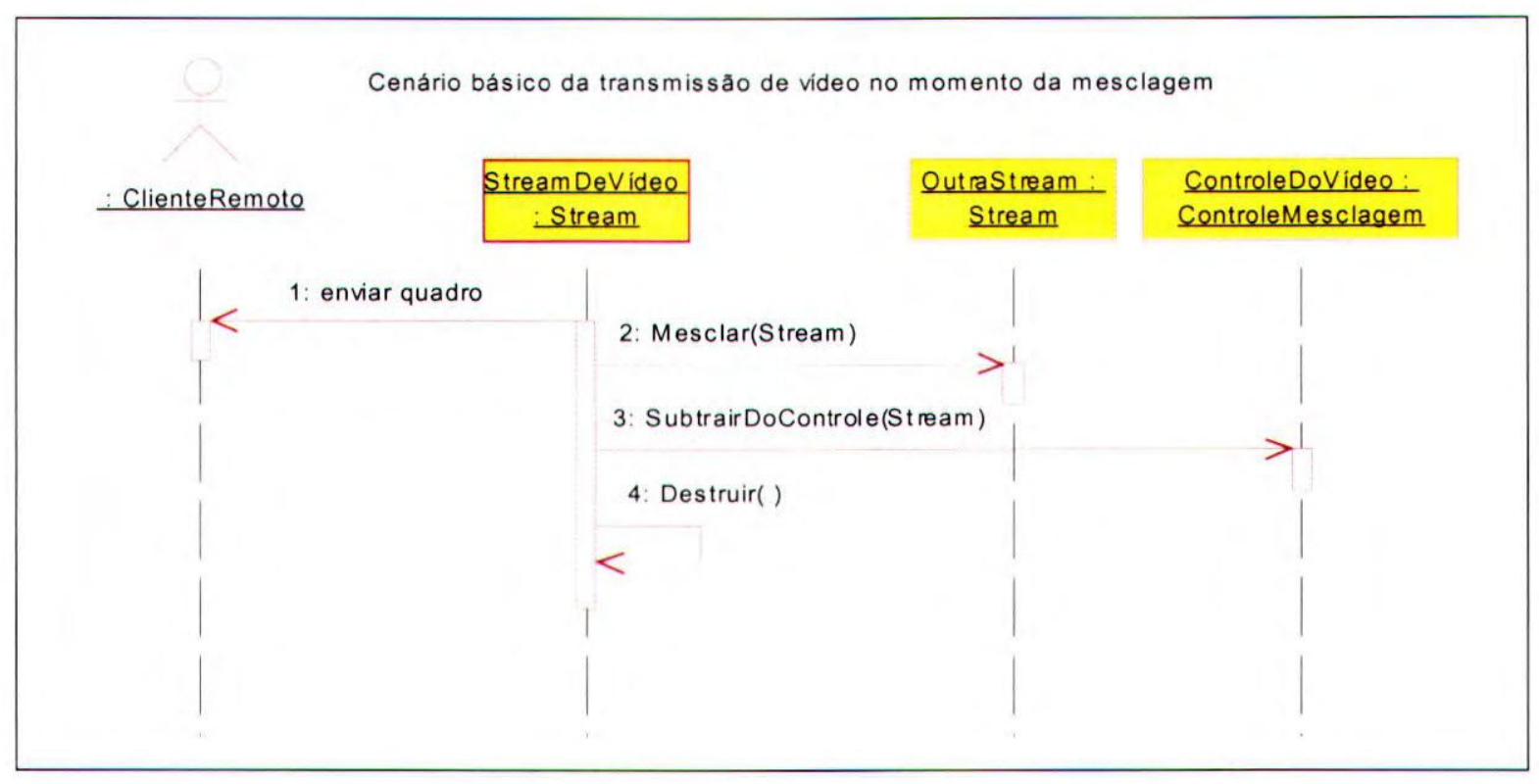

Figura 6.14: Cenário típico da mesclagem

No momento da mesclagem, a stream envia o último quadro para o cliente e então inicia o processo de mesclagem com a outra stream. Na mesclagem, a referência de uma stream é passada para a outra, ou seja, a requisição deve ser retirada da stream que será mesclada e deve ser associada a stream que continuará a transmissão. Pela requisição é que se obtém o endereço a ser enviada a transmissão (veja a associação entre stream e requisição). Quando uma stream responde a mais de uma requisição, ocorre o multicasting.

O respectivo cenário do IP multicast é similar ao cenário do ATM, embora possua algumas diferenças. Como no IP multicast, o transmissor não necessita ter conhecimento dos receptores, a stream somente precisaria transmitir para o endereço multicast, no qual os clientes interessados terão que se associar (através do membership report, tratado no capítulo 4). Logo, a stream a ser desalocada não precisa passar a sua referência como parâmetro Mesclar(Stream) para a stream que prosseguirá a transmissão. A stream a ser destruída somente precisará informar ao cliente o novo endereço multicast DefEndMulticast (endereco, porta), da stream que prosseguirá com a transmissão. O cliente, por sua vez, torna-se um membro deste grupo (endereço). O restante das operações é similar ao cenário ATM. Este cenário é ilustrado na Figura 6.15. 


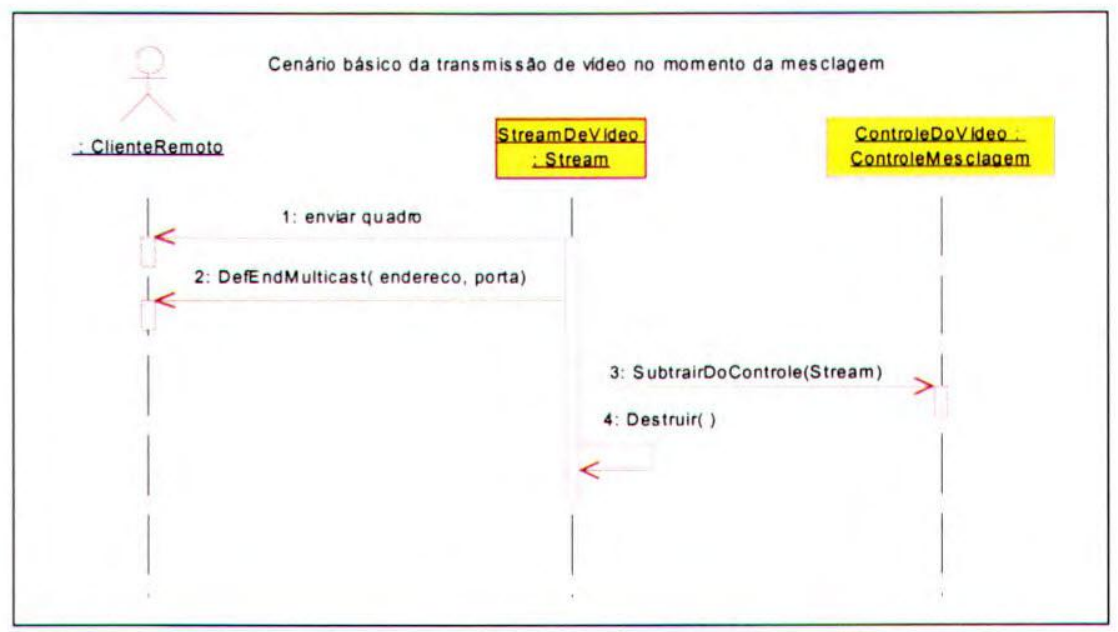

Figura 6.15: Cenário básico da transmissão de vídeo no momento da mesclagem

\subsubsection{Cenário típico da definição de velocidade ótima de transmissão}

Quando a primeira stream da janela fizer a chamada FecharJanela(), indicando que o intervalo de mesclagem terminou, o controle de mesclagem irá enviar a mensagem Criar(ControleMesclagem) que irá iniciar a criação da árvore de mesclagem. A árvore de mesclagem irá obter os dados dos streams restantes da janela de mesclagem, isto é, irá coletar a referência de todos os streams. Obtido a referência dos streams, a árvore de mesclagem irá criar os nós Criar(StreamMesclagem), sendo que cada nó representa um stream. Cada nó irá enviar a mensagem LerQuadroAtual () , requisitando o quadro corrente. O fluxo de mensagens da Figura 6.16 , ilustra um pouco mais este cenário.

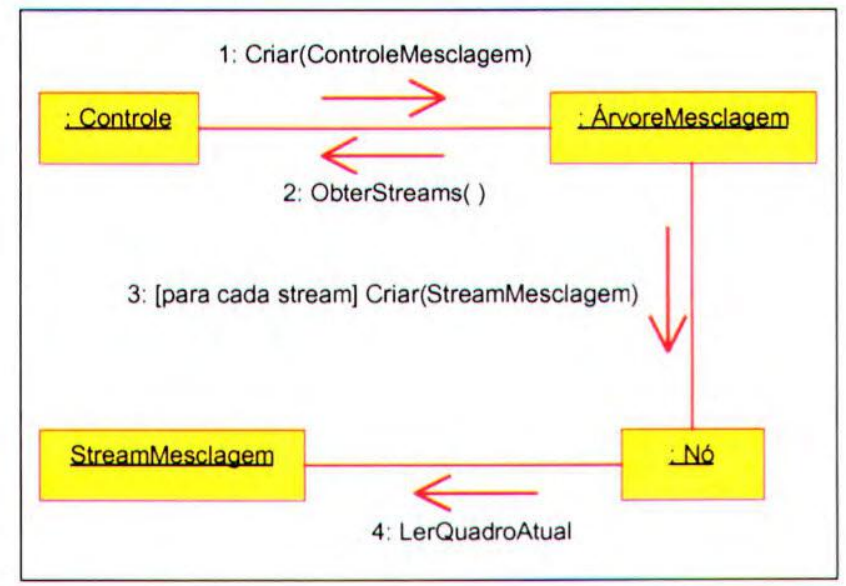

Figura 6.16: Fluxo de mensagens para criação da árvore de mesclagem

O controle de mesclagem inicia então o cálculo do dynammic programming, CalcularVelocidades(), de forma a obter a árvore de mesclagem de menor custo (ou seja, ArvoreVelocidades) através do cálculo da combinação de todas as possíveis streams. Como 
resultado, a árvore de mesclagem terá a posição de mesclagem de todas as streams, bem como suas futuras velocidades. Em seguida, o controle de mesclagem envia a mensagem, AjustarStreams ( $)^{22}$, para a árvore de mesclagem de forma que esta possa enviar as novas alterações para cada nó, AjustarStream(). Cada nó, por sua vez, envia para a sua respectiva stream, a nova taxa de apresentação das stream, a posição de mesclagem, e com qual stream será feita a mesclagem. Este fluxo de mensagens é ilustrado na Figura 6.17:

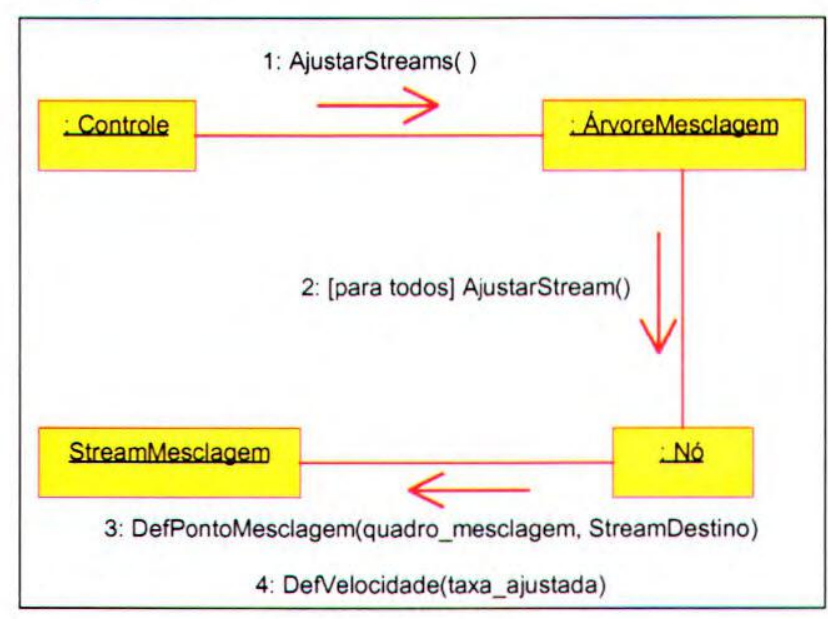

Figura 6.17: Fluxos de mensagens para $o$ ajuste de velocidades

Com isso, algumas streams terão que mudar a sua velocidade, por exemplo, passar da velocidade máxima para a velocidade mínima, bem como a alteração do ponto de mesclagem e a stream com a qual irá mesclar (que durante o intervalo de mesclagem correspondia a primeira stream do intervalo). O processo de alteração consiste em mudar o arquivo-fonte do vídeo para um arquivo-fonte que contenha o layout dos dados voltados para a determinada velocidade que se deseja, e fazer uma busca interna no arquivo para iniciar a transmissão do ponto posterior onde interrompeu a transmissão no arquivo anterior. Por exemplo, se a stream estivesse transmitindo o quadro 999 de um arquivo-fonte com velocidade máxima, quando recebeu a mensagem para mudar para a velocidade mínima, a stream teria que fazer a mudança do arquivo-fonte e iniciar a transmissão a partir do quadro 1000. Se o arquivo-fonte for gerado através da técnica de interpolação, onde se altera o número total de quadros, então será ainda necessária uma função de conversão do número do quadro.

${ }^{22}$ A iniciação para fazer o ajuste, parte do Controle de mesclagem, de forma a deixar as ações do algoritmo mais separadas o possível. Por exemplo, pode-se querer somente realizar testes (por exemplo de performance e/ou corretivo) no algoritmo de programação dinâmica, sem necessitar ajustar realmente as streams. 


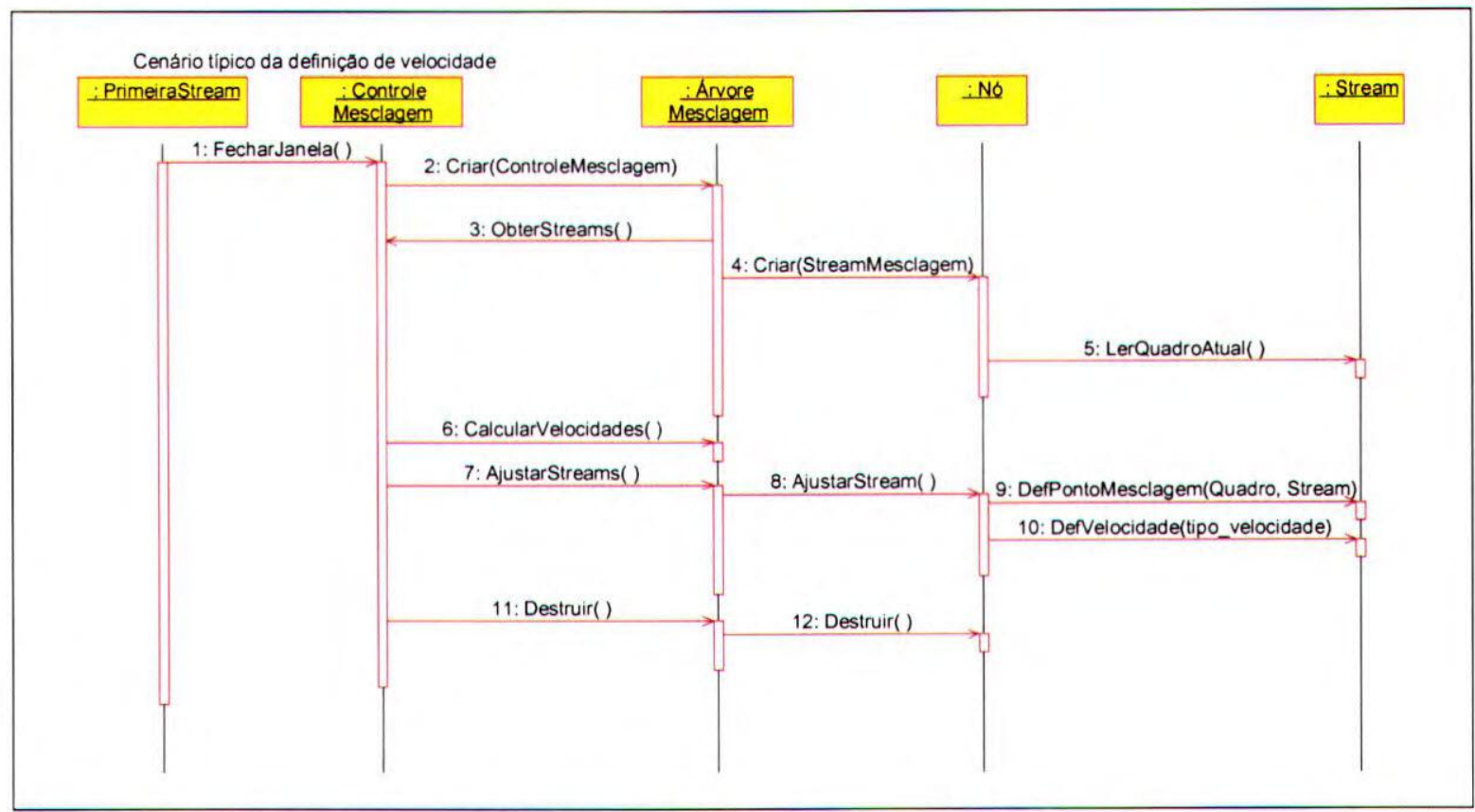

Figura 6.18: Cenário da definição da velocidade ótima (algoritmo de programação dinâmica)

Por último, como ilustrado na Figura 6.18, não sendo mais necessária manter a estrutura da árvore de Mesclagem e os nós na memória, o controle de mesclagem envia a mensagem Destruir() para a Árvore, que por sua vez, elimina os nós que compõe a árvore.

Como dito, sendo esta é uma aplicação de tempo-real, para que se possa obter todos os benefícios da técnica do piggybacking, todo o processo envolvendo o cálculo do dynamic programming e a alteração da velocidade das streams em progresso, não deverá levar mais tempo do que o período de tempo gasto para o envio de um quadro.

\subsubsection{Cenário do encerramento da transmissão}

O cenário, apresentado na Figura 6.19, representa o encerramento da transmissão da primeira stream do intervalo, isto corresponde ao final da transmissão para todas as requisições presentes no intervalo snapshot.

Neste cenário, após a primeira stream enviar o último quadro do vídeo, esta envia uma mensagem para o controle de mesclagem para este apagar as referências (SubtrairDoControle(Stream)). Recebendo esta mensagem, o controle apaga a sua última referência. Logo não sendo mais necessário, acaba por liberar a memória ocupada por si própria ("dispose (ControleMesclagem) ", ou seja, autodestrói). Após enviar a mensagem para o controle de mesclagem, a primeira stream também libera o espaço de memória ocupada por si própria, finalizando assim todo o processo iniciado durante esse ciclo (ou seja, "intervalo snapshot"). 


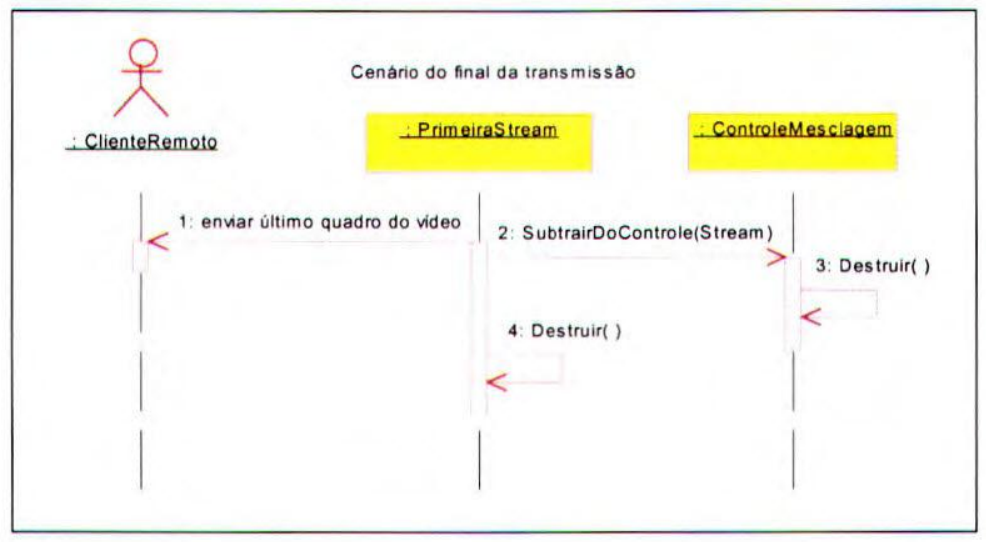

Figura 6.19: Cenário da finalização transmissão da primeira stream do intervalo.

\subsection{Diagrama de Estados}

O diagrama de estados, ilustrado na Figura 6.20, tem por objetivo definir os principais estados do algoritmo bem como os eventos principais que ocasionam transições entre estes estados.

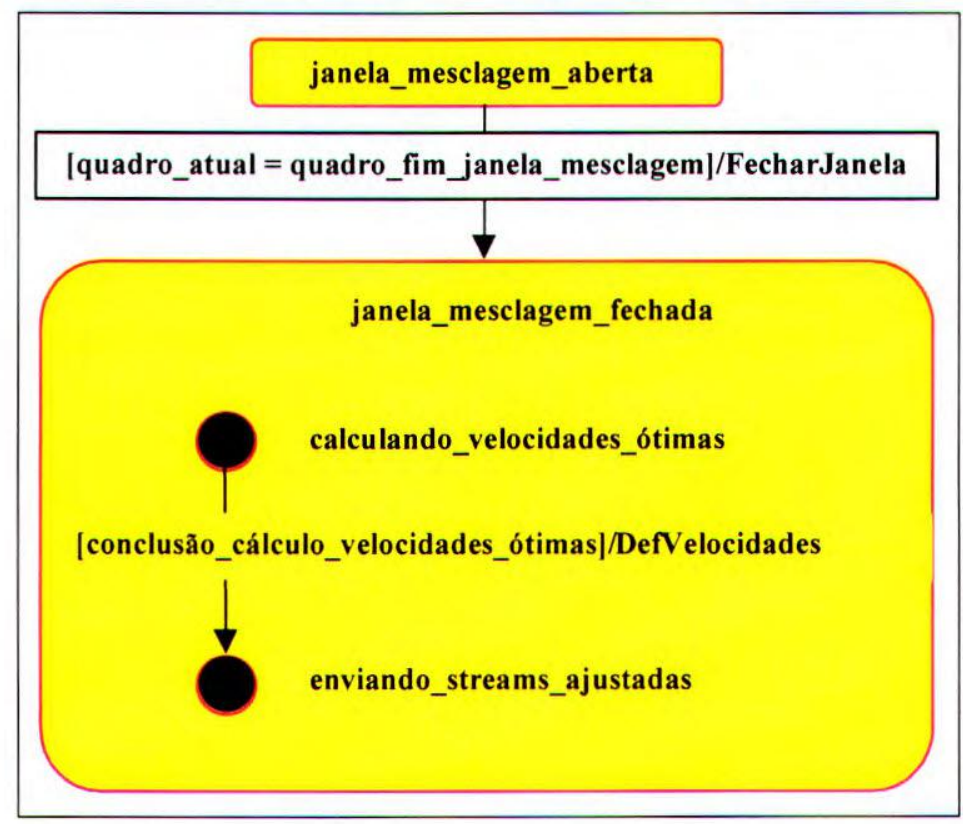

Figura 6.20: Estados do controle de mesclagens

Após a primeira requisição do intervalo ser feita, é aberta a janela de mesclagem. O objeto de controle de mesclagem irá calcular para a primeira o quadro que corresponde ao término da janela de mesclagem. Quando a primeira stream, exibir este quadro, é enviada uma mensagem ao controle de mesclagem para fechar a janela de mesclagem e logo iniciar o algoritmo de programação dinâmica. Após o término do algoritmo, tendo como resultado a árvore de mesclagem ótima, os resultados são enviados para as streams que necessitam alterar as suas informações. 
A análise estática, ou estrutural, especificará as relações estruturais entre objetos. A modelagem da análise estrutural utilizará o diagrama de classes e o diagrama de componentes para especificar os processos paralelos.

\subsection{Diagrama de Classe do servidor de Video-on-Demand}

Este diagrama dá uma visão geral das classes, métodos e parâmetros do algoritmo Snapshot, apresentando como se dá à interatividade entre o cliente (usuário) e o servidor de vídeo Snapshot. A seguir, são explicadas as relações apresentadas na Figura 6.21:

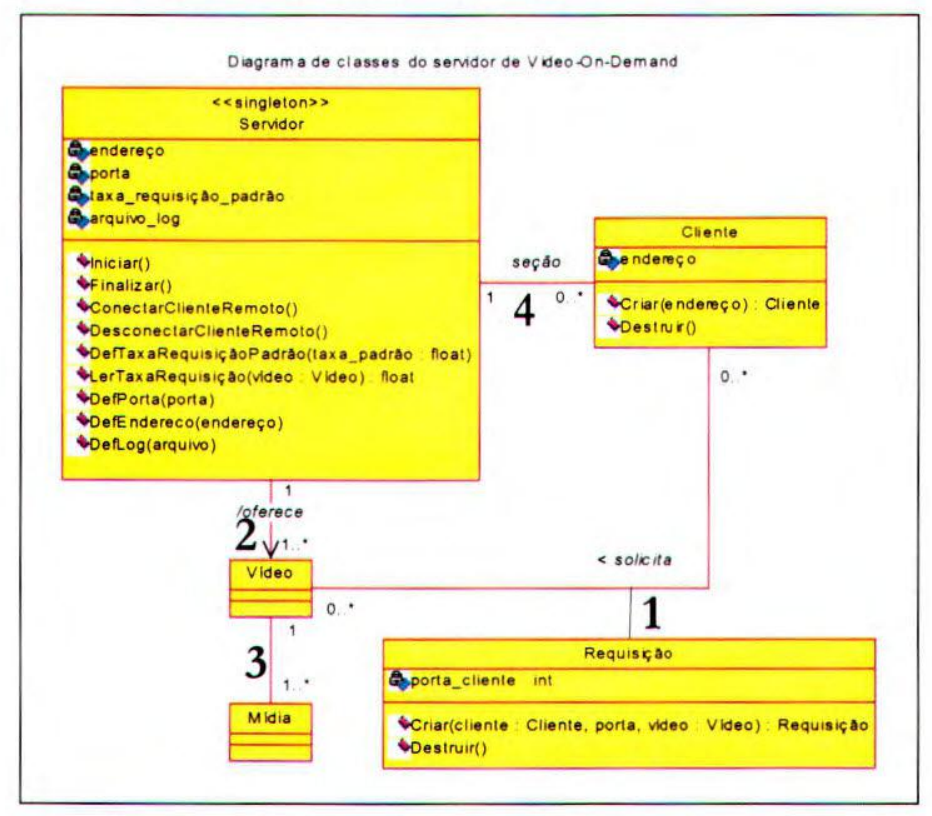

Figura 6.21: Diagrama de Classe Geral do sistema

1 Requisição: Esta classe existe em função da solicitação por um vídeo feita pelo cliente.

2 Servidor e Vídeo: O servidor tem como função principal oferecer um ou vários vídeos.

3 Video e Mídia: O Vídeo corresponde ao filme e é composto pela Mídia que corresponde ao arquivo que contém a mídia, sendo cada arquivo voltado para uma determinada velocidade.

4 Servidor e Cliente: Em uma seção o servidor de vídeo snapshot poderá servir zero ou mais clientes, ou seja, o servidor ficará executando um daemon em uma determinada porta à espera de clientes. Os clientes, que compartilharão os dados da mídia, serão servidos por apenas um servidor. 


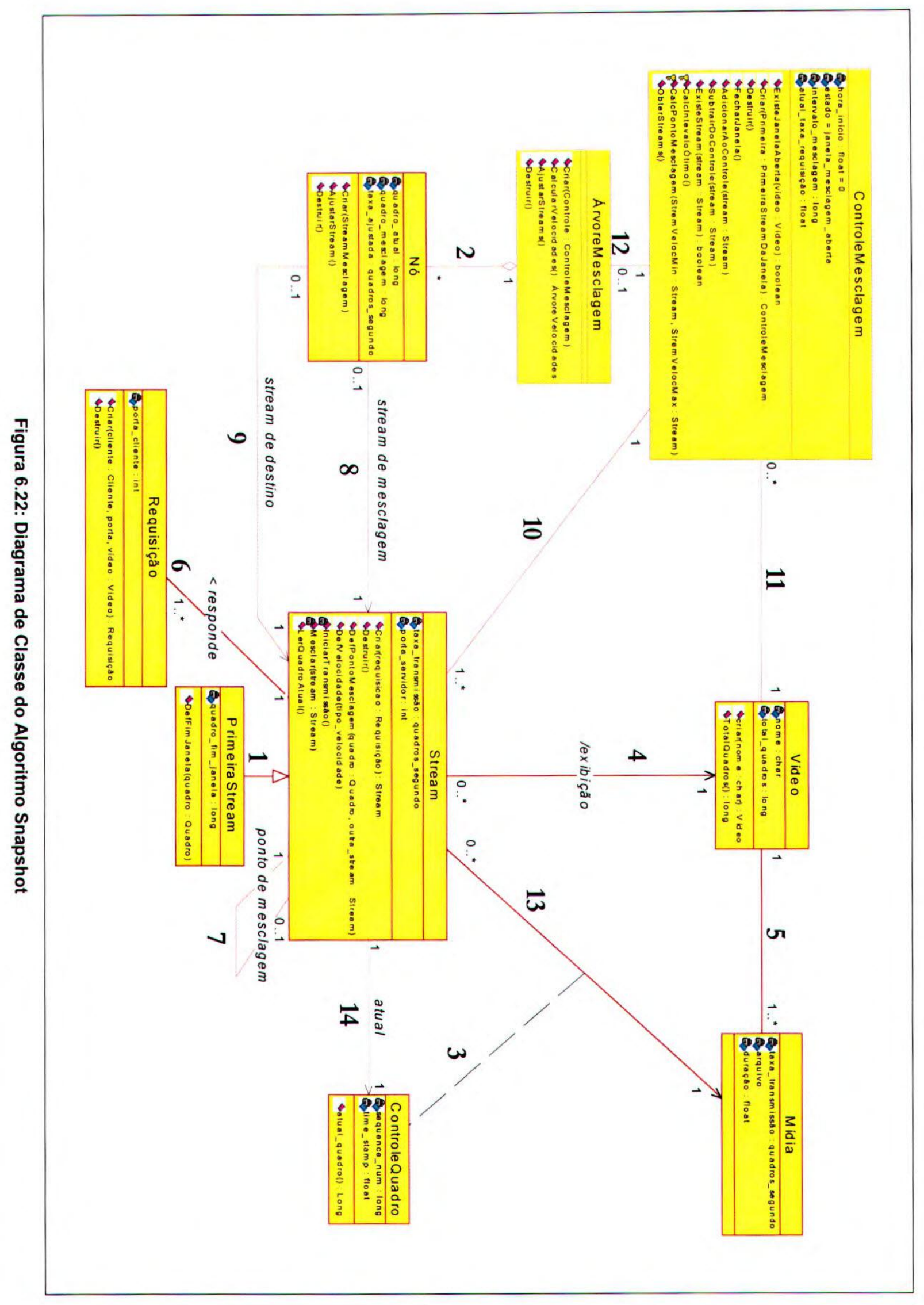

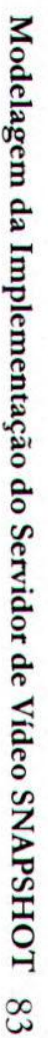


O diagrama de classe, apresentado na Figura 6.22, é composto por todas as classes que compõe o servidor de snapsbot contendo a definição de seus métodos e parâmetros, os tipos de relacionamento como herança e agregação, direções de navegabilidade e a cardinalidade entre as classes. A comunicação entre as classes é feita através das chamacias de métodos, as quais foram apresentadas nos diversos cenários tratados acima. A seguir, são explicadas as conexões entre as classes:

1 - Herança: De acordo com as regras do snapshot a primeira stream do intervalo é tratada de modo à parte, representando uma exceção as outras streams pertencentes ao mesmo intervalo. Por exemplo, o momento do fechamento da janela de mesclagem e início do algoritmo de programação dinâmica, é definido por esta stream. Logo, além das características tradicionais de todas as streams do intervalo, a primeira stream ainda desempenha um papel adicional. Conseqüentemente, a classe PrimeiraStream herda todos os atributos e métodos da classe Stream, além de possuir atributos e métodos próprios.

2 - Agregaçāo: O algoritmo de programação dinâmica tem com resultado uma árvore binária de mesclagem de menor custo, ou seja, uma combinação de mesclagens (nós internos), onde o número total de quadros a ser transmitidos é o menor possível. Logo esta árvore é formada por nós, sendo que os nós-folhas representam os streams que sendo transmitidos. A árvore de mesclagem, representada pela classe ArvoreMesclagem, é formada por nós (agregação), sendo cada nó representado pela classe No.

3 - Associação de dependência: A classe ControleQuadro tem por objetivo manter a informação sobre o quadro corrente sendo transmitido pela stream. Esta informação, como se pode confirmar pelos cenários, é de extrema importância para o sucesso das mesclagens, pois é através desta informaçào que a stream saberá em que momento deverá mesclar. Logo, esta classe está vinculada a relação entre a Stream e a Mídia.

4 - Direção de Navegabilidade: A seta representa a direção de navegabilidade. Por exemplo, neste caso, da classe Stream se obtém classe Video, mas da classe Video não se obtém Stream. Um stream exibe (/exibição) um video, logo é uma relação unidirecional.

5 - Vídeo-Mídia: Pelo algoritmo, para cada filme o servidor deverá manter três cópias do mesmo, embora cada cópia possui o layout dos dados direcionado para uma determinada velocidade, a saber: lenta, normal e rápida. A classe Video corresponde ao filme e a classe Midia ao arquivo que contém a mídia, logo é a classe Midia que mantém informações como duração, velocidade, nome do arquivo que contém a mídia. A classe Video conterá os atributos como o nome e o númeto total de quadros.

6 - Stream-Requisição: A classe Stream é responsável por transmitir a mídia requisitada pela classe Requisição, de acordo com o cenário típico de início de envio por Snapshot. Isto ocorre via a 
chamada do método Criar(Requisição), feita pelo objeto da classe Requisição. Nesta chamada o objeto Requisição, que contém o objeto Cliente (contém o endereço do cliente), o objeto Video e o atributo porta (do cliente), por são transmitidas as informações de controle, é passado para a classe Stream. Tendo todas essas informações, a classe Stream é capaz responder a requisição para o cliente.

7 - Ponto de Mesclagem: De acordo com o snapshot, toda stream poderá ter zero ou um ponto de mesclagem em um determinado instante do progresso do mesmo. A primeira stream da janela, por ser uma exceção as outras streams, é a única a chegar ao final do vídeo, atendo a todos os clientes pertencentes a janela de mesclagem. Por isso, não possui ponto de mesclagem. As outras streams, antes de iniciarem a transmissão do vídeo para o cliente, ficará sabendo em qual quadro ocorretá a mesclagem e com qual stream, veja cenário típico de envio por SNAPSHOT. As stream que não conseguirem mesclar antes do fechamento da janela de mesclagem, poderá ter o ponto de mesclagem alterado pelo algonitmo de programação dinâmica, mas entretanto, só haverá um ponto de mesclagem em um determinado instante.

8 - Stream de destino: No momento da criação da árvore de mesclagem, cada objeto nó a ser criado corresponde a uma stream em progresso, veja cenário típico da definição de velocidade ótima de transmissão. Á esta stream foi dado o nome de Stream de destino. O nó através desta relação, consegue obter a informação sobre o atual quadro da stream. Esta informação é imprescindível para a realização do algonitmo de programação dinâmica.

9 - Stream de mesclagem: Após o cálculo da programação dinâmica, cada nó poderá ter o ponto de mesclagem, a stream com o qual irá mesclar e a velocidade, alterados. Logo, cabe a cada nó por sua vez, enviar esta informação para seus respectivos streams.

10 - Controle de Mesclagem e as Streams: O controle de Mesclagem, como o próprio nome diz, é o responsável pelo controle das mesclagens de todas as streams. O Controle de Mesclagem coordena todo o ciclo de vida das streams, atuando em todos os eventos que ocorrem com as mesmas. Para isso, cada evento sofrido por uma stream é notificado, processado e armazenado no Controle de Mesclagem. Por exemplo, no início da transmissão de cada stream, o controle de mesclagem é responsável além de outras tarefas, por calcular o intervalo ótimo de mesclagem, dada a taxa de requisição do vídeo. Através deste resultado, gera o ponto de mesclagem das streams com a primeira stream do intervalo ou determina o quadro que marca o fim da janela de mesclagem quando se trata da primeira stream do intervalo, isto no momento do início do envio (veja cenátio típico de envio por SNAPSHOT). $\mathrm{Na}$ verdade, o controle de mesclagem é o responsável por coordenar todas as ações requisitadas pelo algoritmo.

11 - Controle de Mesclagem e Video: Como no algoritmo Snapshot, o controle de sincronização dos streams de vídeo é feito somente para os streams que transmitem o mesmo vídeo, o 
objeto de controle de mesclagem fica responsável por somente este vídeo. Embora um vídeo, em um determinado instante poderá estar sendo controlado por zero ou mais objetos de controle de mesclagem.

12 - Controle de Mesclagem e Árvore de Mesclagem: Esta conexão é responsável pela construção e cálculo da árvore de mesclagem. Os procedimentos para tal tarefa, foram tratados no cenário típico da definição de velocidade ótima de transmissão.

13 - Stream e a Mídia: Para atender a uma requisição do cliente a Stream deverá ser capaz de ter acesso ao arquivo que contém a mídia correta. Para isso, como dito anteriormente, a stream recebe a requisição do cliente. A velocidade é definida dependendo se a janela está ou não aberta. A partir disto, a mídia requisitada é enviada para o cliente. Esta relação, como se pode ver, é unidirecional: a stream necessita da mídia, mas não vice-versa.

14 - Stream e o Controle de Quadro: Como dito anteriormente, a informação sobre o atual quadro da stream é fundamental para determinar o momento exato que um evento deverá ocorrer, por exemplo, fim da janela de mesclagem, ponto de mesclagem, etc. A stream obtém tal informação do objeto de controle de quadro, que possui como atributos: o timestamp do quadro e o número da seqüência.

Este diagrama apresenta o escopo de acesso aos métodos e parâmetros da classe, através de símbolos que seguem a nomenclatura. A seguir, uma legenda para estes símbolos:

Tabela 6.3: Escopo de acesso do diagrama de classe do snapshot

\begin{tabular}{|c|c||}
\hline SÍMBOLO & ESCOPO DE ACESSO \\
\hline $\mathbf{6}$ & Private(privado) \\
\hline $\mathbf{6}$ & Public(público) \\
\hline$\nabla^{\bullet}$ & Private(privado) \\
\hline
\end{tabular}




\subsection{Diagrama de Componentes}

O diagrama de componentes, como o próprio nome diz, está relacionado aos componentes que formam o servidor, apresentando os processos que rodam em paralelo.

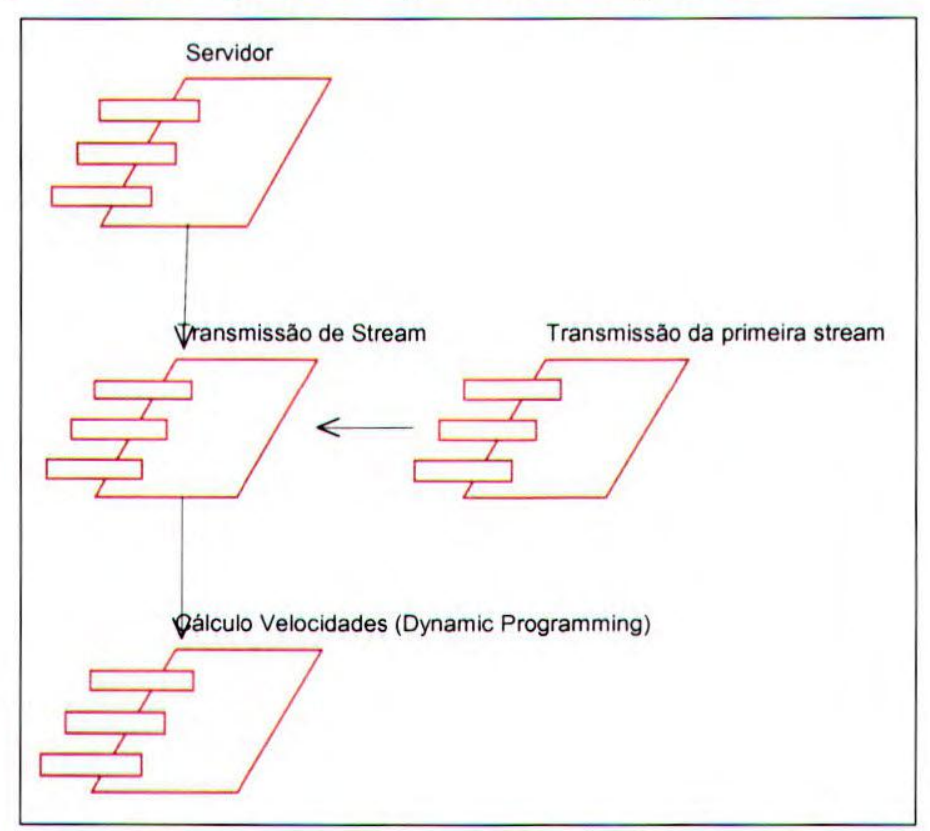

Figura 6.23: Diagrama de Componentes do Snapshot

Pelo diagrama da Figura 6.23, percebe-se que o cálculo do dynamic Programming deve ocorrer paralelamente à transmissão dos streams. Novamente, este cálculo para um melhor aproveitamento, não deverá ser superior ao envio de um quadro.

\subsection{Considerações Finais}

Este capítulo apresentou a modelagem de uma aplicação para a técnica SNAPSHOT com finalidades de testes e avaliações servindo de base para a implementação de um software, abordando questões como a metodologia utilizada para construir a modelagem, a análise de requisitos, funcionalidade do sistema; a análise dinâmica, apresentando os diagramas de seqüência e de estados; a análise estática, ou estrutural, apresentando os diagramas de classes e de componentes. Este trabalho modela a técnica do snapshot satisfazendo as regras impostas pelo algoritmo, sendo fundamental para suavização para codificação, a qual seguindo os passos do modelo, gerará códigos estruturados e de fácil manutenção, além de proporcionar uma visão abrangente do sistema. 


\section{Capítulo 7 - Conclusões}

\subsection{Considerações}

O assunto em questão é atual e de fundamental importância para o contínuo desenvolvimento das pesquisas no grupo de pesquisas do Intermídia sobre a transmissão de vídeo, além de interesses ligados à área de multimídia, hipermídia, redes de alto desempenho, interação usuário/máquina.

Este projeto tem por objetivo propor um modelo de implementação para o algoritmo do Snapshot. Esta técnica foi escolhida, dentre as várias técnicas (cada qual com suas otimizações) baseadas no snapshot, por apresentar todas as características básicas do adaptive piggybacking. Este modelo não impõe restrições de implementação, tais como, linguagem de programação a ser utilizada (embora preferencialmente que esta seja orientada a objetos), tecnologias de suporte (embora tenha sido proposto o estudo de algumas, devido as suas semelhanças com as necessidades do algoritmo), ou sistema operacional. Embora não trate destas questões, este modelo servirá de auxílio para a futura implementação do algoritmo, pois apresenta todas as classes, métodos e parâmetros necessários para a implementação. Para o seu desenvolvimento foi utilizada uma ferramenta de Engenharia de Software integrada, chamada Rational Rose 98 da Rational Software Corp.®, facilitando geração de códigos de modo estruturado. Estes códigos corresponderiam a terceira camada da arquitetura do Snapshot, apresentado na Figura 7.1. A arquitetura geral do sistema é ilustra da abaixo:

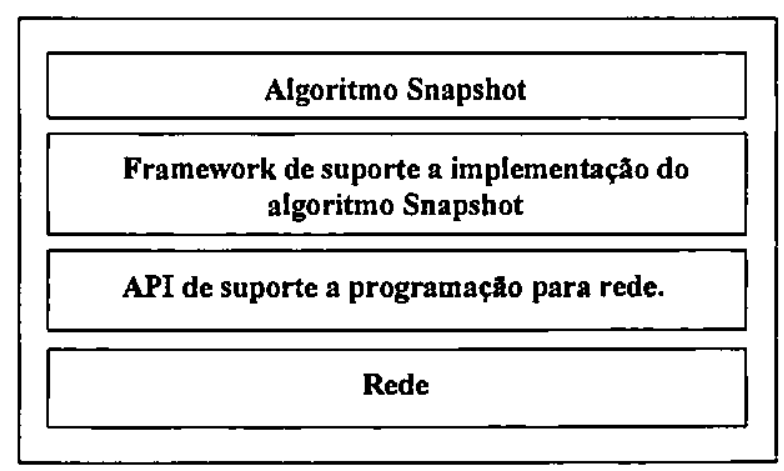

Figura 7.1: Modelo da arquitetura de implementação do Snapshot 
Foram tratados ainda o estudo e parte da implementação da primeira camada da arquitetura, abordando a transmissão dos pacotes multicast em variados tipos de rede. Para finalizar o projeto, seria necessária a construção do framework, correspondente a segunda camada da arquitetura da Figura 7.1, o qual serviria como plataforma de suporte para o modelo proposto.

\subsection{Contribuições do Trabalho}

A principal contribuição deste trabalho de mestrado foi a construção do modelo de implementação (orientado a objeto) do algoritmo Snapsbot. Este modelo tem como vantagem, além do fato de estar próximo ao código, fornecer ao programador uma visão estruturada do algoritmo, através de cenários que retratam a interação entre os objetos, via chamadas de funções com os respectivos parâmetros, que compõe o Snapshot. Como contribuições adicionais associadas ao desenvolvimento do trabalho pode-se citar:

- Estudo de plataformas de suporte a programação multimidia, por exemplo, RealSystem G2, da RealNetworks e o JMF, da SunMicroSystems. Como resultado destes estudos foram gerados softwares que utilizam recursos destas plataformas para a transmissão dos dados via multicast. Estes softwares realizam a captura, transmissão e apresentação de streams de vídeo através do protocolo RTP/RTCP, não tratando por enquanto, da sincronização dos mesmos. Embora a sincronização não tenha sido realizada, os programas e os conhecimentos adquiridos representam um avanço para a implementação do snapshot.

- Foi estudado o multicast, sendo neste trabalho tratado como o mesmo é realizado no ATM e no protocolo IP. Como resultado destes estudos foram gerados softwates referentes a $1^{2}$ camada da arquitetura (Figura 7.1). Entretanto ainda não apresentam a capacidade de alteração das streams em progresso necessária para a realização da mesclagem.

\subsection{Trabalhos Futuros}

O próximo passo, seria implementar uma biblioteca de suporte (framework) voltada para as necessidades do algoritmo proposto, servindo também de interface para a rede. Após a implementação da biblioteca que atenda a estes requerimentos, então começaria a implementação do algoritmo propriamente dito seguindo os passos da modelagem. Como última etapa, seguiria a realização dos testes.

Como sugestão para a realização dos testes, pode-se ainda citar: 
- Avaliação de performance do sistema. Por exemplo, alterando o tamanho da janela de mesclagem, aumento gradual da taxa de requisição. Pensando nos futuros testes, a realização de algumas tarefas é feita em módulos separados. Como exemplo, o algoritmo de programação dinâmica é feito de forma divisivel, isto é, o comando enviado pelo controle de mesclagem para a árvore de mesclagem é divıdido em partes (Criar (StreamMesclagem), Ajustarstream(), Destruir()) para que futuros testes, como testes de performance e corretivos, pudessem ser realizados.

- Variações do sistema que pudesse aumentar a interatividade do cliente. Por exemplo, inserindo comando como rewind e forward, o que acarretaria uma complexidade extra ao sistema. 


\section{Referências Bibliográficas}

[Agg96a] Aggarwal, J.L;; Wolf; Yu. On Optimal Piggyback Merging Policies for Video on demand Systems. Technical Report RC 20337 (90078), IBM Research Division, Fevereiro 1996.

[Agg96b] Aggarwal, J.L.; Wolf; Yu.Adaptative Piggybacking Schemes for Video on demand Systems. Technical Report RC 20635 (91350), IBM Research Division, Novembro 1996.

[ATM94] ATM Forum. ATM User-Network Interface Specification 3.1, 1994

[Bak95]

Baker, F. Requirements for IP version 4 Routers, RFC1812, Junho 1995.

[Bal96]

[Bra93]

[Car95]

Balabanian, V.; Casey, L.; Greene, N.; e Adams, C. An Introduction to Digital Storage Media Command and Control, IEEE Communications Magazine, vol 34, No. 11 (November 1996).

Ballardie, A. Core Based Trees (CB'T version 2) Multicast Routing, Setembro 1997.

Braudes, R.; Zabele, S. Requirements for Multicast Protocols. Maio 1993

Cardozo, E. et al. Sistemas Multimídia, Universidade Estadual de Campinas - Faculdade de Engenharia Elétrica, 1995.

[Cha94] Chang, Y.H.; Coggins, D.; Pitt, D.; Skellem, D.; Thapar, M.; Venkatraman, C. An Open-System Approach to Video on Demand. IEEE Commun. Magazine, vol. 32, pp.68-80, maio de 1994.

[Che94] Chervenak, A.L. Tertiary Storage: Na Evaluation of New Applications, tese de doutorado, CSD, Universidade da Califórnia, Berkeley, 1994.

[Cha94] Chang, Y. H. et al An Open-System Approch to Video on Demand, IEEE Commun. ilagazine, vol.32, pp.52-59, Agosto 1994.

[Dan96] Dan, A; Sitaram,D; Shahabuddin, Perwez. Dynamic batching policies for an on-demand video server. Multimedia Systems, 4: 112-121, 1996.

[Dee89] Deering, S. Host Extensions for IP Multicasting", RFC 1112, Standford University, Agosto 1989.

[Est97] Estrin, D. Protocol Independent Multicast Sparse Mode (PIM-SM): Protocol Specification, Julho 1997.

[Fen97] Fenner, W. Internet Group Management Protocol, version 2, Novembro 1997.

[Flu95] Fluckiger, F. Understanding Networked Multimedia, Englewood Cliffs, NJ: Prentice Hall, 1995.

[Fon97a] Fonseca, N.L.S.; Franco, C.M.R.; Schaffa, F. Projeto de Redes para o Suporte a Aplicaçōes "Distributed Home Theatre". Anais do 15 " SBRC, maio de 1997.

[Fon97b] Fonseca, N.L.S.; Façanha, R.A; Rezende, P. J. Reduzindo a Demanda de Banda Passante em Setvidores de Vídeo. Relatório Técnico, IC-Unicamp, Novembro 1997. 
[Fon98]

[Gol95]

[Gol96]

[Hac98]

[Hän94]

[Hei93]

[Hod93]

[Hod95]

[Kam94]

[Lau93]

[Lit94]

[Moy94]

[Ne195]

[Ozd94]

[Per94]

[Pis98]

[Pry95]

[Rea99]

[Rum99]

[Sch99]

Fonseca, N.L.S.; Façanha, R.A. A política de Piggybacking S2 . Relatório Técnico, IC-Unicamp, Abril 1998.

Golubchik, C.S.L. Reducing I/O Demand in Video on demand Storage Servers. ACM Sigmetrics, pp. 25-36, 1995. Ottawa, Canadá.

Golubchik, L.; Lui, J.C.S.; Muntz, R. Adaptive Piggybacking: A Novel Technique for Videoon-Demand Systems. Technical Report RC 20337 (90078),IBM Research Division, T.J.Watson Research Center, Novembro 1996

Hachisuca, A.M.M. Desenvolvimento de um Sistema Servidor de Vídeo para Aplicações Multimídia. Dissertação de mestrado, ICMC-USP, 1998.

Händel, R; Huber, M.N.; e Schröeder, S. ATM Networks, Concepts, Protocols, and Applications, Addison-Wesley: Reading, MCA, 1994.

Heinanen, J. Multiprotocol Encapsulation over ATM Adaptation Layer 5, RFC 1483, USC/Information Science Institute, Julho 1993.

Hodge, W.W.; Martin, S.; Powers, J.T. Video on Demand: Architectures, System, and Applications, Society of Motion Picture and Television Engineers Journal. vol. 102, pp.791803, setembro de 1993.

Hodge, W.W. Interactive Television. New York: McGraw-Hill, 1995.

Kamath, M. Buffer Management for Continuous Media Sharing in Multimedia Database Systems, Techical Report 94-11, University of Massachusetts, Fevereiro 1994.

Laubach, M. Classical IP and ARP over ATM, RFC 1577, Hewlett-Packard Laboratories, Dezembro 1993.

Little, T.D.C.; Venkatesh, D. Prospects for Inte ractive Video on Demand. IEEE Multimedia Magazine, vol. 1, pp. 14-24, 1994.

Moy, J. Multicast Extensions to OSPF, RFC 1584, Maio 1994.

Nelson, M.N.;Linton, M. A Highly Availahle, Scalable ITV System, Proc. Fifteenth Symp. On Operating Systems Prin., ACM, pp. 54-67, 1995

Ozden, B. A Low-cost storage server for movie on demand databases, VLDB, 1994.

Perez, M.; Liaw, F.;Grossman, D. ATM Signaling Suport for IP over ATM, Internet Draft, IP over ATM Working Group, draft-ietf-ipatm-sig-02.txt, Novembro 1994.

Pissioli, M. Sistema para Transmissão de Vídeo via ATM. Mini-dissertação de mestrado, ICMC-USP, junho de 1998.

Prycker, M. Asynchronous Transfer Mode, Prentice Hall: Upper Saddle River, NJ, 1995.

RealNetworks, Inc. SureStream, disponivel em: http://www.realnetworks.com/surestream.htm Visitado em: Agosto 2000.

Rumbaugh, J. The Unified Modeling Language Reference Manual Addison-Wesley Object Technology Series, Agosto 1999.

Schader, M. The Unified Modeling Language: Technical Aspects and Applleations, Addison-Wesiey Object Series, Junho 1999. 

Video-on-Demand, Relatório Técnico, 1999.

[Ste95] Steinmetz, R; Nahrstedt, K. Multimedia: Computing, Communications and Applications, Englewood Cliffs, NJ: Prentice Hall, 1995.

[Sti96] Stiller, B. A Survey of UNI Signaling Systems and Protocols for ATM Networks, University of Cambridge, Computer Laboratory New Museums Site, Pembroke Street Cambridge, 1996

[Sun99] Sun Microsystems, Inc Java ${ }^{\text {TM }}$ Media Framework - API Guide disponivel em: http:www.sun.com/jmf2.0/developers/api/guide.html; Califómia, USA. Setembro 1999.

[Tob93] Tobagi, F. A. Streaming RAID - a disk array management system for video files. $A C M$ Multimedia Conference, páginas 393-399, 1993.

[Tan96] Tanembaum, A.S. Computer Networks, Prentice-Hall, $3^{2}$ edição, 1996

[Wai88] Waitzman, C. P; Deering, S. Distance Vector Multicast Routing Protocol, RFC 1075, Novembro 1988. 